\title{
Experimental market microstructure and empirical cost of capital studies
}

Citation for published version (APA):

van Dijk, M. A. (2002). Experimental market microstructure and empirical cost of capital studies. [Doctoral Thesis, Maastricht University]. Universiteit Maastricht. https://doi.org/10.26481/dis.20020926md

Document status and date:

Published: 01/01/2002

DOI:

10.26481/dis.20020926md

Document Version:

Publisher's PDF, also known as Version of record

\section{Please check the document version of this publication:}

- A submitted manuscript is the version of the article upon submission and before peer-review. There can be important differences between the submitted version and the official published version of record.

People interested in the research are advised to contact the author for the final version of the publication, or visit the DOI to the publisher's website.

- The final author version and the galley proof are versions of the publication after peer review.

- The final published version features the final layout of the paper including the volume, issue and page numbers.

Link to publication

\footnotetext{
General rights rights.

- You may freely distribute the URL identifying the publication in the public portal. please follow below link for the End User Agreement:

www.umlib.nl/taverne-license

Take down policy

If you believe that this document breaches copyright please contact us at:

repository@maastrichtuniversity.nl

providing details and we will investigate your claim.
}

Copyright and moral rights for the publications made accessible in the public portal are retained by the authors and/or other copyright owners and it is a condition of accessing publications that users recognise and abide by the legal requirements associated with these

- Users may download and print one copy of any publication from the public portal for the purpose of private study or research.

- You may not further distribute the material or use it for any profit-making activity or commercial gain

If the publication is distributed under the terms of Article $25 \mathrm{fa}$ of the Dutch Copyright Act, indicated by the "Taverne" license above, 


\section{Experimental Market Microstructure and Empirical Cost of Capital Studies}


O 2002 Mathijs A. van Dijk ISBN 9090161198 


\title{
Experimental Market Microstructure and Empirical Cost of Capital Studies
}

\author{
PROEFSCHRIFT
}

ter verkrijging van de graad van doctor aan

de Universiteit Maastricht,

op gezag van de Rector Magnificus, Prof. dr. A.C. Nieuwenhuijzen Kruseman, volgens het besluit van het College van Decanen,

in het openbaar te verdedigen

op donderdag 26 september 2002 om 16.00 uur

door

Mattheus Albertus van Dijk 


\section{Promotor:}

Prof. dr. C.G. Koedijk

\section{Beoordelingscommissie:}

Prof. dr. C.C.P. Wolff (voorzitter)

Prof. dr. F.C. Palm

Prof. dr. C.G. de Vries (Erasmus Universiteit Rotterdam) 


\section{Voorwoord}

Bij het schrijven van dit proefschrift heb ik veel opgestoken over onder andere financiêle markten, ondernemingsfinanciering, experimenteel en empirisch onderzoek, college geven, schrijven, samenwerken en presenteren. Ook het leven in Maastricht heeft me veel geleerd: savoir vivre, gastvrijheid, Limburgs verstaan, vasteloavend vieren en 'pils' in plaats van 'bier' bestellen (dit heb ik inmiddels weer afgeleerd). Ik heb mijn eigen interesses, talenten en beperkingen beter leren kennen. Dit voorwoord biedt mij de gelegenheid om collega's, huisgenoten, vrienden en familie te bedanken voor de steun, de inspiratie en het plezier die ze mij gaven tijdens deze leerprocessen.

Vier mensen in het bijzonder waren voor mij belangrijk bij de totstandkoming van dit proefschrift. Kees dank ik voor zijn vertrouwen en zijn positieve houding. Hij bood me de vrijheid om mijn eigen ontwikkeling door te maken, zonder daarbij zijn betrokkenheid te verliezen. Bovendien kon hij me zeer goed motiveren als dat nodig was. Peter was altijd bereid mij te laten delen in zowel zijn brede econometrische kennis als zijn sterke economische inturtie. Ik denk met plezier terug aan zijn enthousiasme en zijn belangstelling. Ronald heeft me niet alleen aan een aio-plek in Maastricht, maar ook nog aan onderdak geholpen. Ik heb veel gehad aan zijn adviezen en grappen. Zonder Irma had mijn tijd in Maastricht er heel anders uitgezien. Ik ben haar dankbaar voor talloze leuke, vertwijfelde, mooie, verwarrende en grappige gesprekken.

Ik denk met genoegen terug aan de stimulerende en ontspannen sfeer op de sectie Financiering van de Universiteit Maastricht. Mijn dank gaat uit naar alle collega's en met name naar Christian, Kim, Mark, Marlies, Piet, Rogér en de dames van het secretariaat. Ik ben de sponsors van mijn bezoek aan Princeton University in de herfst van 1999 erkentelijk voor hun bijdrage aan een fantastische tijd.

Ik heb veel profijt gehad van de samenwerking met mijn coauteurs. Hoofdstuk 3 is gebaseerd op Flood, Koedijk, van Dijk, and van Leeuwen (2001); hoofdstuk 4 op Koedijk, van Dijk, and van Leeuwen (2001), hoofdstuk 6 op Koedijk, Schotman, and van Dijk (1998); hoofdstuk 7 op Koedijk, Kool, Schotman, and van Dijk (2001) en hoofdstuk 8 op Koedijk and van Dijk (2002). Aan een groot aantal mensen ben ik dank verschuldigd voor commentaar op delen van dit proefschrift. 
Naast mijn academische activiteiten bewaar ik ook erg goede herinneringen aan de avonden weekenden en vakanties die ik doorbracht met vrienden. Ik dank met name Enrico, Jean-Pau en Liesbeth, Paul, Ramon, Sander en Nienke, en Tom voor hun bezoeken aan het zuiden es hun gastvrijheid in het westen. Dankzij mijn huisgenoten heb ik drie mooie jaren beleefd of Plankstraat 13.

Tenslotte wil ik papa, mama en Marleen bedanken voor hun grote betrokkenheid en steun.

Mathijs A. van Dijk

Rotterdam, juli 2002 


\section{Contents}

\section{CHAPTER 1}

$\begin{array}{lr}\text { Introduction } & 1\end{array}$

1.1 Background and Motivation 1

1.2 Outline 4

PART I ASYMmetric INFORMATION IN MULTIPLE-DEALER FinANCIAL MARKETS

CHAPTER 2

Introduction to Part I: Market Microstructure Research 9

$\begin{array}{lll}2.1 & \text { Introduction } & 9\end{array}$

2.2 Information-Based Microstructure Models 11

2.3 Market Design Issues: Transparency 13

2.4 Experimental Market Microstructure Research 14

\begin{tabular}{ll}
2.5 & Outline of Part I \\
\hline
\end{tabular}

$\begin{array}{lll}2.6 & \text { Conclusions } & 16\end{array}$

CHAPTER 3

Dividing the Pie: Asymmetrically Informed Dealers and Market Transparency $\quad 17$

$\begin{array}{ll}3.1 \text { Introduction } & 17\end{array}$

3.2 Experimental Design and Terminology 22

$\begin{array}{llr}3.3 & \text { Data } & 28\end{array}$

$\begin{array}{lll}3.4 & \text { Results } & 36\end{array}$

$\begin{array}{lll}3.5 & \text { Conclusions } & 48\end{array}$

CHAPTER 4

Asymmetric Information and Inter-Dealer Trading $\quad 51$

4.1 Introduction 51

4.2 Literature 52

4.3 Experimental Design $\quad 54$

$\begin{array}{lll}4.4 & \text { Data } & 56\end{array}$

$\begin{array}{llr}4.5 & \text { Results } & 57\end{array}$

$\begin{array}{lll}4.6 & \text { Conclusions } & 71\end{array}$ 


\section{PART II EXChANGE RATES AND THE COST OF CAPITAL OF INTERNATIONAL CoMpanies}

CHAPTER 5

Introduction to Part II: Puzzles in International Finance

$\begin{array}{lll}5.1 & \text { Introduction } & 75\end{array}$

$\begin{array}{lll}5.2 & \text { Puzzles in International Financial Markets } & 77\end{array}$

$\begin{array}{lll}5.3 & \text { Outline of Part II } & 83\end{array}$

$\begin{array}{lll}5.4 & \text { Conclusions } & 84\end{array}$

\section{CHAPTER 6}

$\begin{array}{lr}\text { The Re-Emergence of PPP in the 1990s } & 85\end{array}$

$\begin{array}{lll}6.1 & \text { Introduction } & 85\end{array}$

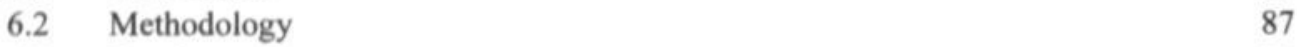

$\begin{array}{llr}6.3 & \text { Results } & 89\end{array}$

$\begin{array}{lll}6.4 & \text { Conclusions } & 94\end{array}$

\section{CHAPTER 7}

The Cost of Capital in International Financial Markets: Local versus Global Beta 97

$\begin{array}{lll}7.1 & \text { Introduction } & 97\end{array}$

7.2 The International CAPM and the Domestic CAPM 99

$\begin{array}{lll}7.3 & \text { Data } & 101\end{array}$

$\begin{array}{lll}7.4 & \text { Empirical Results } & 104\end{array}$

7.5 Local, Global, and Currency Factors: A Variance Decomposition 117

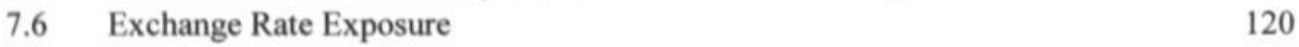

$\begin{array}{ll}7.7 & \text { Conclusions } \\ & 122\end{array}$

CHAPTER 8

$\begin{array}{lr}\text { The Cost of Capital of Cross-Listed Firms } & 125\end{array}$

$\begin{array}{lll}8.1 & \text { Introduction } & 125\end{array}$

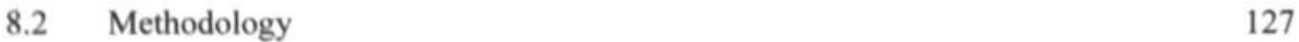

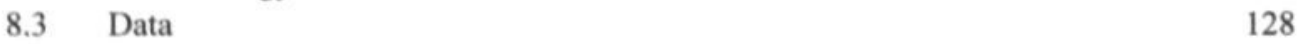

$\begin{array}{lll}\text { 8.4 Empirical Results: Interlisted Stocks } & 129\end{array}$

8.5 Empirical Results of Benchmark Sample: Domestic Stocks 135

$\begin{array}{lr}8.6 & \text { Conclusions } \\ \end{array}$

CHAPTER 9

Summary

References 


\section{Chapter 1}

\section{Introduction}

\subsection{Background and Motivation}

In the past decades, we have observed a continuing process of globalization of international capital markets. Stulz (1998, p. 1) asserts that "Over the last fifty years, the barriers to international investment have crumbled among developed economies and have fallen dramatically among many emerging markets." Both formal restrictions to international investments arising from laws and regulations and less formal obstacles in the form of, for instance, political risk and lack of accounting harmonization have been reduced. The launch of the European Monetary Union at the beginning of 1999 has buttressed this process. The International Monetary Fund (1998) mentions three trends that illustrate the globalization of capital markets. First, cross-border transactions in bonds and equities have grown. For Germany, securities transactions between residents and nonresidents amounted to 5 percent of GDP in 1990 and over 250 percent of GDP in 1997. Second, corporations increasingly raise funds in capital markets abroad. For example, the value of international equity issues by Dutch firms has risen by approximately 750 percent over the period 1990-1997. Third, companies more often list their shares at financial exchanges abroad. Over 460 international firms from 53 countries were listed at the New York Stock Exchange at the end of November 2001, compared to 77 cross-listings in 1988. Furthermore, businesses more and more engage in activities abroad. Despite the crises in Mexico, Asia, Russia, and Latin America, world foreign direct investment flows have shown a sevenfold increase over the $1990 \mathrm{~s}$ to $\$ 1.1$ trillion in 2000 (see the World Bank (2001)).

These developments have triggered more intense competition among international financial exchanges. Huisman and Koedijk (1998, p. 463) note: "In the last decade we have 
witnessed a strong increase in consolidation and competition among exchanges worldwide." A number of exchanges have recently announced mergers and strategic alliances. For example, the National Association of Securities Dealers (NASD) and the American Stock Exchange (AMEX) announced a merger in 1998. Moreover, several European stock markets have applied alterations to their trading mechanism in order to attract order flow. In 1997, the London Stock Exchange launched electronic order book trading for blue chip stocks via the Stock Exchange Electronic Trading System (SETS). This was accompanied by stricter trade publication regulations. SETS features automatic and immediate disclosure of all trades. These alterations in the institutional structure of financial exchanges have stimulated attention for market design issues. The market microstructure literature studies the price formation process at securities markets and specifically concentrates on the impact of institutional design on market performance.

Several recent theoretical and empirical market microstructure studies have attempted to assess the effect of trade and quote disclosure, inter-dealer trading and dealer versus auction markets on market liquidity, price efficiency, and bid-ask spreads. Madhavan (1992) and Pagano and Röell (1996) research the effect of trade publication on price formation in a theoretical framework. Both articles find an important effect of trade publication regulations on market performance and viability. An empirical study by the London Stock Exchange (1999) examines trading costs before and after the introduction of SETS and reports a considerable decline in bid-ask spreads. One of the few empirical papers in the academic literature on trade disclosure is Gemmill (1996). Gemmill studies the impact of delayed publication of prices for block trades at the London Stock Exchange. The author finds that the three different regimes for the publication of last-traded prices in the period 1986-1996 show remarkably little difference in terms of spreads and the speed of price adjustment.

While these studies yield interesting and relevant insights into the impact of trading mechanism design on market performance, a number of methodological concerns have been raised. Theoretical market microstructure studies generally need strong behavioral assumptions in order to keep the models tractable. An important drawback of empirical research is that it is difficult to isolate the effect of a change in the trading mechanism of an exchange. Moreover, not all the information available at a financial market place is recorded, which makes it hard to study the way information is assembled and prices are formed. An experimental methodology may bypass some of these caveats. Experiments allow for a controlled market design change without greatly restricting the strategic actions of the participants.' Glosten (1999, p. 2) deems that "Experimental markets can provide modeling insights into what are important dynamic issues to consider." In part I of this thesis we employ experiments in order to study the effects of transparency and inter-dealing trading on

\footnotetext{
A disadvantage of experimental market microstructure research may be that it is hard to simulate the complexity and thrill of trading actual financial securities.
} 
market performance. Our laboratory multiple-dealer asset market bears resemblance to the institutional structure of NASDAQ and the foreign exchange market.

Notwithstanding the continuing integration of international goods and capital markets, recent international finance literature finds a remarkably small impact of international factors on domestic markets. For example, recent work by Warnock (2001) shows that foreign equities currently comprise of only around 12 percent of U.S. investors' equity portfolios. Standard portfolio theory predicts that equity investors hold the market-weighted world stock portfolio in integrated capital markets. This would imply a far larger portion of foreign equities in U.S. stock portfolios. This empirical finding is referred to as the home bias puzzle. Other puzzles in international finance include the foreign exchange exposure puzzle, the country versus industry diversification puzzle, the uncovered interest parity puzzle, and the purchasing power parity puzzle. The latter two puzzles fall in the larger category of the exchange rate disconnect puzzle, "... a name that alludes broadly to the exceedingly weak relationship (except, perhaps, in the longer run) between the exchange rate and virtually any macroeconomic aggregates." (Obstfeld and Rogoff (2000), p. 34, emphasis in the original)

In part II of this thesis we attempt to offer additional empirical perspectives on several of the puzzles in international financial markets. We propose an alternative framework for analyzing purchasing power parity using panel data. We examine the exchange rate exposure of a large number of firms with three distinct estimation methodologies. Furthermore, we pinpoint a further conundrum in international finance: the pricing error puzzle. This puzzle signifies that domestic and international versions of the capital asset pricing model lead to a different estimate of the cost of capital for a relatively small number of firms. As an example, the Royal Dutch Petroleum Company operates in more than 135 countries and realized more than 50 percent of sales abroad in 2000. Over the period 1980-1999, the cost of capital of this company amounted to 13.9 percent according to the single factor international capital asset pricing model. The cost of capital computed with the single factor domestic capital asset pricing model was 14.1 percent over the same period. Even though Royal Dutch is significantly exposed to fluctuations in exchange rates and other international factors, financial managers would thus make a remarkably small mistake if the domestic, instead of the international, version of the capital asset pricing model were used for cost of capital calculations.

\subsection{Outline}

The core of this thesis consists of seven chapters. Part I studies the impact of the institutional design on the performance of financial securities markets. Part II empirically re-examines several of the puzzles in international financial markets. In this subsection we briefly discuss the set-up and main conclusions of each of the chapters. 
Chapter 2 provides an introduction to part I and surveys the recent developments in the market microstructure literature. The chapter starts by discussing the main theoretical information-based market microstructure models developed in the $1980 \mathrm{~s}$. In these models, a spread between the bid and the ask price of a market maker arises because of adverseselection costs. The rationale for this result is that market makers compensate the losses to informed traders by making money from uninformed liquidity trades. An important issue in market microstructure research is the effect of the design of financial markets on their performance. We review several theoretical and experimental studies dealing with market transparency. The transparency of a financial market concerns the amount of information market participants receive on the trading process. Recent research suggests that transparency involves trade-offs between liquidity and efficiency.

In chapter 3 we investigate the issue of transparency in a laboratory multiple-dealer asset market. We distinguish between pre-trade and post-trade transparency. The former involves the publication of quotes, while the latter concerns the disclosure of transaction information. In our quote-driven market, five market makers compete for the order flow from computerized informed and liquidity traders. An important feature of our experiments is that we employ asymmetrically informed dealers. At the beginning of each trading round, one of the market makers receives information about the underlying value of the traded asset. We find that pre-trade transparency slows down price efficiency, but leads to lower bid-ask spreads. Post-trade transparency, on the other hand, stimulates price discovery and impairs liquidity.

Chapter 4 consists of an experimental study of the impact of a parallel inter-dealer market in a multiple-dealer setting. In general, two distinct motives for inter-dealer trading can be distinguished. First, market makers can reduce the risk of their inventory positions by trading in the inter-dealer market. Second, market makers can exploit private information in transactions with other dealers. We focus on the asymmetric information motive. In our experiments, four dealers make a market for a single security and trade with computerized informed and liquidity traders. As information about transactions between market makers and external customers is not publicly disclosed, asymmetric information is a key characteristic of our experimental set-up. In contrast, inventory risk is relatively small, so risk sharing is unlikely to be an important motive for inter-dealer trades. Our analysis indicates that external customers face higher execution costs (that is, wider bid-ask spreads) in the market with interdealer trading. Recent literature primarily examines inter-dealer trading motivated by risk sharing and generally concludes that external customers of an exchange are better off when inter-dealer trading is allowed. Our results suggest that public policy discussions should pay more attention to the role of asymmetric information in the inter-dealer market.

Chapter 5 comprises an introduction to part II and reviews the recent empirical literature on five puzzles in international finance. The uncovered interest parity puzzle reflects the empirical finding that changes in the spot exchange rate are unrelated to the forward premium. Similarly, many studies fail to find a relation between (changes in the) exchange 
rates and (changes in the) consumer price indices of two countries. This is referred to as the purchasing power parity puzzle. The home bias in equities puzzle signifies that investors hold a far smaller percentage of their wealth in foreign assets than we would expect in integrated markets. We call the conundrum that stock market indices of industrialized countries exhibit surprisingly low correlations the "country versus industry diversification puzzle". Finally, the foreign exchange exposure puzzle reflects the fact that the excess returns on stocks show remarkably little relation to exchange rate returns. Chapter 5 suggests that, while various plausible explanations have been offered for each of the puzzles mentioned above, more research is required in order to get to the bottom of these issues.

Chapter 6 takes up the gauntlet of reassessing the evidence for both absolute and relative purchasing power parity (PPP). The motivation for this chapter stems from the critique of O'Connell (1998) on recent panel studies. O'Connell shows that the cross-sectional dependence of real exchange rates against a common numeraire leads to potentially large biases in the size and the power of panel tests of PPP. We cope with O'Connell's critique by using a generalized least squares estimation technique that makes our results invariant to the choice of the numeraire currency. A second focal point of our study is that we allow for a separate evaluation of (relative) PPP for each currency pair in the sample. Recent panel studies impose the restriction that PPP holds equally well for each currency. We find that for a sample of 17 countries for the period 1972-1996, relative PPP offers a reasonable description of quarterly movements in exchange rates, particularly for horizons longer than one year. Our results suggest that the supposition of PPP is not equally accurate for all currencies in the sample. The evidence for PPP is relatively strong for the German mark and considerably weaker for the U.S. dollar.

In chapter 7 we examine the issue whether international and domestic versions of the capital asset pricing model produce different estimates of the cost of capital. We extend a paper by Stulz (1995b). Stulz investigates whether the domestic CAPM and the single factor international CAPM lead to a different estimate of the cost of capital for the Swiss multinational Nestlé. He concludes that this so-called "pricing error" is sizeable for Nestlé and suggests that multinational firms from small, open economies may exhibit substantial pricing errors in general. We derive formal statistical tests for the pricing error between the domestic CAPM and the multifactor ICAPM including exchange rate factors. We examine the magnitude of the pricing error for a sample of almost 3,300 firms from nine industrialized countries over the period 1980:02-1996:06. Our results indicate that a statistically significant pricing error arises for only approximately 5 percent of the firms in our sample. We show that firms within a country by and large share a common exposure to the global market and currency factors. The strong country factors in the data may partly explain why the pricing error is small for most firms. We demonstrate that pricing error tests are very similar to tests for foreign exchange exposure. Consistent with the literature, we find that exchange rate exposure is significant for only about 14 percent of the companies. When we alter our testing 
methodology in order to account for the strong country factors in the data, however, we dete significant exposure to currency fluctuations for $\mathbf{4 5}$ percent of the corporations.

In chapter 8 we concentrate on the 336 firms with foreign equity listings in the samp described above. Recent research indicates that firms with international cross-listings a typically large multinational corporations with a strong international focus. We conjecture th these firms may well show a substantial pricing error. As global factors probably have a larł impact on the stock returns of interlisted companies, the domestic CAPM could lead to different estimate of their cost of capital than the multifactor ICAPM. Our results indicat however, that the pricing error is significant for just 12 percent of the cross-listed firms, whi roughly 4.4 percent of our benchmark sample of companies without cross-border listing exhibit a pricing error. Exposure to exchange rate fluctuations is significant for over 8 percent of the interlisted corporations, compared to roughly 40 percent of the benchmar group of domestic firms.

Chapter 9 presents a summary and a conclusion of this thesis. 


\section{PART I}

\section{ASYMMETRIC INFORMATION in Multiple-Dealer Financial Markets}





\section{Chapter 2}

\section{Introduction to Part I:}

\section{Market Microstructure Research}

\subsection{Introduction}

The past decade has been turbulent for financial exchanges across Europe. The introduction of the Euro and the outset of the European Monetary Union have increased capital mobility. Moreover, the number of international cross-listings has risen substantially. Therefore, nowadays investors often have several alternative venues for trading the asset of their choice. They increasingly compare financial exchanges on the basis of efficiency, liquidity, and trading costs. This has led to tougher competition between European exchanges and induced several exchanges to enter strategic alliances or alter their trading mechanisms.

Two examples illustrate this development. On October 20, 1997 the London Stock Exchange introduced electronic order book trading for the FTSE 100 via the Stock Exchange Electronic Trading System (SETS). Since the "Big Bang" in 1986, dealers had advertized their prices electronically, but traded with each other over the phone. The launch of SETS signified a switch form a quote-driven trading mechanism to an order-driven system. This was accompanied by an increase in transparency through immediate disclosure of all trades. The London Stock Exchange claims that the introduction of SETS has significantly reduced transaction costs. Since 1997, the exchange has implemented several adjustments to SETS, such as the removal of a minimum order size and the inclusion of more stocks.

On March 20, 2000 the CEOs of the Paris Bourse, Amsterdam Exchanges (AEX), and Brussels Exchanges (BXS) announced their agreement to create a merger between the Belgian, Dutch, and French exchanges. The resulting pan-European exchange, Euronext, was formed as a response to the "growing expectations of investors for the development of a single European stock market" (Euronext press release (2000)). The three exchanges agreed 
on introducing the French Nouveau Système de Cotation (NSC) as the central trading system for all Euronext stocks. In Amsterdam, stock trading via the NSC electronic order book started on October 29, 2001. The Trading System Amsterdam (TSA) was abandoned and the "hoekman" (specialist) disappeared for the most liquid funds. ${ }^{2}$ This represented a switch from a quote-driven to an order-driven system. The current "open outcry" in option trading at the Amsterdam exchange will gradually be replaced by electronic trading. Since early November 2001, options on three funds have been traded via the quote-driven Next Derivatives System (NDS), which is a hybrid form of the French NSC and the Dutch Switch system. After the completion of the acquisition of the London International Financial Futures and Options Exchange (LIFFE), all Euronext derivatives trading will eventually be executed through the electronic Connect system currently employed by LIFFE.

A relevant question is to what extent these and other alterations in the trading mechanism affect the performance of an exchange in terms of efficiency, liquidity, and transaction costs. The literature on market microstructure attempts to provide an answer to this question. O'Hara (1995, p. 1) defines market microstructure as "the study of the process and outcomes of exchanging assets under explicit trading rules." In contrast to most research in economics, which abstracts from the specific way a good is transferred from one agent to another, microstructure studies explicitly focus on the effects of the trading mechanism on the price and quantity traded.

In part I of this thesis we present two experimental market microstructure studies. In chapter 3 we analyze the implications of different quote and trade disclosure regimes on the efficiency and transaction costs of the market. These transparency effects are considered in a market in which one of several competing market makers has got private information about the underlying value of the asset. In chapter 4 we investigate whether allowing for inter-dealer trades is beneficial for market performance in an asymmetric information setting. Both chapters employ an experimental continuous multiple-dealer version of the Glosten and Milgrom (1985) model.

In this introductory chapter we provide a condensed overview of the market microstructure literature. Our purpose is to present a survey of the current state of theoretical and experimental market microstructure research. We focus on several fundamental information-based models and on studies dealing with market transparency. In section 2.2 we examine various models of securities markets in which a spread between the bid and the ask price of a dealer arises because of asymmetric information about the value of the asset. These include the well-known studies of Glosten and Milgrom (1985) and Kyle (1985). Section 2.3 discusses the recent theoretical literature dealing with market design issues, such as the effect of transparency on efficiency and liquidity. Experimental microstructure research is reviewed in section 2.4. This section also relates the studies presented in chapters 3 and 4 to the papers

For illiquid stocks they have been replaced by an "animateur" or liquidity provider, which implicitly divulges a quote by entering a buy and a sell order in the limit order book. 
of Flood, Huisman, Koedijk, and Mahieu (1999) (hereafter FHKM), and Flood, Huisman, Koedijk, and Röell (1999) (hereafter FHKR). In section 2.5 we present an outline of the experimental market microstructure studies in part I of this thesis. Section 2.6 offers a conclusion.

\subsection{Information-Based Microstructure Models}

In the initial theoretical microstructure models, the dealer's inventory position is the main factor influencing the price-setting strategy. An example is Ho and Stoll (1981). Their study is one of the first to explicitly analyze the behavior of the dealer by formulating their optimization problem. Ho and Stoll present a multiperiod model in which the risk averse dealer is confronted with a stochastic order flow. Order flow is affected by the dealer's bid and ask prices. The dealer acts as monopolistic market maker and is assumed to maximize the expected utility of total wealth after $T$ periods. This depends to a large extent on the stochastic return the dealer's portfolio earns. ${ }^{3}$

In the $\mathrm{Ho}$ and Stoll model, a positive spread basically exists because of costs associated with inventory risk. It is often argued that the bid-ask spread consists of three components: order-processing costs, inventory costs, and adverse-selection costs. ${ }^{4} \mathrm{~A}$ large part of the literature employs a setting in which adverse-selection costs are the predominant economic source of the spread. As this is also the case in our experiments, the remainder of this section concentrates on three major asymmetric information models: Glosten and Milgrom (1985), Kyle (1985), and Admati and Pfleiderer (1988). These information-based models show that, in competitive markets without transaction and inventory costs with risk neutral agents, a spread can originate from adverse-selection problems.

The Glosten and Milgrom model can be regarded as a multiperiod version of the model described in Copeland and Galai (1983). Glosten and Milgrom assume the dealer is risk neutral and acts competitively. They make the market in a single asset, the terminal value of which is given by the random variable $V$. There are two types of traders: informed traders and uninformed (liquidity) traders. There is no strategic trading in this model, so both types are assumed to trade probabilistically. There are no order-processing and inventory costs. As the market maker is competitive, they set the bid and ask prices equal to the conditional expectation of the terminal value $V$. After each trade, they update their beliefs by applying Bayes' Rule. Eventually, prices converge to the underlying value $V$. Glosten and Milgrom show that the adverse-selection problems result in a positive bid-ask spread. This is the case because whether a trader submits a buy or a sell order affects the dealer's conditional expectation of the terminal value. Other major results are that transaction prices follow a

As there is no asymmetric information about the fixed intrinsic value of the stock, $p$, Ho and Stoll introduce inventory uncertainty by assuming a stochastic stock dividend.

See e.g. Campbell, Lo, and McKinlay (1997), section 3.2. 
martingale and that the market can collapse if the fraction of traders with private information is too large.

Kyle (1985) allows the informed trader to choose the timing and size of the trades in order to maximize profits. In his model, the orders of a single risk neutral strategic insider and several uninformed noise traders are batched and submitted to a risk neutral market maker. The market maker observes the aggregate net order flow and sets a market-clearing price. There is a finite number of trading rounds. The uninformed order quantity in any trading round is random and independent of the quantities in other rounds. The insider knows the distribution of uninformed trades. As Kyle analyzes an order-driven trading mechanism, a bid-ask spread does not exist. However, his model does characterize how information is incorporated in security prices when the informed trader acts strategically. Again, the market maker is assumed to earn zero expected profit and the price is set equal to the conditional expected value of the asset given the net order flow. Kyle shows that an equilibrium exists in which information is gradually incorporated into prices. The speed of the price discovery process depends to a large extent on the variance of the uninformed order flow.

Admati and Pfleiderer (1988) extend the Kyle (1985) model to include strategic uninformed traders. This may have important consequences for the strategic behavior of the market maker and the informed trader. At the beginning of each of the $T$ trading rounds, three types of traders submit orders to the risk neutral market maker: nondiscretionary liquidity traders, strategic uninformed traders, and strategic informed traders. Discretionary outsiders are liquidity motivated, but they can choose when they submit their exogenously given order. In contrast to Kyle's model, information is short-lived. In each trading round, an independent random shock to the value of the asset occurs. This shock becomes public information at the start of the next round. This means that the insiders, who receive a noisy signal of the exogenous shock, essentially face a one-period problem. Following Kyle (1985), Admati and Pfleiderer assume that the price the market maker sets depends linearly on the aggregate order flow. Discretionary outsiders are assumed to take the market maker's pricing rule as given, which implies that in equilibrium they all trade in the same trading round in order to "hide" from the informed trades. This finding possibly explains why trading at many real-life exchanges is concentrated in particular time periods within a trading day. Note that this result is strongly connected to the notion of (Nash) equilibrium used in most theoretical market microstructure studies. If trading is not concentrated, at least some liquidity traders have an incentive to deviate from their strategy. How the equilibrium can actually be attained is not assessed.

Several authors successfully elaborate on the basic Kyle (1985) and Admati and Pfleiderer (1988) models discussed here. ${ }^{5}$ Allowing the discretionary uninformed traders to

\footnotetext{
5 Notably, Foster and Viswanathan (1990) generalize the Admati-Pfleiderer model by incorporating longlived private information. Admati and Pfleiderer (1988) refine their own model in two distinct ways: by introducing endogenous information acquisition and by allowing discretionary outsiders to divide their trades among several trading periods.
} 
act truly strategically, however, implies that the problem becomes intractable. Moreover, even if a pure-strategy equilibrium exists, a closed-form solution cannot generally be found. This may well be one of the main reasons why many subsequent studies build on the relatively uncomplicated models described in this section.

\subsection{Market Design Issues: Transparency}

An important strand of the market microstructure literature deals with questions of market design. In this section we discuss several theoretical studies that analyze the effects of market transparency on the transmission of information at an exchange. Transparency can be defined as the extent to which market participants receive information on the trading process. We restrict our attention to a limited number of papers that illustrate the general methodology and are directly relevant for our experimental research.

Madhavan (1992) considers whether a quote-driven or an order-driven market structure best facilitates price discovery. In a quote-driven market (also known as a continuous dealer market), traders obtain prices from market makers before they submit orders. In an order-driven system, which can be organized as either a continuous auction or a batch auction, a market-clearing price is set after orders are submitted. These trading mechanisms differ in their degree of transparency, as dealers in the dealer market and in the continuous auction generally receive more transaction information than dealers in the batch auction. Madhavan shows that price efficiency is greater in the quote-driven system than in the continuous auction. The equilibria of these markets coincide when entry into market making is free. The batch auction is more robust to adverse selection problems. That is, even when the number of insiders is high relative to the number of uninformed traders, an equilibrium may still exist in the batch auction. The viability of this market is purchased at the expense of transparency. Traders thus face higher costs of gathering market information.

Pagano and Röell (1996) examine how transparency affects the trading costs of uninformed traders and thus the liquidity of the market. They distinguish four different market types: the transparent auction, the batch auction, the continuous auction, and the dealer market. In a transparent auction, all orders submitted in a trading round are executed at a single price, but the price-setting auctioneer does observe all individual orders. In a batch auction, only the aggregate order flow is disclosed. A continuous auction involves immediate execution of all individual market orders, which implies that market participants only have information about past trades. Finally, in a dealer market orders are cleared separately by a single market maker, who does not observe orders satisfied by other market makers. The transparent auction is the most transparent system. The batch market exhibits a lower degree of transparency than the transparent auction, but cannot be ranked relative to the dealer market. The continuous auction is less transparent than the transparent market, but more transparent than the dealership system. Pagano and Röell show that in general greater 
transparency leads to lower expected trading costs for uninformed traders at the expense if the informed. Insiders find it harder to hide in markets that exhibit a high level of trae disclosure. Trading costs for uninformed traders in a continuous auction are smaller than ifa dealer market, but larger than in transparent markets. Surprisingly, the batch auction does $\mathrm{pt}$ necessarily lead to higher outsider losses than the transparent auction for all trade sizes.

Both Madhavan (1992) and Pagano and Röell (1996) make a number of simplifyig assumptions in order to keep the models tractable. They analyze the impact of transparencyn a strictly static context with risk neutral dealers. Moreover, Pagano and Röell initially assuıe that the strategic behavior of the insider is the same in all four market types. Dropping tis assumption in the second part of the paper leads to less unambiguous results. In that case, te relationship between liquidity and transparency crucially depends on the distributionl assumptions on noise trading and the insider's signal about the underlying value. Pagano ad Röell are still able to show that in a number of specific cases trading costs for uninformd traders, averaged across all trade sizes, are smaller in more transparent markets. Te generality of this result is not yet clear, however.

The complexity of the theoretical assessment of the impact of transparency has id several authors to believe that these and related market design issues are more effectivy anglvzed in an exnerimental setting . In the next section we consider several exneriment market microstructure papers. An introduction to the experimental set-up of chapters 3 and 4 is provided by briefly discussing two closely related studies.

\subsection{Experimental Market Microstructure Research}

Addressing market design issues using laboratory asset markets is relatively new to the market microstructure literature. In this section we consider four recent experimental studies: Schnitzlein (1996), Bloomfield and O'Hara (1999), FHKM (1999), and FHKR (1999).

Schnitzlein employs an experimental asset market based on the Kyle (1985) framework. He compares liquidity and trading costs in a continuous auction to those in a call auction that bears close resemblance to Pagano and Röell's transparent auction. In both markets, computerized noise traders as well as a single insider submit orders to three competing dealers. In the call auction, all orders are batched and executed at the best price available in the market (that is, the lowest ask or the highest bid, depending on whether the net order is a buy or a sell order), but the dealers observe all individual orders prior to trading. In the continuous auction, noise traders' orders of random size, direction, and arrival time are submitted during a two-minute interval, while the insider is allowed to submit any number of market orders. Following Pagano and Röell (1996), Schnitzlein expects higher outsider losses and less liquidity in the continuous auction. Transparency is lower in the continuous auction, because not the entire order flow is observed prior to the market-clearing auction. The statistical evidence strongly supports this hypothesis. 
Bloomfield and O'Hara analyze a laboratory dealer market under three different transparency regimes: transparent, semiopaque, and opaque. Both trades and quotes are disclosed in the transparent setting. In the semiopaque setting, quotes are published and trades are not. Neither quotes nor trades are disclosed in the opaque setting. At the beginning of each trading round, two market makers set bid and ask quotes for the security. Two computerized noise traders, two computerized informed traders, and two human liquidity traders observe the quotes and determine their order size. Orders are executed at the best price available. The human traders can determine the timing of their orders, but have a target amount of money to raise or invest. The main results of the Bloomfield and O'Hara study are threefold. Firstly, trade disclosure enhances price efficiency. Secondly, the publication of trades leads to wider opening spreads, as market makers have fewer incentives to compete for order flow. Thirdly, the market makers' profits rise at the expense of both informed and noise traders when trades are disclosed. Surprisingly, quote disclosure does not significantly affect market performance.

FHKM and FHKR develop the experimental framework of chapter 3 and 4 . For a detailed description of the experimental set-up, we refer to the next chapter. Here, we review the main results of FHKM and FHKR. FHKM investigate quote disclosure effects in a continuous multiple-dealer version of the Glosten and Milgrom model, which resembles foreign exchange markets. Dealers only observe transactions in which they themselves are involved. Like Bloomfield and O'Hara, FHKM find a trade-off between efficiency and liquidity. While Bloomfield and O'Hara conclude that trade disclosure improves efficiency and harms liquidity, FHKM, however, find that roughly the opposite is true for quote disclosure. They attribute their results to search costs. Quote disclosure decreases the search costs market makers face, which leads to tighter spreads. On the other hand, price discovery is hampered as dealers more successfully try to prevent being hit at the "wrong" side of the market. FHKR examine trade disclosure in a setting in which market makers have limited information about the quotes of competitors. FHKR find that transparency enhances price efficiency, but leads to significantly wider opening spreads. Moreover, informed traders less easily hide their trades in a transparent market, which benefits uninformed traders. These results are similar to the findings of Bloomfield and O'Hara.

\subsection{Outline of Part I}

Part I of this thesis consists of two experimental market microstructure studies. In chapter 3 we examine the effect of transparency in a multiple-dealer financial market with asymmetrically informed dealers. In our experimental set-up, five professional securities traders make a market for a single security. In each trading round one of the dealers (the "insider") receives information about the security's true value. We vary the level of both trade and quote disclosure across the trading rounds. We find that price efficiency is reduced by quote disclosure and increased by trade disclosure. The insider's profits are greatest when 
price efficiency is lowest. Market liquidity, measured by dealers' bid-ask spreads, is improved by the central publication of live quotes and reduced by the public disclosure of trades. The publication of quotes and trade disclosure thus involve opposite trade-offs between efficiency and liquidity. Our results are consistent with FHKM, FHKR, and Bloomfield and O'Hara.

Chapter 4 analyzes the effects of inter-dealer trading in a multiple-dealer asset market. The literature distinguishes two motives for inter-dealer trading: risk sharing and asymmetric information. Recent literature predominantly focuses on the former motive and generally finds that inter-dealer trading motivated by risk sharing leads to lower execution costs for external customers. In contrast, we investigate inter-dealer trading in a market in which asymmetric information is the main motive for inter-dealer trading. Four undergraduate economics students act as market makers in our experiments. Our main result is that spreads are substantially wider in markets with inter-dealer trading. We put forward two explanations for this finding. First, market makers tend to concentrate on exploiting private information and have fewer incentives to quote competitive prices in the market with inter-dealer trading. Second, the adverse-selection component of the bid-ask spread is larger when inter-dealer trading is allowed. We conclude that external customers of an exchange are worse off when inter-dealer trading is allowed in an asymmetric information setting. We argue that the asymmetric informative motive should play a more pronounced role in public policy discussions on inter-dealer trading.

\subsection{Conclusions}

Exchanges world-wide increasingly face competition from securities markets abroad. In the past decade, many financial markets have used modifications in the design of the trading mechanism as a strategic tool for attracting investors. This has led to increased attention for market microstructure research. In the 1980s, several major microstructure models evolved, e.g. Glosten and Milgrom (1985), Kyle (1985), and Admati and Pfleiderer (1988). These and other models have the disadvantage of becoming intractable when both informed and uninformed traders are allowed to act fully strategically. This outlines a major objection to drawing policy implications from theoretical research on market design issues. As it is very hard to isolate the effects of a change in the trading mechanism in empirical research, several authors have turned their attention to experimental methodologies. In part I of this thesis we analyze several market design issues in an experimental continuous multiple-dealer market. 


\section{Chapter 3}

\section{Dividing the Pie: Asymmetrically Informed Dealers and Market Transparency}

\subsection{Introduction}

Information is central to the structure and performance of financial markets. Indeed, a primary function of financial markets is to assemble and analyze information with the goal of accurate valuation of investment prospects. Asymmetric information is thus of obvious importance; the ability of financial markets to weigh and balance information from disparate sources and impound it in securities prices is basic to their function. The interactions among immediate participants - the brokers, dealers, market makers, and specialists directly involved in transacting on exchange floors and over-the-counter (OTC) networks - are crucial to a market's ability to process information. We consider specifically the role of asymmetric information across dealers in an experimental multiple-dealer securities market. There are two broad issues at play here: the impact of asymmetric information on market performance and the impact of the institutional structure on information aggregation and dissemination.

Regarding the former, it is well documented that the presence of asymmetric information has substantial effects on the performance of financial markets. The literature has largely focused on asymmetries among investors outside the trading floor. An important topic has been "insider trading": the use (or abuse) of proprietary information by corporate insiders. This is the traditional definition of insider trading. We distinguish sharply, however, between such traditional corporate insiders and securities dealers who are better informed than their peers in a multiple-dealer environment. Although both are clearly examples of asymmetric information, the nature and implications of the asymmetries will typically differ between these two cases, as detailed below.

The key issues regarding corporate insiders are fairness, price efficiency, and market 
liquidity. For example, the Securities Exchange Act of 1934 in the U.S. effectively outhws trading by corporate insiders as "unfair." On the other hand, Leland (1992) argues hat corporate insiders can bring new and relevant information into the market, making it nore price-efficient and future prices less volatile, as prices reflect more information sooner. However, frequent trading by corporate insiders can reduce market liquidity, as uninforned and liquidity-motivated investors trade less, due to their informational disadvantage. Thus, separate from the issue of fairness, a trade-off between efficiency and liquidity ex sts. Significantly, this trade-off is not the same in different market microstructures. For example, Leland (1992, p. 883), Pagano and Röell (1996, p. 581), and Schnitzlein (1996, p. 613) all conclude that any discussion of whether insider trading helps or hurts markets should ake place in the context of a specific market microstructure or trading mechanism. Specifically, the opportunities for the better informed to hide and exploit their private information - and thus the size and allocation of private and public gains from insider trading - depend diretly on the trading mechanism. ${ }^{6}$

In contrast, we focus on a microstructure that is relatively neglected in the literat ire, namely multiple-dealer markets. The nature of inter-dealer informational asymmetrie: is fundamentally different from those generated by corporate insiders. Inter-dealer asymmeties typically arise from information - such as private order flow or the rumor mill - that should already be impounded in prices in a semi-strong-form efficient market. On the other hand, the information available to corporate insiders should only be impounded in prices if markets are fully strong-form efficient. For example, Copeland and Friedman (1991), using an experimental double-auction study, place this question in the context of the rational expectations modeling literature. They distinguish theoretically between no, full, and partial revelation of expectations (NRE, FRE, and PRE, respectively), where NRE corresponds essentially to semi-strong-form efficiency, and FRE corresponds to strong-form efficiency.

Their results are generally supportive of the PRE. Moreover, the potential social benefits of allowing insider trading - namely that it draws insiders into the market to reveal their information via trading - do not obtain as readily for dealers with inside information, since by definition dealers are already active in the market.

There is thus some question as to the benefits of inter-dealer trade. If markets are not already semi-strong-form efficient, then inter-dealer trading can impound information from dealers' private order flow, thus improving price quality. Moreover, in many markets, dealers may broker trades for corporate insiders, so that the dealer effectively becomes a surrogate corporate insider. ${ }^{7}$ Because microstructural rules concerning the publication of quote and

6 An example of a recent policy debate regarding asymmetries in this context involves the issue of protected trading on NASDAQ; see Franks and Schaefer (1995).

7 Reviewing the extant evidence, Copeland and Friedman (1991, p. 265) note that, "all public information but probably not all private information is fully reflected in securities prices. The question then becomes when and to what extent private information becomes incorporated, or, from the opposite perspective, what is the value of private information to the investor?" (emphasis in the original). Notably, "private information" in their context would include private messages received by traders, analogous to inter-dealer information asymmetries. 
transaction details may affect the revelation and aggregation of material information, the interaction between such rules and inter-dealer information asymmetries becomes an interesting theoretical and practical issue. For example, market makers on the Stock Exchange Automated Quotation (SEAQ) system in London have argued for delayed publication of the details of trades, ostensibly to encourage the provision of liquidity to investors for large transactions (see FHKR (1999) and Office of Fair Trading (1994)). Such publication delays create inter-dealer information asymmetries, allowing an affected dealer to unwind their resulting inventory before their competitors recognize their predicament. The informational question thus extends to issues of dealers' inventories, risk bearing, and capitalization.

In this chapter we consider the impact of rules concerning the publication of both transaction details (post-trade transparency) and live quotes (pre-trade transparency). These issues have been examined in other recent experimental work by FHKM (1999), Bloomfield and O'Hara (1999), Lamoureux and Schnitzlein (1997), and FHKR (1999), among others. As emphasized by Glosten (1999), the issues and results in this area can be complex and counterintuitive. (The main theoretical issues are considered by O'Hara (1995), and Pagano and Röell (1996). FHKM (1999), Bloomfield and O'Hara (1999), FHKR (1999), and Lamoureux and Schnitzlein (1997) consider the issues in an experimental context.) We focus here on the price discovery process. The obvious presumption would be that increased transparency should speed price discovery and therefore improve price efficiency. In the case of post-trade transparency, Bloomfield and O'Hara (1999) and FHKR (1999) find that this form of transparency (i.e., publication of transaction details via a public ticker or similar technology) indeed does speed price discovery. Notably, however, FHKM (1999) find that increased pre-trade transparency (i.e., the publication of live quotes) actually slows price discovery in a multiple-dealer market; their conclusion is that dealers in an opaque market will reprice more aggressively, to guarantee that they attract order flow. By contrast, in a fully pre-trade transparent market, in which all quotes are always public information, dealers can typically offer much smaller price improvements while nonetheless still guaranteeing that they are the best-price provider. ${ }^{8}$ Finally, Lamoureux and Schnitzlein (1997) find roughly that fully (pre- and post-trade) transparent markets are more price-efficient than fully non-transparent markets. We expect slower price discovery to benefit insiders at the expense of outsiders, as has been argued in the SEAQ case.

Other aspects of the microstructure can affect the nature and extent of the trade-offs involved. In a theoretical paper, Benveniste, Marcus, and Wilhelm (1992) examine relationships between specialists and floor brokers on major securities exchanges. Floor brokers occasionally broker trades from known corporate insiders, and may unilaterally hide or reveal this fact when they transact. Benveniste et al. conclude that reputation effects and lack of anonymity induce floor brokers to reveal private information to the specialist in

8 Note that in the experimental setting of FHKM (1999), post-trade transparency is low. Hence, dealers only observe transactions in which they are involved. 
exchange for anticipated long-run benefits of discretionary services from the specialist (that $i$ tighter spreads, or a willingness to fill the remainder of orders partially filled against tp book). Such a system can produce a Pareto-dominant equilibrium in which floor brokers g better service, the specialist faces lower adverse-selection risks, and prices are moi informative. Benveniste et al. suggest that non-specialist dealer markets such as NASDAQ ai less likely to enjoy such benefits. Garfinkle and Nimalendran (1998) provide empiric support for this hypothesis. In the same vein, Madhavan and Cheng (1997) conclude that th "upstairs" market at the NYSE is used by traders who can credibly signal that they at liquidity motivated (and therefore do not have a special informational advantage), consistei with the theoretical predictions of Seppi (1990).

We consider the interaction between informational transparencies in the tradin mechanism and informational asymmetries among market participants. It is difficult to stud the impact of microstructure on the consequences of asymmetric information using empiric: data. Even if it were possible to identify asymmetries, it would still hardly be feasible $t$ isolate the effects of the trading mechanism. We therefore adopt an experiment: methodology, which places our study in a longer tradition of experimental studies of securitic markets. Sunder (1995, pp. 447-48) provides a useful three-part classification of such studie: He groups papers as those considering: (1) the dissemination of information from the ex-ante informed to the ex-ante uninformed; (2) the market-wide aggregation of diverse ex-ante information sets in the hands of individual traders; and (3) the simultaneous equilibrium in the markets for securities and information (in an environment where information is produced endogenously). This taxonomy is especially apt, since the present study focuses likewise on the interaction of institutions and asymmetric information. Our study falls into the first category, and we are concerned not so much with whether our markets disseminate insider information, but rather how effectively they do so. In our experimental markets, there is no endogenous information production, while information aggregation occurs rather quickly, in the sense that price consensus (all dealer spreads overlapping each other) is readily - if imperfectly - enforced by arbitrage. Our study differs from most experimental double-auction studies (but not all; see, for example, Forsythe, Palfrey, and Plott (1982), and Plott and Sunder (1982)), in that our traders can both buy and sell the asset. Moreover, our dealers must act as market makers, providing bid and ask quotes to other dealers at all times. ${ }^{9}$

Our market framework is based on Glosten and Milgrom's (1985) model; it is a quotedriven, continuous securities market in which five market makers trade a single imaginary

9 The use of market makers - who must quote upon demand - as opposed to non-market-making dealers (who can both buy and sell, but may refuse to quote when asked), is relatively rare in experimental studies, although they are a central feature of most decentralized dealer markets in the real world. There is a large literature on experimental securities markets, and a full discussion of the issues is well beyond the scope of this chapter. Surveys of the literature may be found in Davis and Holt (1993), Duxbury (1995), Friedman and Sunder (1994), Plott (1982), and Sunder (1995), among others. 
security. We use three groups of professional securities dealers as experimental subjects. ${ }^{10}$

The market makers set quotes and trade with each other and with computerized external customers. The latter are either informed traders or noise traders. In each trading round, one of the market makers is randomly chosen to be the "insider". The insider knows the underlying value of the security. Since the insider is a market maker, they both trade and compete on price with the other market makers. In these experiments we use the notion of pretrade and post-trade transparency to distinguish between four different trading mechanisms. Following Pagano and Röell (1996), we define pre-trade transparency as the amount of quoted price information available to market makers, and post-trade transparency as the amount of transaction information available to market makers. We measure the relative private gains (in terms of insider profits) and public gains (in terms of speed of price discovery and size of dealer spreads) associated with various trading mechanisms when information asymmetries are present.

The contribution of this chapter is three-fold. First, we consider four different trading mechanisms in which we explicitly distinguish between pre- and post-trade transparency in our analysis. (Other studies examining insider trading in different trading mechanisms use a quite general notion of transparency; see e.g. Pagano and Röll (1996), and Schnitzlein (1996).) The distinction between price and transaction information is important, as the different types of information flows have different effects on market outcomes. It is also important in terms of inter-market competition, as competing exchanges worldwide implement trading mechanisms that indeed differ in the levels of both pre- and post-trade transparency.

Second, we use an experimental setting in which continuous trading is possible. This provides us with extensive time-series data: thousands of transactions and hundreds of quote settings for each of the trading mechanisms. Most experimental studies on microstructure have only a fraction of this available. Moreover, we use professional market makers as the subjects in our experiment. This is an important advantage over experiments using students as subjects.

10 Friedman and Sunder (1994, chapter 4) raise the possibility that student subjects may be preferable to professionals under some circumstances. Specifically, professional concerns, habits, and experiences may contradict trading procedures in the experimental market, and realistic payoffs (from the perspective of the research budget) may appear inconsequential to gainfully employed professionals. Although this is an important issue, we argue that does not significantly affect our current results. First, we have no indication, either from observing activity in the lab or during the formal post-experiment debriefing of the subjects, that our professional traders (who participated voluntarily) were not taking their task seriously or had failed to correctly understand their objectives and strategies in the experimental market. Moreover, in related research numerous student replications of the results from professional subjects were conducted. Although the students were clearly more likely than the professionals to request additional practice, to employ idiosyncratic trading tactics, and to ask basic questions about trading rules and procedures, the final results were always qualitatively the same. Regarding the magnitude of payoffs, our relatively small cash amounts are undoubtedly insufficient to induce the same sort of risk aversion that obtains in real securities markets. However, it is not clear that the use of student subjects would make the experiments more realistic in this regard. 
Third, we offer an alternative view of insider trading by giving the insider a different role than in most other studies (e.g. Kyle (1985), Glosten and Milgrom (1985), Easley and O'Hara (1992), and Schnitzlein (1996)). Generally, the insider is regarded as an external customer submitting orders to the financial market. Market makers then compete for the order via their quoted prices, and the order is typically executed against the best price. In contrast, our insider is a market maker, competing directly on price with other market makers. (Lyons (1996a), for example, examines the role of private order flow as a source of inter-dealer information asymmetries in a multiple-dealer market.) Our set-up is closest institutionally to multiple-dealer financial markets such as NASDAQ or the foreign exchange market.

We find an inverse connection between insider profits and the price efficiency of the market. Slow price discovery allows insiders greater opportunities to accumulate speculative inventories at advantageous prices. At the same time, however, we find that post-trade transparency (i.e., a public ticker) improves price discovery, while pre-trade transparency reduces price discovery. Consequently, post-trade transparency reduces insider profits, while pre-trade transparency increases them. Meanwhile, increased pre-trade transparency reduces dealers' uncertainty and reduces market liquidity (as measured by bid-ask spreads), while post-trade transparency induces dealers to compete for private order flow, thus reducing spreads and increasing liquidity.

The chapter is organized as follows. In section 3.2 we explain the experimental design and we introduce some terminology. Section 3.3 discusses the data obtained from the experiments and section 3.4 presents some results. Section 3.5 summarizes the results and concludes.

\subsection{Experimental Design and Terminology}

This section presents the experimental set-up. Our goal is to investigate how transparency affects the impact of asymmetric information on a financial market. More specifically, we examine price discovery (i.e., the convergence of dealer prices to the underlying value), the distribution of profits, and bid-ask spreads. Our tests involve a computerized experimental securities market in which a number of human dealers (including one with an informational advantage, referred to as the "insider") trade continuously with each other and non-marketmaking customers. Trading is for a single imaginary security.

\subsubsection{Market Design}

Our experimental microstructure is essentially the continuous multiple-dealer version of the pure dealership market used by Glosten and Milgrom (1985). In their model, a specialist sets quotes and confronts investors who observe the quoted bid and ask prices and decide whether to trade (one unit at a time). The specialist is free to reset the bid and/or ask prices any time. The investors represent both informed and liquidity traders and do not compete with the 
specialist, since they do not set limit orders in the market. Note that this market is quotedriven, in the sense that the specialist first sets quotes and then confronts orders from traders. This is the main difference between our experimental design and Kyle's (1985) order-driven framework. In the latter model, the quantities traded by both informed and liquidity traders are first batched, and the market maker then determines a market-clearing price. (See Madhavan (1992) for an overview of the differences between quote-driven and order-driven markets. The Kyle model is the underlying framework of the experimental market used by Schnitzlein (1996).) Our experimental design is thus most similar to the quote-driven experimental markets used by Bloomfield and O'Hara (1999), FHKM (1999), and FHKR (1999). There are two significant differences here, compared with the experimental design of Bloomfield and O'Hara (1999). First, our market makers both set quotes (required) and initiate trades (voluntary), thereby allowing for inter-dealer trading. Inter-dealer trading is a significant component of a number of important markets, including futures and options exchanges, the OTC stock market, and the interbank foreign exchange and money markets. Second, our market is continuous rather than sequential, in the sense that the dealers may trade and revise their quotes at any time during the round. The most important difference with FHKM and FHKR is that in their experiments there is no strategic, price-competing insider present. Moreover, we consider pre-trade and post-trade transparency simultaneously. FHKM analyze the effect of pre-trade transparency when post-trade transparency is low. FHKR examine the impact of post-trade transparency when pre-trade transparency is low.

\subsubsection{The Role of the Dealers}

A priori, the security's true (underlying) value is unknown to all human dealers but one. Before the start of each trading round all dealers receive a note. One of these notes has the true value printed on it, making the dealer who receives it the insider; the other notes have no information. The true value of the security can be seen as an ex-post liquidation value as used in, among others, the Kyle and the Glosten and Milgrom models. Each participant is the insider in either two or three rounds. All dealers are informed that there is exactly one insider in every round. The true value is revealed publicly at the end of each trading round.

At the start of each round, each dealer is given an initial endowment of 1000 esquires (a fictional numeraire currency). Dealers are instructed to maximize their end-of-round wealth by trading on the security. Wealth is expressed in esquires. Dealers can gain or lose wealth during each round by buying and selling the security (i.e., by jobbing) and by building a long or short inventory of the security (speculating). Dealers are not instructed about possible trading strategies, neither when they are the insider nor when they are an outsider. Each dealer trades according to their own expectations and predilections. If, at the end of the round, a dealer has a non-zero inventory position in the security, the trading software converts the inventory to cash (esquires) at the security's true value, thus realizing any capital gain or loss on the position. 
The true value is set at random and differs in each practice and session round (the values appear in tables 3.1-3.6). The true value in any round is unrelated to the values in any other rounds. In effect, trading in every round can be regarded as trading for a new security. Dealers are told only that the true value is somewhere between a minimum of 1 and a maximum of 200. At the start of each round, the (non-insider) dealers do not have any prior information about the true value in that round, apart from the information that the price is uniformly distributed on the $[1,200]$ range.

\subsubsection{Quoting, Trading, and Pre-Trade Transparency}

At the start of each round, each dealer is obliged to enter a quote (that is, a bid price and an ask price) within 10 seconds. Dealers who fail to enter an initial quote within the first 10 seconds are penalized at the rate of 10 esquires per second after that, until an initial quote is entered. Thereafter, every dealer always has a quote outstanding, at which the other market makers and the external customer can trade. (We use the terms "external customer" and "robot" interchangeably.) The maximum individual spread is limited to 30 esquires."

The primary parameters in our experiments are the level of pre-trade transparency and the level of post-trade transparency. These parameters define our trading mechanisms. Both variables can assume one of two values: high or low. When the level of pre-trade transparency is high (we also refer to this as "full quote disclosure"), all outstanding price quotes appear continuously on the trading screen of each market maker. Bid and ask prices appear in separate queues in the center of the screen. Best prices are at the top of the queue; that is, bid (ask) prices are ranked from the top of the screen down in decreasing (increasing) order. Next to every price, the identity of the dealer who quoted this price appears, with the letters "A" through "E" indicating the five market makers, and " $R$ " denoting the (non market making) robot. If at any time the bid (ask) price of several dealers is the same, then the most recently quoted price is at the top (i.e., strict price-and-time priority holds). An example of the trading screen appears in figure 3.1. A financial markets analogy is the basic NASDAQ retail trading screen. When a dealer opts to buy (sell), they automatically do so at the lowest (highest) quoted ask (bid) price.

When the level of pre-trade transparency is low (this situation is also referred to as "no quote disclosure"), no price information is publicly available. Instead, prices and transactions are communicated on a strictly bilateral basis. Dealers call each other to obtain price quotes. The dealer who receives a call does not respond actively. They do not even notice that they are being called; instead, their most recently quoted bid and ask prices automatically appear on the caller's screen. Then, the caller has the option to buy, sell, or do nothing. The size of a trade is always equal to one.

11 This restriction is imposed to prevent dealers from effectively exiting the market by quoting infinite spreads. 


\section{Figure 3.1}

\section{Trading Sereen}

This figure depicts an example of a trading screen in the market without quote disclosure. All dealers have their own trading screen. The window on the left presents the cash balance (790 esquires), this dealer's inventory (2 shares long), this dealer's outstanding quote of $(90-110)$, and this dealer's approximate profit, based on the price of the last transaction in which they were involved (1010 esquires). The window also shows the time remaining in this round. When this dealer calls another dealer, bid and ask quotes appear in the center window. In the heading of this window, "ID" denotes the identity of the quoting dealer, "Sell" denotes the quoted bid (at which this dealer can sell), and "Buy" denotes the quoted ask (at which this dealer can buy). In the market with full quote disclosure where all quotes are disclosed publicly, all bids are presented below "Sell" ranked from highest to lowest and all asks are presented below "Buy" ranked from lowest to highest. Information on past transactions appears at the right of the trading screen. By default, it displays the details of the last 20 transactions; the dealer can scroll through the list with the PageUp and PageDown keys. For all transactions, the identities of the buying (under heading "buy") and the selling ("sel") dealer are displayed, along with the number of shares traded and the transaction price. For example, the first row indicates that this dealer (his identity is depicted by ${ }^{\circ}$ ) bought one share for 100 esquires from dealer $B$. The five dealers' identities are denoted by letter ranging from " $A$ " through " $E$ ". The robot is denoted with the letter " $R$ ". The fourth transaction is thus an example of a trade in which the robot sold one share to this dealer for 110 esquires.

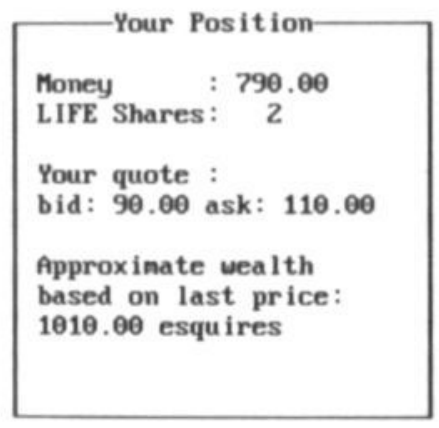

Tine renaining: $158 \mathrm{sec}$

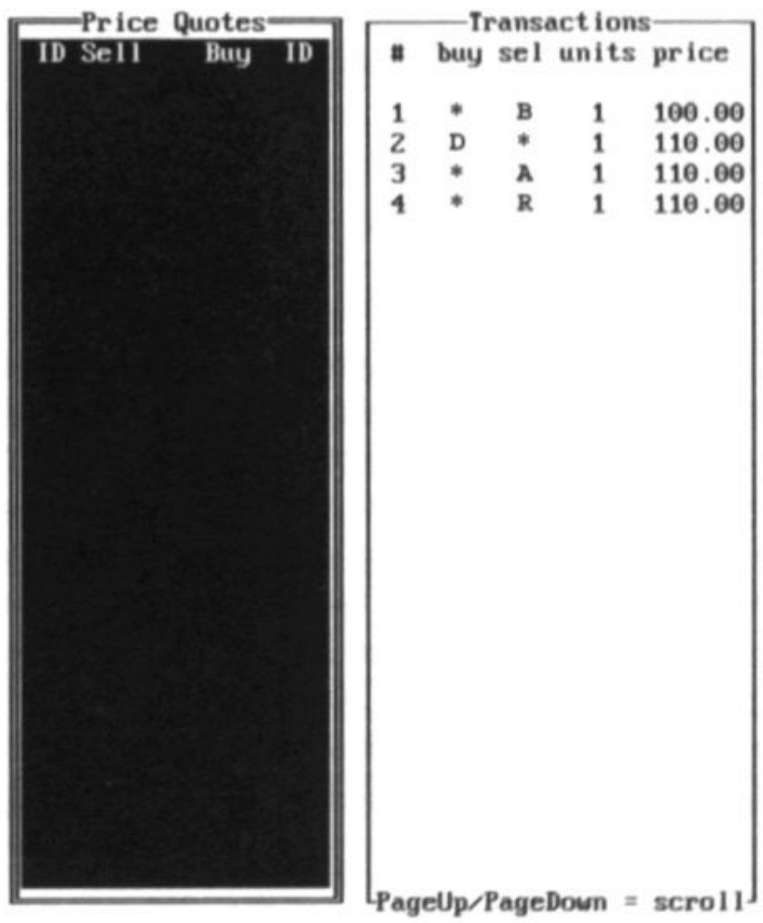




\subsubsection{Transaction Information and Post-Trade Transparency}

A high level of post-trade transparency implies that there is full and immediate trade disclosure. That is, every dealer receives information about all transactions that have occurred. A financial markets analogy is a public stock ticker that reports the details of the day's trades. The information appears in a transaction history window on the trading screen and consiss of the identities of the buyer and seller, the transaction size (which always equals one share in our set-up) and the price at which the transaction cleared. When the level of post-tade transparency is low, only transactions in which a particular dealer was involved are listed in their window. There is no delay in trade disclosure.

\subsubsection{Robot Behavior}

As mentioned above, the experiment involves two types of subjects. In addition to the five human dealers, there is a computerized (robot) trader in our market. This robot does not set quotes and cannot be called by the market makers. The robot represents an external custoner of the securities market. The robot is programmed to trade every 7 seconds against the test prices in the market. ${ }^{12}$ Prior to each robot transaction, it is determined by chance whether the trade is an informed or an uninformed one. The noise level - i.e., the a priori probability, $\alpha$, that a trade is informed - equals 0.5 in all rounds. At the start of the experiment, the dealers are told this probability. The dealers can therefore expect about half of the robot trades to be informed. Note that the market makers are never told whether a particular robot trade was informed or uninformed. However, given their knowledge of the probability that a robot is informed $(\alpha)$, dealers may be able to filter relevant price information by observing robot transactions.

If the robot initiates an informed trade, it buys (sells) if the lowest ask price (highest bid price) at that time is below (above) the true value of the security. The robot does not trade if quoted bid-ask spreads surround the true value. Note that the robot maximizes its expected profits only at the trade level; there is no dynamic strategy. Over the whole round the robot is restricted to trading only at multiples of 7 seconds. Since informed robot trades depend on the true value, these transactions contain direct information about the true value. If a robot initiates an uninformed trade, a binomial random draw (with probability one half) determines whether the robot sells or buys; if it sells (buys), it does so against the highest bid price (lowest ask price) available. Details of robot transactions follow the same post-trade transparency rules as inter-dealer transactions. As the identity of the robot is denoted with the letter " $R$ ", a robot trade that appears in the transaction history window is distinguishable from inter-dealer trades.

12 The frequency of robot trades in our experiments is taken from FHKM (1999). While FHKM employ two robots, each programmed to trade every 7 seconds, we have limited the number of robots to one, because there is an important additional source of private information in our experiments. We strongly believe that our results do not critically depend on either the frequency of robot trades or the number of robots. 


\subsubsection{Rounds and Parameters}

Together, the two experimental parameters - the level of pre-trade transparency (high or low) and the level of post-trade transparency (high or low) - are combined in a full-factorial design (i.e., using all four possible combinations). In addition, there are two nuisance parameters, namely the true value of the security, which changes each round, and the particular sequence in which the experimental variables are implemented.

We ran the experiments with three groups of human subjects. Each group of subjects traded in two "sessions" consisting of six five-minute trading rounds per session. In order to control for possible learning effects, the first group started with a session with no quote disclosure, and then moved on to a session of full quote disclosure; the second group, on the other hand, followed the opposite sequence. The third group followed the same sequence as the first (except that they completed only four rounds with each pre-trade transparency treatment). Within each session, post-trade transparency alternated between low and high from round to round. Each trading session followed two five-minute practice rounds, one in which the level of post-trade transparency was low and the other in which it was high. The practice rounds acquaint the subjects with the trading system and provide a chance to ask questions. In the "real" (i.e., the non-practice) rounds, subjects were paid for their results. The data reported here come from the real sessions.

At the end of each round, all dealers learn their final wealth. Esquires are translated into Dutch guilders according to the following payment scheme, which is explained to the dealers before the start of the experiment (1 USD was around $1.75 \mathrm{NLG}$ at the time of the first two experiments and around $2.30 \mathrm{NLG}$ at the time of the third experiment). In every round, 15 guilders are divided among all market makers, making this a fixed-sum game. Because the true value strongly influences the insider's speculative profits, and because the insider has an overwhelming informational advantage, we adjust the final guilder payments so that they do not depend linearly on the insider's esquire wealth, but rather on their wealth compared with other dealers. A linear payoff scheme would create incentives for speculative behavior by the outsiders. ${ }^{13}$ Specifically, if the insider fails to earn the highest esquire wealth, their guilder payoff is zero. Otherwise, they receive 6 guilders if their esquire wealth is more than three

\footnotetext{
13 The purpose of our admittedly complex payoff scheme is to cap payoffs to the insider, to prevent the game from becoming a winner-take-all contest (which would disrupt risk-sharing among the dealers). Because the insider begins trading with such an extreme informational advantage, guilder payoffs to the four outsiders under a traditional linear payoff scheme would typically be minuscule. This creates incentives for risk-seeking behavior by the outsiders (that is, speculating as heavily as possible on a random guess about the true value, in hopes of keeping pace with the insider); similar effects were revealed in pretests of the experimental software using student subjects. The three payoff buckets for the insider are intended to maintain an incentive for active trading at the margin. Note that this payoff scheme is not a classic "beat-the-market" tournament, in the sense of James and Isaac (2000). First, only the insider is singled out for a relative payoff rule. Second and more importantly, there is not a fixed exogenous distribution for the true value. Rather, the true value is non-random, and dealers are able to learn it in the course of trading. so that persistent price bubbles (rational deviations of quoted prices from the true value) are extremely unlikely, and indeed do not occur in our data. Lastly, we are comforted by the fact that our results appear to conform closely to the earlier results of FHKR (1999) and FHKM (1999), who use an affine payment scheme.
} 
times that of the best outsider; 5 guilders if their esquire wealth is between two and three times that of the best outsider; and 4 guilders when their esquire wealth is between one and two times that of the best outsider. What is left after the insider has been paid is divided among the other market makers according to their esquire wealth.

\subsection{Data}

The data was collected from experiments held at the laboratory of the Center for Research in Experimental Economics and Political Decision Making (CREED) at the University of Amsterdam. The subjects in the first experiment, conducted on January 27, 1997, are five professional option traders from Optiver. In the second experiment, conducted on February 3, 1997, five professional equity traders from ABN Amro Bank, de Generale Bank, and Oudhoff Effecten participated. These subjects acted as market makers in 12 independent rounds, divided into two six-round sessions. The third replication, involving five professional options traders from Amsterdam Options Traders, was conducted on April 21, 1999. Unfortunately, an operating system failure at the CREED lab forced us to abandon this set of replications before we were done. Eight rounds of usable data were produced, however. We do not expect this to affect our results.

Tables 3.1-3.6 present the settings in each round and some basic summary statistics. In the trading mode without quote disclosure we obtain, on average, 45 quote settings, 130 transactions in which only outsiders (i.e., the four dealers who did not receive inside information) are involved, 180 transactions between the insider and an outsider, and 37 transactions initiated by the robot. Disclosing quotes leads to more activity in the market. In the trading mode where quotes are disclosed there were, on average, 65 quote settings, 197 transactions in which only outsiders are involved, 291 transactions between the insider and an outsider, and 35 transactions initiated by the robot. These averages are taken over all three subject groups. 
Table 3.1

Summary Statistics

This table contains summary statistics of the trading rounds without quote disclosure for the first group of subjects.

\section{Group 1}

session 1: no quote disclosure

\begin{tabular}{|c|c|c|c|c|c|c|}
\hline Round no. & 1 & 2 & 3 & 4 & 5 & 6 \\
\hline \multicolumn{7}{|l|}{ Settings } \\
\hline Post-trade transparency & L & H & L & $\mathbf{H}$ & L & $\mathrm{H}$ \\
\hline$\alpha$ & 0.5 & 0.5 & 0.5 & 0.5 & 0.5 & 0.5 \\
\hline True value & 61 & 44 & 152 & 186 & 19 & 151 \\
\hline \multicolumn{7}{|l|}{ Results } \\
\hline \# Quotes set & 38 & 35 & 50 & 61 & 69 & 40 \\
\hline \multicolumn{7}{|l|}{$\#$ Trades } \\
\hline Total & 315 & 442 & 121 & 199 & 279 & 328 \\
\hline Outsiders ' & 149 & 180 & 44 & 53 & 125 & 80 \\
\hline Insider $^{2}$ & 132 & 220 & 44 & 105 & 116 & 215 \\
\hline Robot & 34 & 42 & 33 & 41 & 38 & 33 \\
\hline \multicolumn{7}{|l|}{ Avg. dealer spreads } \\
\hline Outsiders & 29 & 26 & 26 & 27 & 23 & 27 \\
\hline Insider & 24 & 30 & 22 & 25 & 24 & 23 \\
\hline
\end{tabular}

Average end-of-round capital ${ }^{3}$

Dealers

Outsiders

-Std. deviation

$-430$

$-945$

(2401)

$-95$

$-1265$

$-1175$

$-451$

(450) (1938) (2283)

Insider

1733

3410

203

4408

4085

Trades in which only (human) outsiders are involved.

2 Trades in which the insider is involved.

3 Expressed in esquires and excluding the initial amount of capital. 
Table 3.2

Summary Statistics

This table contains summary statistics of the trading rounds with quote disclosure for the first group of subjects.

\section{Group 1}

session 2: quote disclosure

Round no.

2

3

4

5

6

\section{Settings}

Level of post-trade

L H

L

H

L

H

transparency

$\alpha$

0.5

0.5

0.5

0.5

0.5

0.5

True value

186

81

134

64

49

165

Results

\# Quotes set

91

74

87

78

98

61

\# Trades

\section{Total}

Outsiders '

673

518

638

816

664

652

Insider $^{2}$

351

252

247

322

213

Robot

280

238

363

453

449

42

28

28

41

412

38

Avg. dealer spreads

Outsiders

15

17

13

25

18

Insider

30

12

23

19

21

12

Average end-of-round capital ${ }^{3}$

Dealers

Outsiders

- Std. deviation

Insider

15041

(3740)

$-4089$

(133)

(134)

$-417$

(484)

(3173)

1719

504

\footnotetext{
1 Trades in which only (human) outsiders are involved.

2 Trades in which the insider is involved.

3 Expressed in esquires and excluding the initial amount of capital.
} 
Table 3.3

Summary Statistics

This table contains summary statistics of the trading rounds without quote disclosure for the second group of subjects.

\section{Group 2}

session 2: no quote disclosure

\begin{tabular}{lcccccr} 
Round no. & $\mathrm{I}$ & 2 & 3 & 4 & 5 & 6 \\
\cline { 2 - 7 } & & & & & & \\
$\begin{array}{l}\text { Settings } \\
\text { Level of post-trade }\end{array}$ & $\mathrm{L}$ & $\mathrm{H}$ & $\mathrm{L}$ & $\mathrm{H}$ & $\mathrm{L}$ & $\mathrm{H}$ \\
$\begin{array}{l}\text { transparency } \\
\alpha\end{array}$ & 0.5 & 0.5 & 0.5 & 0.5 & 0.5 & 0.5 \\
True value & 61 & 44 & 152 & 186 & 19 & 151
\end{tabular}

Results

$\begin{array}{lcccccc}\text { \# Quotes set } & 38 & 42 & 41 & 36 & 45 & 44 \\ \begin{array}{l}\text { \# Trades } \\ \text { Total }\end{array} & 289 & 551 & 330 & 558 & 324 & 337 \\ \text { Outsiders }^{1} & 121 & 228 & 154 & 306 & 114 & 104 \\ \text { Insider }^{2} & 134 & 281 & 141 & 210 & 169 & 202 \\ \text { Robot } & 34 & 42 & 35 & 42 & 41 & 31\end{array}$

Avg. dealer spreads

$\begin{array}{lllllll}\text { Outsiders } & 22 & 23 & 23 & 27 & 26 & 24 \\ \text { Insider } & 15 & 30 & 23 & 27 & 28 & 23\end{array}$

Average end-of-round capital ${ }^{3}$

Dealers

$\begin{array}{lcccccc}\text { Outsiders } & -324 & -1961 & -549 & -3764 & -1003 & -594 \\ - \text { Std. deviation } & (949) & (4406) & (1673) & (12243) & (1722) & (1679)\end{array}$

$\begin{array}{lllllll}\text { Insider } & 1358 & 7698 & 2015 & 13118 & 3521 & 2139\end{array}$

\footnotetext{
Trades in which only (human) outsiders are involved.

Trades in which the insider is involved.

3 Expressed in esquires and excluding the initial amount of capital.
} 
Table 3.4

\section{Summary Statistics}

This table contains summary statistics of the trading rounds with quote disclosure for the second group of subjects.

Group 2

session 1: quote disclosure

$\begin{array}{lllllll}\text { Round no. } & 1 & 2 & 3 & 4 & 5 & 6\end{array}$

Settings

Level of post-trade

L $\quad$ H

L

H

L

H

transparency

$\alpha$

$0.5 \quad 0.5$

0.5

0.5

0.5

0.5

True value

186

81

134

64

Results

\# Quotes set

39

57

56

40

45

\# Trades

Total
Outsiders '
Insider $^{2}$
Robot

580

501

398

514

449

748

178

265

135

155

283

359

205

237

163

426

43

31

26

326

248

39

Avg. dealer spreads

Outsiders

23

25

24

33

38

Insider

26

23

17

25

22

20

$16 \quad 14$

29

Average end-of-round capital ${ }^{3}$

Dealers

Outsiders

$-6334$

$-371$

$-365$

$-733$

$-543$

$-1376$

- Std. deviation

(10157)

(976)

(561)

(753)

(1045)

(4146)

Insider

24902

1565

1539

2834

2127

Trades in which only (human) outsiders are involved.

2 Trades in which the insider is involved.

3 Expressed in esquires and excluding the initial amount of capital. 
Table 3.5

Summary Statistics

This table contains summary statistics of the trading rounds without quote disclosure for the third group of subjects.

\section{Group 3}

session 1: no quote disclosure

$\begin{array}{lllll}\text { Round no. } & 1 & 2 & 3 & 4\end{array}$

\section{Settings}

Level of post-trade

L

H

L

H

transparency

$\alpha$

0.5

0.5

0.5

0.5

True value

61

44

152

186

Results

\# Quotes set

48

47

49

45

\# Trades

Total

118

513

209

638

Outsiders ${ }^{1}$

67

137

116

Insider $^{2}$

24

334

486

Robot

27

42

36

Avg. dealer spreads

Outsiders

21

23

96

72

41

4

Insider

10

27

21

24

28

26

Average end-of-round capital ${ }^{3}$

Dealers

Outsiders

- Std. deviation

Insider

Trades in which only (human) outsiders are involved.

2 Trades in which the insider is involved.

${ }^{3}$ Expressed in esquires and excluding the initial amount of capital. 
Table 3.6

Summary Statistics

This table contains summary statistics of the trading rounds with quote disclosure for the third group of subjects.

\section{Group 3}

session 2: quote disclosure

Round no.

1

2

3

4

\section{Settings}

Level of post-trade

L

$\mathrm{H}$

L

H

transparency

$\alpha$

0.5

0.5

0.5

0.5

True value

186

81

134

64

Results

\# Quotes set

49

72

72

65

\# Trades

Total

371

179

458

200

Outsiders ${ }^{\prime}$

159

86

83

91

Insider $^{2}$

182

66

340

69

Robot

30

27

35

40

Avg. dealer spreads

$\begin{array}{lll}\text { Outsiders } & 20 & 18 \\ \text { Insider } & 21 & 18\end{array}$

18
18

23

25

Average end-of-round capital ${ }^{3}$

Dealers

Outsiders

$-1169$

$-216$

$-848$

- Std. deviation

(2346)

(267)

(1373)

Insider

4367

853

3296

275

Trades in which only (human) outsiders are involved.

2 Trades in which the insider is involved.

3 Expressed in esquires and excluding the initial amount of capital. 
Table 3.7

Summary Statistics for Each Trading Mechanism

In this table the summary statistics for individual rounds depicted in tables $\mathbf{3 . 1}$ through $\mathbf{3 . 6}$ are averaged over all three groups and eight rounds to obtain summary statistics for the four trading mechanisms.

\begin{tabular}{|c|c|c|c|c|}
\hline Trading Mechanism ' & LL & LH & $\mathrm{HL}$ & $\mathrm{HH}$ \\
\hline Number of quotes set & 47.3 & 43.8 & 67.2 & 62.4 \\
\hline \multicolumn{5}{|l|}{ Number of trades } \\
\hline Total & 248.1 & 445.8 & 528.9 & 516.0 \\
\hline Outsiders & 108.8 & 150.5 & 191.1 & 202.4 \\
\hline Insider & 104.0 & 256.6 & 302.6 & 279.0 \\
\hline Robot & 35.4 & 38.6 & 35.1 & 34.6 \\
\hline \multicolumn{5}{|l|}{ Average dealer spreads } \\
\hline Outsiders & 23.9 & 25.1 & 20.1 & 21.1 \\
\hline Insider & 21.8 & 26.4 & 22.8 & 17.3 \\
\hline \multicolumn{5}{|l|}{ Average end-of-round capital } \\
\hline Outsiders & -518.1 & -1737.5 & -2024.5 & -358.6 \\
\hline Insider & 1837.3 & 6361.6 & 7722.5 & 1337.9 \\
\hline \multicolumn{5}{|l|}{ Price discovery } \\
\hline Time to convergence ${ }^{2}$ & 185.8 & 241.3 & 138.6 & 105.5 \\
\hline \multicolumn{5}{|l|}{ Percentage price error ${ }^{3}$} \\
\hline after 100 seconds & 0.39 & 0.57 & 0.39 & 0.32 \\
\hline after 200 seconds & 0.12 & 0.23 & 0.32 & 0.15 \\
\hline after 300 seconds & 0.06 & 0.09 & 0.18 & 0.14 \\
\hline
\end{tabular}

I LL: low pre-trade transparency, low post-trade transparency

LH: low pre-trade transparency, high post-trade transparency

HL: high pre-trade transparency, low post-trade transparency

$\mathrm{HH}$ : high pre-trade transparency, high post-trade transparency

2 Average number of seconds until the average quote midpoint for all dealers has converged to less than 5 esquires away from the underlying true value.

3 Average price error after $t$ seconds, divided by the average price error after 20 seconds. 


\subsection{Results}

The following analysis examines the speed of price discovery, the level of insider profitability, and bid-ask spreads (as measures of efficiency, unfairness, and liquidity, respectively). We regard them as functions of pre-trade and post-trade transparency, and we consider the full-factorial $2 \times 2$ matrix of transparency arrangements. We adopt a two-letter notational shorthand, in which the first letter indicates the pre-trade transparency treatment and the second letter indicates post-trade transparency. For example, "HL" indicates a high pre-trade and low post-trade transparency regime. The summary statistics aggregated for each transparency regime appear in table 3.7, and offer a preview of the more detailed results discussed below. Our results are consistent with the earlier work of FHKR (1999), Bloomfield and O'Hara (1999), Madhavan (1995), and FHKM (1999), who also examine price discovery in multiple-dealer experimental markets. However, neither of these earlier papers considers all four transparency combinations examined here, and neither includes an asymmetrically informed dealer.

\subsubsection{Price Efficiency}

In this section we concentrate on the effect of pre- and post-trade transparency on the informational efficiency of prices. In our experiments, information about the true value of the security is brought into the market via transactions of the informed robot trader and the market maker with inside information. As the expected flow of informed robot transactions is constant over the different trading regimes, differences in price efficiency should reflect differences in the transparency regime. As we show in the next subsection, these differences in price discovery have important implications for insider profitability: insiders profit more when price discovery is slow.

Following Bloomfield and O'Hara (1999), FHKR (1999), FHKM (1999), and Schnitzlein (1997), we use price errors to measure the efficiency of the market. Our hypothesis on the effect of transparency on price efficiency is based on the results of, among others, Bloomfield and O'Hara (1999), FHKR (1999), and Pagano and Rőell (1996). These studies find that increasing post-trade transparency leads to greater efficiency. The presumption would be that it is relatively hard for insiders to hide private information when transaction information is widely available to the non-insider market makers. In contrast, FHKM (1999) find a search-cost effect that causes increased pre-trade transparency to reduce efficiency in a multiple-dealer market. For simplicity, we state our null-hypothesis to apply equally to both pre- and post-trade transparency:

\section{H1: The decline of the price errors is faster in (pre-trade and/or post-trade) transparent markets than in less (pre-trade and/or post-trade) transparent markets,}

while acknowledging that low pre-trade transparency may behave counter intuitively. 


\section{Figure 3.2 \\ Price Errors}

This figure shows the average price errors for each combination of transparency variables; e.g. "low, high" refers to low pre-trade and high post-trade transparency. Price errors are defined as the absolute difference between the true value of the security and the average midpoint of outstanding quotes. The price errors are averaged across all rounds with the specified combination of transparency variables. The first 20 seconds of each round are omitted in order to allow time for all dealers to submit their first quotes.

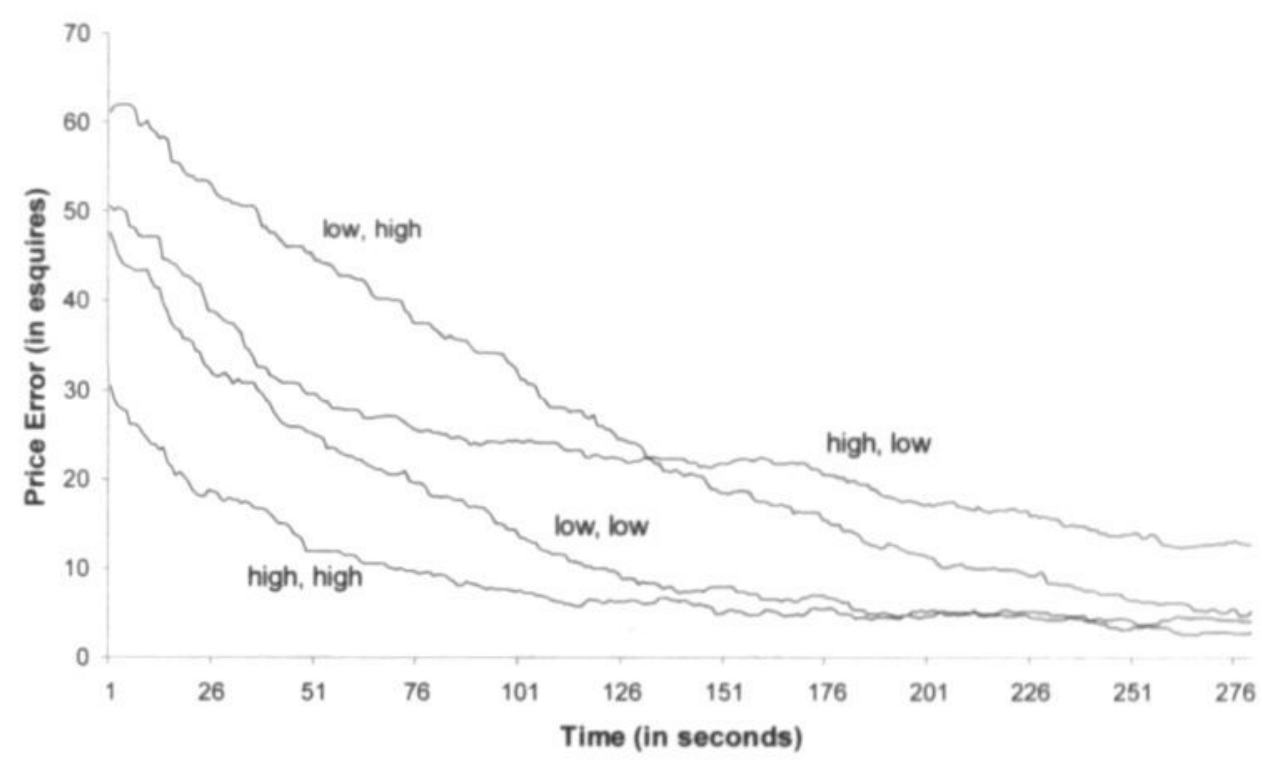

Figure 3.2 shows the average price error time path for each of the four trading mechanisms. We define price errors as the absolute difference between the average midpoint of all outstanding quotes and the underlying value of the security. Since the only ex-ante information uninformed market makers have about the underlying value is that it lies between 1 and 200, their best initial guess should be that the underlying value is around 100 . This guess is reflected in the value of the price error at the beginning of each round, which is generally close to the absolute difference between the true value and 100. As shown in figure 3.2 and the last panel of table 3.7 , price errors clearly move towards zero after the first 20 seconds, a pattern observed in all four trading mechanisms. Price errors decline as more information about the underlying value of the security is brought into the market. By definition, the better the market's ability to transmit information, the faster price errors decline. While the average price error paths in figure 3.2 disguise considerable round-to-round variation in initial errors and convergence rates, the most and least transparent cases ( $\mathrm{HH}$ and LL) appear to perform well relative to the others. 
This supposition is borne out by a more controlled statistical analysis. In table 3.8 we average price errors across all three groups and all rounds with a common transparency regime. Averages of dealer spread midpoints are taken at 50 -second intervals throughout the trading round, and are normalized by the initial error for the round. (The initial error is defined as abs(100 - TrueValue $)$, since the expected starting quote for the uninformed dealers is 100.) Normalization compensates for differences in the true value of the security across rounds, allowing meaningful averages and comparisons. The bulk of price discovery occurs during the first 150 seconds of trading, and the $\mathrm{HH}$ and $\mathrm{LL}$ regimes outperform $\mathrm{HL}$ and $\mathrm{LH}$ over this interval. After 150 seconds, average price errors are over twice as large for $\mathrm{HL}$ $(38 \%)$ and $\mathrm{LH}(36 \%)$ as they are for either HH (17\%) or LL (15\%). Over the full 300 second period, $\mathrm{LH}$ also performs quite well.

Table 3.8

Normalized Price Errors in Different Trading Mechanisms

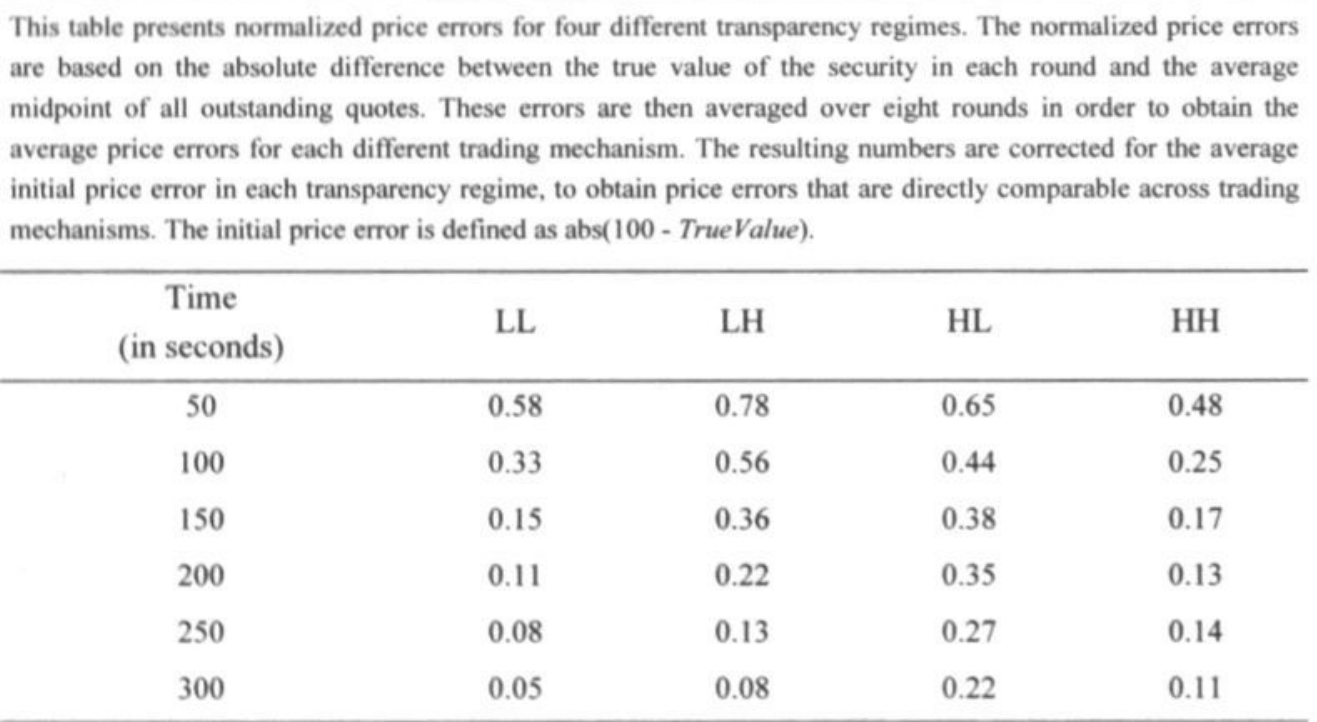

More formally, we estimate an individual effects panel model to examine the price efficiency in each of the four different trading mechanisms used in the experiments. (For details on estimating fixed individual effects panel models, see Baltagi (1995).) Thus, we regress the price errors obtained in all 32 rounds on a constant, 32 individual-round dummies and four trend dummies. The dummy variables are included in order to isolate the effects of transparency. 
The estimated equation is

$$
\mid \mathrm{P}_{t r i}-\text { TrueValue }, \mid=\beta_{0}+\sum_{i=1}^{32} \beta_{i} \mathrm{I}(r=i)+\sum_{j=L, L H, M L, H H} \beta_{j} \mathrm{I}(k=j) t+\varepsilon_{t r k},
$$

where $t$ denotes time in seconds, $r$ the trading round, $k$ the trading mechanism, $P_{t r k}$ is the average midpoint over all bid and ask quotes at time $t, \mathrm{I}(r=i)$ is a dummy variable for trading round which is equal to 1 if the trading round is equal to $i(i=1, \ldots, 32)$ and zero otherwise, $\mathrm{I}(k=j)$ is a dummy variable for trading mechanism which is equal to 1 if the trading mechanism is equal to $j(j=\mathrm{LL}, \mathrm{LH}, \mathrm{HL}, \mathrm{HH})$ and zero otherwise, and $\varepsilon_{\text {rrk }}$ is an i.i.d. error term. We impose the restriction $\beta_{l}=0$. Because the variance of the error term $\varepsilon_{\text {rrk }}$ may decrease as time passes and price errors converge to zero, we have employed standard errors that are robust to heteroskedasticity. Since dealers' behavior changes after price discovery is achieved - trends in prices typically level off abruptly at this point - we discard observations after the point in time at which price errors have converged to a value less than or equal to five. Moreover, we omit the transactions completed in the first twenty seconds of each trading round in order to ensure that all market makers have submitted bid and ask quotes. OLS estimates for equation (3.1) are presented in table 3.9a. The third column shows the estimate of the intercept, while the estimates of the trading mechanism dummies are depicted in the fourth column. Larger negative values for the slope coefficient imply faster price discovery. The estimates of the 32 individual-round dummies represent differences in the underlying value in each round and the identity of the insider. They are omitted to conserve space. The coefficients for the dummies are generally significantly different from zero, indicating that the underlying value and the personal characteristics of the insider may influence market outcomes.

Table $3.9 \mathrm{a}$ generally confirms the conclusions from table 3.8 , with the exception that the LL regime does not perform relatively as well in the regression analysis as it did in the more straightforward comparison of table 3.8. Table 3.9 thus largely supports hypothesis $\mathrm{HI}$, that efficiency is greater when transparency is higher. The results show a clear ranking of the different trading mechanisms, although estimates of the slope coefficients in table $3.9 \mathrm{a}$ are not significantly different from one another at a $5 \%$ level, as revealed in table $3.9 \mathrm{~b} .{ }^{14}$

\footnotetext{
14 Estimating equation (3.1) with transaction data rather than average spread midpoints yields larger (that is, more negative) slope coefficients for the low pre-trade transparency cases, and smaller coefficients for the high pre-trade cases. Using transaction price data, the estimated slopes are: LL $(-0.243)$, LH $(-0.302), \mathrm{HL}(-0.129)$, and $\mathrm{HH}(-0.232)$. The seemingly faster price discovery for the LL and LH cases is due to the fact that a significant minority of trades are made at off-market prices (a result of incomplete search by the dealer hitting the quote). Note that price trends become apparent in early trading, so that when prices trend upward (downward), the preponderance of dealers hit the asks (bids) of their peers. Meanwhile, we conjecture that the seemingly slower price discovery for the $\mathrm{HL}$ and $\mathrm{HH}$ cases reveals skewness in the typical distribution of quoted prices at a particular point in time. Recall that purchase (sale) orders go automatically to the best ask (bid) under high pre-trade transparency. Thus, if prices are trending upward (downward), quoting dealers are more aggressive about keeping their ask (bid) off the market to avoid being hit. The result is greater dispersion in ask (bid) prices, creating a gap between mean and median prices overall.
} 
Table 3.9a

Price Efficiency

This table presents the estimated intercept and the coefficients of the trading mechanism dummies from the fixed effects panel model depicted in equation (3.1). Robust standard errors are presented in parentheses. Significance at the $5 \%$ level is denoted by ${ }^{*}$. The number of data points is 4535 . The R-squared of the regression is equal to 0.756 .

\begin{tabular}{|c|c|c|c|c|}
\hline & $\begin{array}{c}\text { Pre-Trade } \\
\text { Transparency }\end{array}$ & $\begin{array}{c}\text { Post-Trade } \\
\text { Transparency }\end{array}$ & Estimated Intercept & $\begin{array}{c}\text { Estimated Slope } \\
\text { Coefficient }\end{array}$ \\
\hline LL & low & low & & $\begin{array}{l}-0.207^{*} \\
(0.030)\end{array}$ \\
\hline LH & low & high & $\begin{array}{c}\beta_{0}: 57.72^{*} \\
(2.449)\end{array}$ & $\begin{array}{l}-0.228^{*} \\
(0.034)\end{array}$ \\
\hline HL & high & low & & $\begin{array}{l}-0.138^{*} \\
(0.021)\end{array}$ \\
\hline $\mathrm{HH}$ & high & high & & $\begin{array}{l}-0.317^{*} \\
(0.141)\end{array}$ \\
\hline
\end{tabular}

Table 3.9b

Matched Pair Tests of Transparency Effect on Price Efficiency

This table presents the implications of changing the level of pre-trade and post-trade transparency on the price efficiency in the market. The effects of pre-trade and post-trade transparency on price efficiency are computed using the coefficients for the trading mechanism dummies in equation (3.1). The standard errors depicted in this table are robust to heteroskedasticity. None of the effects is statistically different from zero at the $95 \%$ confidence level.

\begin{tabular}{cccc}
\hline $\begin{array}{c}\text { Invariable } \\
\text { Transparency }\end{array}$ & Transparency Effect & $\begin{array}{c}\text { Trading } \\
\text { Mechanisms }\end{array}$ & Effect on Estimated Slope \\
\hline $\begin{array}{c}\text { low post-trade } \\
\text { transparency }\end{array}$ & pre-trade & LL vs. HL & 0.069 \\
$\begin{array}{c}\text { high post-trade } \\
\text { transparency }\end{array}$ & pre-trade & LH vs. HH & $(0.038)$ \\
low pre-trade & & & -0.089 \\
transparency & post-trade & LL vs. LH & $(0.145)$ \\
high pre-trade & & & -0.021 \\
transparency & post-trade & HL vs. HH & $(0.041)$ \\
\hline
\end{tabular}


The notable exception to the notion that more transparency is better is the least transparent microstructure (i.e., LL), in which efficiency is better than in the case with high pre-trade and low post-trade transparency $(\mathrm{HL})$; this difference is marginally statistically significant. This result confirms the earlier work of FHKM (1999), who find that price discovery is faster under LL than $\mathrm{HL}$; they argue that search costs can explain this counterintuitive result, as high pre-trade transparency sharply reduces the incentives for aggressive price improvements. The results of table 3.9 also confirm the conclusions of FHKR (1999), who find that price discovery is faster under LH than LL. Neither FHKR nor FHKM include an asymmetrically informed dealer in their experiments.

Lastly, we consider the implications of conditioning on only one of the transparency variables at a time. Row $\mathrm{A}$ of table 3.10 reports the results of estimating a modified version of equation (3.1), in which there are only two transparency dummies, based on the degree of pretrade transparency. In other words, the $\mathrm{HL}$ and $\mathrm{HH}$ rounds are pooled, as are the $\mathrm{LL}$ and $\mathrm{LH}$ rounds. The difference across coefficients for the pooled groups is marginally significant, and the search cost effect described by FHKM appears to dominate: price discovery is faster when pre-trade transparency is low. Moreover, the insider finds it easier to hide when quotes are publicly observed. Similarly, row B pools the HL and LL rounds (as well as the LH and HH rounds) to examine the impact of post-trade transparency. In this case, the transparency effect described by FHKR seems to dominate, as price discovery is faster when post-trade transparency is high. This difference is also marginally statistically significant.

\title{
Table 3.10
}

\section{Pooled Effects of Pre-Trade and Post-Trade Transparency on Efficiency}

\begin{abstract}
In the fixed effects panel model depicted in the first row (case A) of this table, LL and LH rounds are pooled (first column), as are $\mathrm{HL}$ and $\mathrm{HH}$ (second column), to examine the effect of conditioning solely on pre-trade transparency. In the second row (case B), LL and HL are pooled, as are LH and HH for a similar analysis of the effect post-trade transparency. Robust standard errors are in parentheses. Significance at the $5 \%$ level is denoted by $\bullet$. The differences between low-transparency and hightransparency estimates are not significantly different from zero at the $95 \%$ confidence level in either case $A$ or $B$. The number of data points is 4535 . The $R$-squared of regression $A(B)$ is equal to $0.748(0.750)$.
\end{abstract}

\begin{tabular}{cccc}
\hline Regression & $\begin{array}{c}\text { Estimated } \\
\text { Intercept }\end{array}$ & $\begin{array}{c}\text { Slope Estimate } \\
\text { Low Transparency }\end{array}$ & $\begin{array}{c}\text { Slope Estimate } \\
\text { High Transparency }\end{array}$ \\
\hline A: pre-trade & $57.053^{*}$ & $-0.221^{*}$ & $-0.160^{*}$ \\
transparency & $(2.162)$ & $(0.023)$ & $(0.026)$ \\
B: post-trade & $57.146^{*}$ & $-0.170^{*}$ & $-0.235^{*}$ \\
transparency & $(2.400)$ & $(0.021)$ & $(0.033)$ \\
\hline
\end{tabular}




\subsubsection{Insider Profits}

The profits for the inside dealer are closely related to price efficiency in that round. A slow convergence of price errors indicates that the propagation of information is slow. Although the insider's speculative inventory strategy is essentially unchanged by faster price discovery, their ability to acquire inventory at advantageous prices diminishes more quickly. Hence insider profits should be relatively large when efficiency is weak, and vice versa. In the preceding subsection we found evidence favoring our hypothesis that the speed of price discovery is positively dependent on market transparency, with the exception that the least transparent regime (LL) performs relatively well in this regard, consistent with the search-cost effect reported by FHKM (1999). With this exception, then, we expect a generally inverse relationship between insider profits and transparency, since insider profitability should be inversely related to the speed of price discovery. This expectation is consistent with the conclusions of Bloomfield and O'Hara (1999) and Pagano and Röell (1996). Hence, we formulate the following hypothesis:

\section{H2: Insider profits are lower in (pre-trade-and/or post-trade) transparent markets than in less (pre-trade and $/ o r$ post-trade) transparent markets.}

As with hypothesis $\mathrm{HI}$, however, we acknowledge the caveat that increased pre-trade transparency (relative to the LL regime) may increase insider profits by reducing price efficiency.

In comparing insider profits across transparency regimes, we adjust the profits for the underlying value in the trading round. When the true value is extreme (i.e., far from 100), insiders are likely to make larger profits than when it is moderate. As this effect is not due to transparency differences, we normalize total insider profits by the absolute difference between the true value and 100 in each round. Moreover, we look at both average insider profits and average insider profits per transaction. Although it does not affect our conclusions, we regard the latter number as more meaningful, as the number of transactions differs substantially across trading mechanisms (search costs impose a logistical obstacle that reduces transaction rates substantially in the LL case). The penultimate section of table 3.7 presents insider profits (and average outsider losses) under each trading mechanism, averaged across all rounds. Unsurprisingly, outsider losses are closely related to insider profits. More importantly, insider profits are smallest in the most transparent market $(\mathrm{HH})$, which was also the market in which price discovery occurred most quickly. Interestingly, however, the least transparent market (LL) shows similarly small insider profits, a fact consistent with its relatively speedy price discovery, established in the preceding subsection. 


\section{Table 3.11a \\ Insider Profits}

This table depiets the fixed effects panel coefficients for the trading mechanism dummies in equation (3.2). The first column presents the coefficients for total insider profits; the second column depicts the coefficients for total insider profits divided by the total number of insider transactions. The data is pooled over 32 rounds. Robust standard errors appear in parentheses. Significance at the $5 \%$ level is denoted by $\bullet$. The number of observations is equal to 32 . The R-squared amounts to 0.301 for the raw profits and 0.119 for the profits per transaction.

\begin{tabular}{|c|c|c|c|}
\hline $\begin{array}{c}\text { Pre-Trade } \\
\text { Transparency }\end{array}$ & $\begin{array}{l}\text { Post-Trade } \\
\text { Transparency }\end{array}$ & Raw Profits & $\begin{array}{l}\text { Profits per } \\
\text { Transaction }\end{array}$ \\
\hline low & low & $\begin{array}{l}31.43^{*} \\
(20.84)\end{array}$ & $\begin{array}{c}0.266^{*} \\
(0.0704)\end{array}$ \\
\hline low & high & $\begin{array}{l}91.07^{*} \\
(20.84)\end{array}$ & $\begin{array}{c}0.361^{*} \\
(0.0704)\end{array}$ \\
\hline high & low & $\begin{array}{l}115.25^{*} \\
(20.84)\end{array}$ & $\begin{array}{c}0.356^{*} \\
(0.0704)\end{array}$ \\
\hline high & high & $\begin{array}{l}34.16^{*} \\
(20.84)\end{array}$ & $\begin{array}{c}0.196^{*} \\
(0.0704)\end{array}$ \\
\hline
\end{tabular}

Table 3.11b

Matched-Pair Tests of the Effect of Transparency on Insider Profits

This table presents the implications of changing the level of pre-trade and post-trade transparency on the insider profits. The effects of pre-trade and post-trade transparency on insider profits per transaction are computed using the coefficients for the trading mechanism dummies in equation (3.2). The standard errors depicted in this table are robust to heteroskedasticity. None of the effects is statistically different from zero at the $5 \%$ level.

\begin{tabular}{cccc}
\hline $\begin{array}{c}\text { Invariable } \\
\text { Transparency }\end{array}$ & Transparency Effect & $\begin{array}{c}\text { Trading } \\
\text { Mechanisms }\end{array}$ & $\begin{array}{c}\text { Effect on Estimated } \\
\text { Intercept }\end{array}$ \\
\hline $\begin{array}{c}\text { low post-trade } \\
\text { transparency } \\
\text { high post-trade } \\
\text { transparency }\end{array}$ & pre-trade & LL vs. HL & 0.090 \\
low pre-trade & pre-trade & LH vs. HH & $(0.100)$ \\
transparency & post-trade & LL vs. LH & -0.165 \\
high pre-trade & & & $0.100)$ \\
transparency & post-trade & HL vs. HH & $(0.100)$ \\
\hline
\end{tabular}


In order to test $\mathrm{H} 2$ more formally, we again estimate a fixed effects panel model in which we regress total profits per transaction in each of 32 rounds on four trading mechanism dummies. The model is given in the equation

$$
\frac{\pi_{r k}}{\mid 100-\text { TrueValue }, \mid}=\delta_{0}+\sum_{i=1}^{32} \delta_{i} \mathrm{I}(r=i)+\sum_{j=L L, L H, H L, H H} \delta_{j} \mathrm{I}(k=j)+\varepsilon_{r k},
$$

where $r$ denotes the trading round, $k$ the trading mechanism, $\pi_{r k}$ is the average insider profit (either normalized by the number of transactions or non-normalized) in round $r$ and trading mechanism $k, \mathrm{I}(r=i)$ is a dummy variable for trading round which is equal to 1 if the trading round is equal to $i(i=1, \ldots, 32)$ and zero otherwise, $\mathrm{I}(k=j)$ is a dummy variable for trading mechanism which is equal to 1 if the trading mechanism is equal to $j(j=\mathrm{LL}, \mathrm{LH}, \mathrm{HL}, \mathrm{HH})$ and zero otherwise, and $\varepsilon_{r k}$ is an i.i.d. error term. We impose the restriction $\delta_{l}=0$. OLS estimates of equation (3.2) as well as heteroskedasticity robust standard errors appear in table 3.11. Estimates of the 32 individual-round dummies are omitted from the table to conserve space. Again, we see that insider profits are lowest in the most transparent $(\mathrm{HH})$ and least transparent (LL) cases. On the other hand, insiders are best off in the mixed-transparency cases (HL and LH). The pairwise differences in regression slope coefficients between the $\mathrm{HH}$ case and each of the two mixed-transparency cases (i.e., $\mathrm{HH}$ vs. $\mathrm{HL}$, and $\mathrm{HH}$ vs. $\mathrm{LH}$ ) are marginally significant. We conclude that insider profitability is inversely and causally related to the speed of price discovery in the market.

Table 3.12

\section{Effects of Pre-Trade and Post-Trade Transparency on Average Profits}

This table presents the effect of transparency on insider profits by averaging the insider profits over two different transparency regimes. In the first row (case $\mathrm{A}$ ), average insider profits in LL and LH rounds are computed (first column), as are $\mathrm{HL}$ and $\mathrm{HH}$ (second column), to examine the effect of conditioning solely on pre-trade transparency. In the second row (case B), average insider profits in LL and $\mathrm{HL}$ are calculated, as are $\mathrm{LH}$ and $\mathrm{HH}$ for a similar analysis of the effect post-trade transparency. Standard deviations are in parentheses.

\begin{tabular}{ccc}
\hline Transparency Variable & $\begin{array}{c}\text { Average } \\
\text { Low Transparency }\end{array}$ & $\begin{array}{c}\text { Average } \\
\text { High Transparency }\end{array}$ \\
\hline A: pre-trade transparency & 4099 & 4530 \\
& $(3933)$ & $(6784)$ \\
B: post-trade transparency & 4780 & 3850 \\
& $(6524)$ & $(4309)$ \\
\hline
\end{tabular}


As with price discovery, we also consider the implications of conditioning on only one transparency variable at a time. Table 3.12 reports insider profits averaged across each subsample of rounds. Row A of table 3.12 pools results based on pre-trade transparency, with the pooled $\mathrm{LL}$ and $\mathrm{LH}$ results in the first column, and the pooled $\mathrm{HL}$ and $\mathrm{HH}$ results in the second column. Row B similarly pools LL and $\mathrm{HL}(\mathrm{LH}$ and $\mathrm{HH}$ ) in the first (second) column. Although the standard errors are too large for either of the inter-column differences to be statistically significant, the pattern in the calculated averages fits neatly with the results in table 3.10. For the same two subsamples for which price discovery was relatively fast (i.e., low pre-trade and high post-trade; see table 3.10), we find here that insider profitability is relatively low. We confirm our conclusion that price discovery is the determining factor for our insider profitability results.

In summary, the results for insider profits show a clear negative relationship between insider profits and the speed of price discovery, as anticipated. Because the relationship between price discovery and transparency is a non-linear one, the relationship between insider profits and transparency is similarly non-linear. Specifically, although the highesttransparency regime has higher price efficiency and correspondingly lower insider profits than either of the mixed-transparency mechanisms ( $\mathrm{HL}$ or $\mathrm{LH}$ ), the least transparent regime (LL) also stands out with relatively high price efficiency and low insider profits. Thus, the connection between transparency and insider profitability is not immediate, but rather makes its impact via the price discovery process.

\subsubsection{Spreads}

The spread between market makers' bid and ask quotes is generally assumed to consist of three different components: order-processing costs, inventory-holding costs, and adverseselection costs. The first two components are nominally equal to zero in our experiments, and we focus on the latter. ${ }^{15}$ The standard adverse-selection component represents compensation to the dealer for losses to informed investors. However, several papers (e.g. Madhavan (1995)) argue that dealers in a multiple-dealer market should narrow their spreads in an effort to "purchase" informative order flow, with the goal of exploiting the resulting information in subsequent trading, a tactic that should be enforced by inter-dealer competition. Thus, adverse-selection costs subsume both the degree of uncertainty in the market and the degree of (imperfect) competition. The existing literature also indicates that an explicit distinction between pre-trade and post-trade transparency is necessary when examining the relation between transparency and bid-ask spreads. Pagano and Röell (1996) find that the spread size decreases when more price information is available in the market. The argument is that

15 Although there is no nominal inventory-financing cost in our experiments, dealer risk-aversion creates an implicit cost. However, the overriding source of risk for a (non-insider) dealer in our experiments is the adverseselection risk of a trade with an informed robot or dealer. Note also that a recent working paper by Flood, Huisman, Koedijk, and Lyons (1999) argues that search costs in multiple-dealer markets represent a fourth spread component that has not been fully recognized in the literature. 
uncertainty decreases when market makers know more about each other's quotes. On the other hand, Bloomfield and O'Hara (1999) find that spreads increase when more transaction information becomes available in the market. Madhavan's (1995) model concludes that market makers compete more fiercely when they cannot observe other market makers' transactions, since in this case they must attract transactions to themselves to gain the information implicit in the order flow. We thus conjecture that reduced pricing uncertainty under pre-trade transparency should reduce spreads, while reduced competition under posttrade transparency should increase them. We formulate our hypothesis as follows:

\section{H3: Bid-ask spreads are smaller in pre-trade transparent markets than in less pre-trade transparent markets. However, bid-ask spreads are larger in post-trade transparent markets than in less post-trade transparent markets.}

Figure 3.3

\section{Dealer Spreads}

This figure shows the average outsider spreads in the four different microstructures for all three groups of subjects. The average spread in each trading round is defined as the average size of the spread between the bid and ask quotes of all market makers. The lines in this graph were constructed by averaging the spreads of 8 individual rounds with the same trading mechanism. The first 20 seconds of each trading round were omitted from the calculation, as dealers used this time period to enter their first bid and ask quotes.

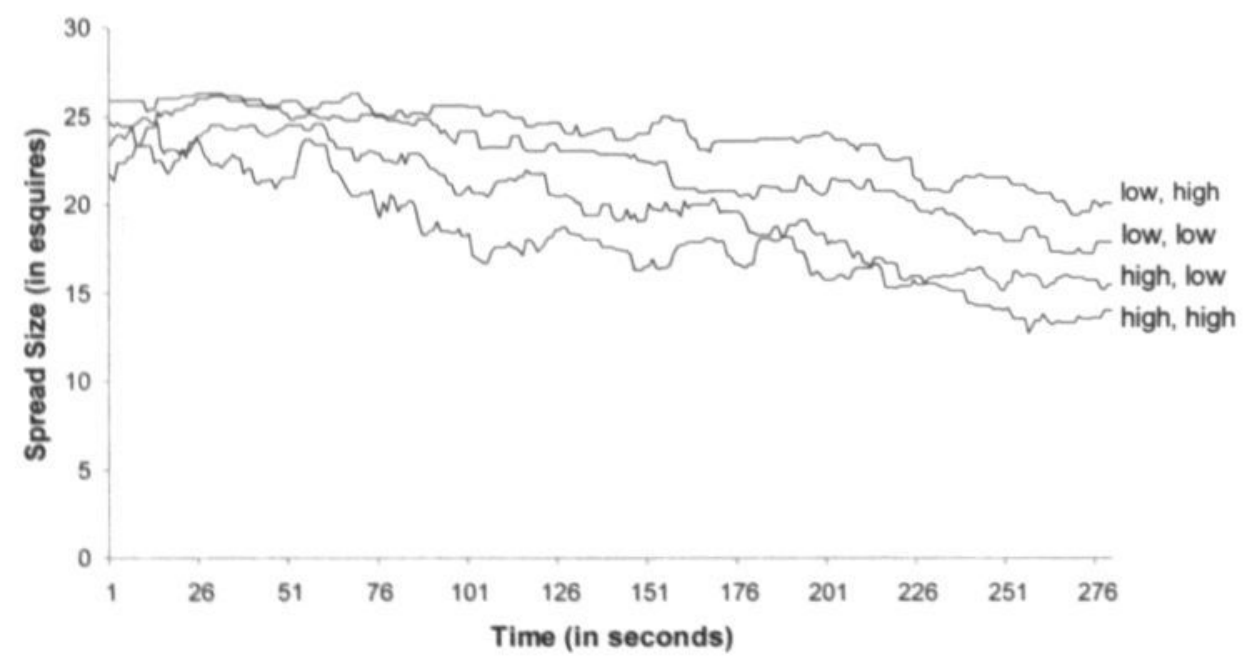


Figure 3.3 shows the average spread size in each of the trading mechanisms, measured as the average bid-ask spread of all outside dealers in the relevant trading rounds. ${ }^{16}$ The initial spreads are high and similar in each trading mechanism, but spreads decrease as information is brought into the market over time. The spreads are nearly uniformly consistent with $H 3$, which translates to the following four conditions:

1. $S_{L L}>S_{H L}$

2. $S_{L H}>S_{H H}$

3. $S_{H H}>S_{H L}$

4. $S_{L H}>S_{L L}$

where $S_{k}$ is the average spread size under trading regime $k$. For at least the first 230 seconds of trading, the average spread size is lowest when pre-trade transparency is high and post-trade transparency is low, indicating that uncertainty is relatively low and competition relatively severe. The reverse holds for the LH market, in which spreads are relatively large. The other predictions of $H 3$ similarly hold in the data.

Table 3.13

Effects of Pre and Post-Trade Transparency on Average Spreads

This table presents the effect of transparency on dealer spreads by averaging the spreads over two different transparency regimes. In the first row (case A), average outsider spreads in LL and LH rounds are computed (first column), as are $\mathrm{HL}$ and $\mathrm{HH}$ (second column), to examine the effect of conditioning solely on pre-trade transparency. In the second row (case B), average outsider spreads in LL and HL are calculated, as are LH and $\mathrm{HH}$ for a similar analysis of the effect post-trade transparency. Standard deviations are in parentheses.

\begin{tabular}{ccc}
\hline Transparency Variable & $\begin{array}{c}\text { Average } \\
\text { Low Transparency }\end{array}$ & $\begin{array}{c}\text { Average } \\
\text { High Transparency }\end{array}$ \\
\hline \multirow{2}{*}{ A: pre-trade transparency } & 24.5 & 20.6 \\
& $(2.39)$ & $(3.65)$ \\
B: post-trade transparency & 22.0 & 23.1 \\
& $(3.88)$ & $(3.36)$
\end{tabular}

16 A naive conjecture is that insider's spread should differ systematically from those of the outsiders, since the adverse-selection incentives apply differently to the insider. However, the insider recognizes the obvious importance of concealing her identity. None of our spread results is changed markedly by including or excluding the insider. 
In order to buttress the evidence in figure 3.3 , table 3.13 presents the average outsider spreads pooled for all trading rounds with the specified transparency treatment. For example, row $\mathrm{A}$ of table 3.13 presents in the first (second) column the average outsider spread for all $\mathrm{LL}$ and $\mathrm{LH}(\mathrm{HL}$ and $\mathrm{HH})$ rounds. As predicted, increased pre-trade transparency narrows dealer spreads. Similarly, in row B, we see that increased post-trade transparency increases spreads. The predictions of $\mathrm{H3}$ continue to hold under a finer-grained analysis. Thus, on average, $S_{L L}=23.9, S_{L H}=25.1, S_{H L}=20.1$, and $S_{H H}=21.1 .{ }^{17}$ Although neither of the intercolumn differences in table 3.13 is statistically significant at the $5 \%$ level, hypothesis $H 3$ is nonetheless clearly supported by the available evidence.

\subsection{Conclusions}

In recent years, market regulators and academic researchers worldwide have debated intensively about the implication and effects of asymmetric information on financial markets. Regulators have been particularly concerned with policies on insider trading, including both traditional corporate insiders as well as asymmetrically informed securities dealers. Numerous studies have investigated the costs and benefits of informational asymmetries for financial markets. In general terms, new information should enter the market as quickly as possible to improve the efficiency of market prices. On the other hand, the strategic use in trading of such an informational advantage can drive away the uninformed, and may therefore reduce market liquidity and the overall demand for securities.

In this chapter we follow the recommendations of Leland (1992), Pagano and Röell (1996), and Schnitzlein (1996), to examine the extent to which market microstructure affects the impact of asymmetric information on market performance. Specifically, we consider a multiple-dealer market in which one of the dealers begins with fundamental information unavailable to the other dealers. We vary two standard transparency rules as experimental variables: the pre-trade publication of dealer quotes (private information or broadcast) and the post-trade publication of transactions (public ticker or private information). The characteristics of the trading mechanism affect how difficult it is for uninformed dealers to detect an insider and infer their strategies; conversely, they affect the ability of the insider to exploit their informational advantage.

As it is very difficult to study insider trading empirically, we obtain our results from an experimental financial market, in which three groups of five professional securities traders act as market makers for a single imaginary security. The dealers set quotes and trade with each other and with both informed and liquidity-motivated clients. In each 5-minute experimental trading round, one of the dealers receives (inside) information about the true

17 Moreover, insider spreads are not appreciably different from those presented in table 3.13. Recalculating table 3.13 with insider spreads, we get in row A (row B) $S_{L_{*}}=24.1$ and $S_{H *}=20.0\left(S_{*_{L}}=22.1\right.$ and $\left.S_{*_{H}}=22.9\right)$. respectively. 
value of the security. We create four different trading mechanisms by varying the two transparency rules. An important innovation is that we model the insider as a market maker in a multiple-dealer market, while most other studies consider an informed external investor. This is relevant, since dealers in multiple-dealer markets will typically have inside information via their private order flow, if not from other sources as well. Moreover, when a limit order book is present, external customers are also able to compete on price to a limited degree.

We obtained our data from a series of 5-minute trading rounds for three groups of subjects. Our results clearly indicate an inverse connection between insider profits and the price efficiency of the market. Slow price discovery allows insiders greater opportunities to accumulate speculative inventories at advantageous prices. However, the connection between insider profitability and transparency is somewhat more complex, because the connection between transparency and price efficiency is non-linear. Post-trade transparency (i.e., a public ticker) improves efficiency. Conversely, however, and consistent with the earlier work of FHKM (1999), pre-trade transparency in our multiple-dealer market slows price discovery, thus increasing insider profitability. Market liquidity, measured by average dealer bid-ask spreads, behaves consistently with theoretical predictions. Increased pre-trade transparency reduces dealers' uncertainty and reduces spreads. On the other hand, eliminating post-trade transparency creates an incentive for dealers to compete for private order flow, thus reducing spreads. 



\section{Chapter 4}

\section{Asymmetric Information and Inter-Dealer Trading}

\subsection{Introduction}

Inter-dealer trading is an important phenomenon in dealership markets. Major financial markets in which inter-dealer trading is allowed are the London Stock Exchange, NASDAQ. and spot foreign exchange markets. Within these markets, the fraction of inter-dealer trades in total trading volume is significant. Viswanathan and Wang (1999) estimate this fraction to be as high as 40 percent for the London Stock Exchange. Gould and Kleidon (1994) arrive at an estimate of 15 percent for NASDAQ. In foreign exchange markets, inter-dealer trading is even more important. According to Lyons (1996b), inter-dealer trades account for roughly 85 percent of total volume in the Forex market.

The literature mentions risk sharing and asymmetric information as the most important motives for inter-dealer trading. Dealers motivated by risk sharing use the inter-dealer market to reduce the risk of their inventory positions. For example, market makers sell parts of large public orders in the inter-dealer market, thereby sharing the inventory risk with others. Dealers motivated by asymmetric information try to exploit private information in the interdealer market. Recent empirical as well as theoretical studies suggest that both motives are important in real life markets.

Although both motivations for inter-dealer trading are relevant, the literature mainly concentrates on the risk sharing motive. Examples of this are Viswanathan and Wang (1999), Reiss and Werner (1998), and Vogler (1997). The general consensus from the risk sharing viewpoint is that customers prefer trading in a market where inter-dealer trading is allowed because they face better prices and lower execution costs. In this chapter we focus on the other motive. We investigate the consequences of allowing for inter-dealer trading in a 
financial market in which private information instead of risk sharing is the most relevant motive for inter-dealer trades. We use an experimental methodology to investigate this issue. This enables us to isolate the effects of inter-dealer trading from other potential differences in trading mechanisms, which is difficult in an empirical setting. Moreover, we can refrain from the strong behavioral assumptions that are often made in theoretical studies like Viswanathan and Wang (1999). The role of the market makers in our experimental market is played by undergraduate economics students.

The emphasis on the asymmetric information motive is the central issue in our experimental market. The liquidation value of the asset that is traded is not stochastic in the sense that unexpected price shocks occur during each experimental round. Therefore, inventory risk is relatively unimportant for the market makers and the proportion of interdealer trades motivated by risk sharing is small. Asymmetric information, on the other hand, is a very relevant motive for market makers to participate in inter-dealer trades, because there is no public disclosure of trades between market makers and informed outside investors.

Our analysis shows that bid-ask spreads are considerably wider when inter-dealer trading is allowed than without inter-dealer trading. The rationale for this result is that in the presence of an inter-dealer market, dealers have fewer incentives to quote competitive prices than when such a market is absent. In the latter situation, market makers have a strong incentive to quote the best prices in order minimize losses to informed customers. In the former case, market makers focus on exploiting their private information in the inter-dealer market. Moreover, the adverse-selection component of the spread is larger in the market with inter-dealer trading.

The recent literature focuses on inter-dealer trading motivated by risk sharing and finds mainly beneficial effects on market performance, notably lower execution costs. We show that when inter-dealer trades are motivated by asymmetric information, external customers are worse off because of higher execution costs. We reckon that the effects of information asymmetries should play a more important role in the assessment of inter-dealer trading.

This chapter is organized as follows. In section 4.2 we discuss the relevant literature for our study. Section 4.3 provides for a description of the methodology. Section 4.4 discusses the data and presents summary statistics. In section 4.5 we present the main results of our analysis. Section 4.6 presents a summary and a conclusion.

\subsection{Literature}

There are essentially three different areas in the literature on inter-dealer trading. The first two areas deal with the two most important motives for dealers to participate in inter-dealer trading: risk sharing and asymmetric information. The third area studies the effects of interdealer trades on the trading and pricing process in a financial market. In this section we 
discuss several relevant studies in each of these areas.

A number of recent empirical papers examine risk sharing as a possible motive for inter-dealer trades. Reiss and Werner (1998) analyze data from the London Stock Exchange and show that it is indeed very likely that risk sharing is an important motive for market makers to participate in inter-dealer trades. They argue that more than 80 percent of interdealer trades after large customer orders are in the direction predicted by risk sharing. Hansch, Naik, and Viswanathan (1998) investigate a different set of LSE data and find that "...a key determinant of variations in inter-dealer trading is inventories and (...) inter-dealer trading plays an important role in managing large inventory positions."

Naik, Neuberger, and Viswanathan (1999) model a dealership market in which the motives for inter-dealer trading are both risk sharing and asymmetric information. Their study focuses on the consequences of trade disclosure in the inter-dealer market, however.

The third strand of the literature concentrates on the effects of inter-dealer trading on market outcomes in general. The well-known paper of Ho and Stoll (1983) provides a model of dealer behavior. In their model there is a strong link between dealer inventories and quote settings in the inter-dealer market. The authors do not compare financial markets with and without an inter-dealer market, but they derive the equilibrium value of the market spread and the equilibrium distribution of inventories when inter-dealer trading is allowed. Moreover, Ho and Stoll determine the conditions for inter-dealer trading to occur.

There are few papers we are aware of that explicitly compare markets in which interdealer trading is allowed with markets in which it is not. Viswanathan and Wang (1999) compare the level of customer welfare in a so-called two-stage trading mechanism in which a period of inter-dealer trading follows a period of public trades with the welfare of the customers in the traditional one-stage trading mechanism. The authors show that in general, customers will prefer the two-stage mechanism because of relatively intense price competition in that market. Although the paper does not focus on information asymmetries, Viswanathan and Wang find evidence that suggests that consumer welfare might be harmed by allowing for inter-dealer trades when the adverse selection problem is large.

Many more studies exist that examine differences in market performance between auction and dealership markets. Examples of theoretical papers in this field are Madhavan (1992) and Pagano and Röell (1996). These studies develop a theoretical model in order to compare auction and dealership markets in the presence of adverse information. Madhavan analyzes price efficiency in a (quote-driven) dealership market and an (order-driven) continuous auction market. Efficiency proves to be greater in the dealership market, although the equilibria of the two systems coincide when entry into market making is free. Pagano and Röell focus on differences in transparency and find that trading costs for uninformed external customers are lower in more transparent markets like the so-called transparent auction. Madhavan and Pagano and Röell offer a slightly different perspective than Viswanathan and Wang (1999), because the latter are able to isolate the effect of inter-dealer trading, while the former authors also deal with other differences between auction and dealership markets 
besides inter-dealer trading. Vogler (1997) compares the market outcomes in an auction and a dealership market in a theoretical setting, but he pays special attention to the fact that dealers are allowed to trade among themselves in the dealership market. He finds that under certain conditions outside investors are able to get a better price in the dealership market than in the auction market. He shows that this mainly arises from the fact that market makers demand a lower risk premium when they are able to share their risk in the inter-dealer market.

Numerous empirical studies exist that investigate differences in auction and dealership markets. Several studies compare the cost of trading stocks that are listed at two different exchanges. De Jong, Nijman, and Röell (1995) compare the trading costs of French shares on the Paris Bourse and on Seaq International. The Paris Bourse is a continuous auction, while Seaq is a dealership market. Using various measures of the bid ask spread, de Jong et al. show that spreads are considerably smaller at the Paris Bourse than at London's Seaq for small orders. Moreover, regression results indicate that the spread is also smaller for large orders at the Paris Bourse. Other studies compare trading costs of comparable stocks at different exchanges. Huang and Stoll (1996) investigate execution costs for 175 comparable firms at NYSE, a continuous auction market, and NASDAQ, a dealership market. They find that spreads are around twice as large for the NASDAQ stocks:

Our methodology stems from FHKM (1999), who investigate the effects of quote disclosure on market performance. They find that in markets with full price disclosure opening spreads are narrower and efficiency is smaller. Flood, Huisman, Koedijk, and Lyons (1999) and chapter 3 apply a similar methodology. The former paper examines trading costs in markets without price disclosure and finds that search costs form an important part of the effective spread. In the previous chapter we investigated market performance in four different transparency regimes in the presence of asymmetrically informed dealers. We concluded that post-trade transparency improves price efficiency, but harms liquidity. Pre-trade transparency decreases efficiency and increases liquidity. Bloomfield and O'Hara (1999) develop an experimental methodology that is related to our experimental setting. They study the effects of trade disclosure on market efficiency and conclude that higher post-trade transparency leads to faster price discovery. Finally, Schnitzlein (1996) investigates the performance of call and continuous auctions in the presence of adverse information in experiments based on the Kyle (1985) model. Schnitzlein's findings indicate that liquidity is greater in the call market, while differences in efficiency are not significant.

\subsection{Experimental Design}

Our study involves an experimental methodology in which four market makers and two computerized external customers trade for a single imaginary asset. Three groups of undergraduate economics students act as the market makers. Each round lasts for four minutes and is independent of all other rounds. That is, information about the security's underlying 
value in the previous round is not relevant in the present round. The external investors represent informed as well as liquidity traders and submit orders to the market. The core of the experimental design is described in section 3.2. This section elaborates on the specific set-up of our inter-dealer trading experiments.

\subsubsection{General Description}

The microstructure of our experimental environment can be regarded as a continuous, multiple-dealer version of the pure dealership market of Glosten and Milgrom (1985). The Glosten and Milgrom market is quote-driven, while on the other hand the well-known Kyle (1985) model is order-driven. Compared with the experimental design in Bloomfield and O'Hara (1999), there are two significant differences. First, market makers in the Bloomfield and O'Hara (1999) study set quotes but are not able to trade in an inter-dealer market. We explicitly concentrate on trades in that market. Second, our market is continuous instead of sequential. Continuous trading has the benefit that it yields large amounts of data. The most important difference with the experiments of chapter 3 is that the level of transparency is not varied over the trading rounds and that no market maker receives information about the underlying value before a trading round.

\subsubsection{Experimental Set-Up}

Before each round, the underlying value is drawn randomly from a uniform distribution between 1 and 200 . The underlying value of the security is completely independent across trading rounds. An overview of the underlying values in all the trading rounds for the three groups of subjects is given in tables 4.1-4.6. The microstructure of our experimental asset market changes after each block of four trading rounds from a situation with inter-dealer trading to a market in which inter-dealer trading is not allowed and vice versa.

In both microstructures, the transaction information available to dealers is limited to trades in which that dealer participates. This information appears at the right hand side of the trading screen of each market maker directly after the execution of the trade. Bid and ask quotes of the four market makers are not disclosed to the other dealers. Dealers have to call each other to obtain information about the bid-ask quotes. Hence, both pre-trade and posttrade transparency are low.

\subsubsection{The Objectives of the Dealers}

At the start of each trading round dealers receive an endowment of 1000 esquires (a fictional numeraire currency). All dealers are instructed to maximize their end-of-round wealth by trading for a single security. End-of-round wealth is defined as the cash balance at the end of the trading round plus the inventory valued at the underlying value of the asset. Before the start of the experiment, the market makers are informed about the distribution of the underlying value. This is the only a priori information market makers have about the value of the asset at the start of each round. The dealers can obtain information about the underlying 
value through transactions with external investors, as discussed below. Dealers do not get instructions about possible trading strategies.

\subsubsection{The Behavior of Market Makers and Investors}

All market makers must enter a quote within 10 seconds of the start of each round (otherwise, a penalty of 10 esquires/sec. accrues). The dealers can change their quote at any time during the round, but cannot otherwise withdraw their quotes. Therefore, at any time in a trading round all dealers have a quote outstanding in the market. The maximum spread size is 30 esquires. Market makers can call other dealers in order to obtain their quote. The quote then shows on the callers' trading screen for 7 seconds. In this period the caller can initiate one or more trades.

Market makers can also trade with two computerized investors (also referred to as robots) who submit orders to the market. These traders do not set quotes and cannot be called by the market makers. They represent external customers of the exchange and proxy for both informed traders and liquidity or noise traders. The two robots are indistinguishable to the market makers. Each is programmed to trade every 7 seconds against the best prices in the market. Whether an investor's trade will be informed or uniformed is determined at random, just prior to each transaction; the probability that the trade is informed equals one half. The market makers are told this probability, and therefore know that, on average, 75 percent of the trades by the external customers are in the right direction. When a market maker is involved in a transaction with a computerized trader, they do not receive any special notification, but the transaction information appears in the transaction history window. An example of the trading screen is depicted in figure 3.1 .

\subsubsection{Payoff to the Subjects}

Before the experiments each dealer receives an initial cash endowment of 100 Dutch guilders. ${ }^{18}$ At the end of the 16 trading rounds the individual trading profits (in esquires) in each of these periods are added up and translated into guilders by dividing by 500 . The initial guilder endowment is added to the resulting amounts, which are then paid to the subjects. The endowment proved to be high enough to prevent bankruptcies. The lowest amount a market maker took home was around 47 guilders, the highest amount was 126 guilders.

\subsection{Data}

We collected the data we analyze in this chapter from the experiments described above, which were held at the Center for Research in Experimental Economics and Political Decision Making (CREED) at the University of Amsterdam on November 26, December 21, and December 22, 1998. The subjects were undergraduate financial economics students from

18 At the time the experiments took place this amounted to about USD 50. 
Erasmus University Rotterdam and Maastricht University, the Netherlands. All three groups were scheduled to participate in 16 trading rounds that lasted for four minutes. In half of these trading rounds inter-dealer trading is permitted, in the other eight it is not. We had to abandon round 16 of group 1 and trading rounds 15 and 16 for groups 2 and 3, however, due to operating system failures at the CREED lab. We strongly believe that this does not affect our results, especially since we reversed the experimental settings for the third group in order to correct for possible learning effects.

In tables 4.1-4.6, summary statistics and experimental settings are presented for groups 1,2 and 3 . The first row of these tables depicts whether inter-dealer trading is allowed in this round. In spite of considerable differences between the three groups, introducing inter-dealer trades clearly leads to a decrease in the number of quote settings. There is not much difference with respect to the profits of the dealers and the robots. In both cases, dealers lose money to the partly informed investors. The fraction of inter-dealer trades in the total number of trades (and thus in total trading volume) is roughly 75 percent on average. This seems realistic in light of estimates of this fraction for real-life markets mentioned in the introduction, which are around 40 percent for the London Stock Exchange and around 85 percent for spot exchange rate markets. The summary statistics aggregated for each transparency regime are presented in table 4.7.

\subsection{Results}

This section investigates the effects of allowing for inter-dealer trading on three important aspects of market performance: dealer profits, price efficiency, and bid-ask spreads.

\subsubsection{Dealer Profits}

As mentioned in the introduction, two motives for inter-dealer trading can be distinguished: risk sharing and information asymmetries. Inter-dealer trades in our experiments are predominantly motivated by asymmetric information as information about the trades in which a market maker is involved is strictly private. Moreover, as quote information is also limited, the dissemination of information about the underlying value of the security in inter-dealer trades is relatively slow. Risk sharing plays a minor role in the behavior of the market makers in the inter-dealer market. Firstly, no unexpected price shocks occur during each trading round, so inventory risk is relatively small. Secondly, the dealers are not motivated to manage their inventory risk through the payment schemes applied. Instead, they receive incentives to maximize profits. 
Table 4.1

Summary Statistics

This table contains summary statistics of trading rounds 1 to 8 for the first group of subjects.

\section{Group 1}

trading round $1-8$

Round no.

$2 \quad 3 \quad 4$

45

6

\section{Settings}

Inter-dealer trading

Pre-trade transparency

yes yes yes yes no no no no

Post-trade transparency

L $\quad$ L $\quad$ L $\quad$ L

$\begin{array}{lllll}\text { L } & \text { L } & \text { L } & \text { L } & \text { L }\end{array}$

L

L L

$\alpha$

$\begin{array}{llll}0.5 & 0.5 & 0.5 & 0.5\end{array}$

L

L

L L

True value

$194 \quad 84$

57

140

0.5

0.5

0.5

0.5

Results

$\begin{array}{lcccccccc}\text { \# Quotes set } & 36 & 35 & 37 & 27 & 43 & 45 & 44 & 40 \\ \begin{array}{l}\text { \# Trades } \\ \text { Total }\end{array} & 145 & 94 & 114 & 127 & 68 & 68 & 68 & 67 \\ \text { Inter-dealer } & 77 & 26 & 47 & 59 & 0 & 0 & 0 & 0 \\ \quad \text { Robots } & 68 & 68 & 67 & 68 & 68 & 68 & 68 & 67 \\ \text { Avg. dealer spread } & 20 & 22 & 22 & 16 & 22 & 19 & 18 & 18\end{array}$

Average end-of-round capital ${ }^{\prime}$

Dealers

$-444$

Robots

$888-562$

$-36$

$-261$

$-752$

$-968$

$-630$

$\begin{array}{llll}522 & 1504 & 1936 & 1260\end{array}$

1772

Expressed in esquires and excluding the initial amount of capital. 
Table 4.2

Summary Statistics

This table contains summary statistics of trading rounds 9 to 15 for the first group of subjects.

\section{Group 1}

trading round $9-15$

$\begin{array}{lccccccc}\text { Round no. } & 9 & 10 & 11 & 12 & 13 & 14 & 15 \\ & & & & & & & \\ \text { Settings } & & & & & & & \\ \text { Inter-dealer trading } & \text { yes } & \text { yes } & \text { yes } & \text { yes } & \text { no } & \text { no } & \text { no } \\ \text { Pre-trade transparency } & \mathrm{L} & \mathrm{L} & \mathrm{L} & \mathrm{L} & \mathrm{L} & \mathrm{L} & \mathrm{L} \\ \text { Post-trade transparency } & \mathrm{L} & \mathrm{L} & \mathrm{L} & \mathrm{L} & \mathrm{L} & \mathrm{L} & \mathrm{L} \\ \alpha & 0.5 & 0.5 & 0.5 & 0.5 & 0.5 & 0.5 & 0.5 \\ \text { True value } & 156 & 198 & 74 & 141 & 57 & 31 & 187\end{array}$

Results

\begin{tabular}{|c|c|c|c|c|c|c|c|}
\hline \# Quotes set & 34 & 26 & 37 & 28 & 39 & 43 & 40 \\
\hline \multicolumn{8}{|l|}{ \# Trades } \\
\hline Total & 110 & 141 & 131 & 174 & 58 & 68 & 68 \\
\hline Inter-dealer & 42 & 73 & 63 & 106 & 0 & 0 & 0 \\
\hline Robots & 68 & 68 & 68 & 68 & 58 & 68 & 68 \\
\hline Avg. dealer spread & 21 & 17 & 20 & 18 & 22 & 2 & 19 \\
\hline
\end{tabular}

Average end-of-round capital ${ }^{1}$

$\begin{array}{llllllll}\text { Dealers } & -245 & -835 & -293 & -402 & -241 & -282 & -731 \\ \text { Robots } & 490 & 1670 & 586 & 804 & 482 & 564 & 1462\end{array}$

Expressed in esquires and excluding the initial amount of capital. 
Table 4.3

Summary Statistics

This table contains summary statistics of trading rounds 1 to 8 for the second group of subjects.

\begin{tabular}{|c|c|c|c|c|c|c|c|c|}
\hline \multicolumn{9}{|c|}{$\begin{array}{l}\text { Group } 2 \\
\text { trading round } 1-8\end{array}$} \\
\hline Round no. & 1 & 2 & 3 & 4 & 5 & 6 & 7 & 8 \\
\hline \multicolumn{9}{|l|}{ Settings } \\
\hline Inter-dealer trading & yes & yes & yes & yes & no & no & no & no \\
\hline Pre-trade transparency & L & L & $\mathrm{L}$ & L & L & $\mathrm{L}$ & L & L \\
\hline Post-trade transparency & L & L & L & L & $\mathrm{L}$ & $\mathrm{L}$ & L & L \\
\hline$\alpha$ & 0.5 & 0.5 & 0.5 & 0.5 & 0.5 & 0.5 & 0.5 & 0.5 \\
\hline True value & 194 & 84 & 57 & 140 & 47 & 173 & 52 & 14 \\
\hline \multicolumn{9}{|l|}{ Results } \\
\hline \# Quotes set & 18 & 20 & 22 & 18 & 30 & 35 & 22 & 38 \\
\hline \multicolumn{9}{|l|}{ \# Trades } \\
\hline Total & 314 & 152 & 274 & 260 & 40 & 34 & 16 & 39 \\
\hline Inter-dealer & 248 & 130 & 227 & 227 & 0 & 0 & 0 & 0 \\
\hline Robots & 66 & 22 & 47 & 33 & 40 & 34 & 16 & 39 \\
\hline Avg. dealer spread & 21 & 14 & 15 & 18 & 14 & 16 & 20 & 18 \\
\hline \multicolumn{9}{|c|}{ Average end-of-round capital ${ }^{1}$} \\
\hline Dealers & -1017 & -61 & -275 & -210 & -250 & -261 & -100 & -337 \\
\hline Robots & 2034 & 122 & 550 & 420 & 500 & 522 & 200 & 674 \\
\hline
\end{tabular}

I Expressed in esquires and excluding the initial amount of capital. 
Table 4.4

Summary Statistics

This table contains summary statistics of trading rounds 9 to 14 for the second group of subjects.

\section{Group 2}

trading round $9-14$

\begin{tabular}{|c|c|c|c|c|c|c|}
\hline Round no. & 9 & 10 & 11 & 12 & 13 & 14 \\
\hline \multicolumn{7}{|l|}{ Settings } \\
\hline Inter-dealer trading & yes & yes & yes & yes & no & no \\
\hline Pre-trade transparency & L & L & L & L & L & L \\
\hline Post-trade transparency & $\mathbf{L}$ & L & L & L & L & L \\
\hline$\alpha$ & 0.5 & 0.5 & 0.5 & 0.5 & 0.5 & 0.5 \\
\hline True value & 156 & 198 & 74 & 141 & 57 & 31 \\
\hline \multicolumn{7}{|l|}{ Results } \\
\hline \# Quotes set & 25 & 25 & 11 & 18 & 24 & 28 \\
\hline \multicolumn{7}{|l|}{ \# Trades } \\
\hline Total & 111 & 361 & 48 & 161 & 25 & 24 \\
\hline Inter-dealer & 84 & 294 & 36 & 133 & 0 & 0 \\
\hline Robots & 27 & 67 & 12 & 28 & 25 & 24 \\
\hline Avg. dealer spread & 18 & 21 & 20 & 20 & 16 & 16 \\
\hline \multicolumn{7}{|c|}{ Average end-of-round capital ${ }^{\prime}$} \\
\hline Dealers & -188 & -812 & -41 & -146 & -107 & -184 \\
\hline Robots & 376 & 1624 & 82 & 292 & 214 & 368 \\
\hline
\end{tabular}

Expressed in esquires and excluding the initial amount of capital. 
Table 4.5

\section{Summary Statistics}

This table contains summary statistics of trading rounds 1 to 8 for the third group of subjects.

\section{Group 3}

trading round $1-8$

Round no.

$1 \quad 2 \quad 3$

4

5

6

7

8

\section{Settings}

Inter-dealer trading

Pre-trade transparency

no no no no yes yes yes yes

Post-trade transparency

L L

L L

L L

L

L

L

L

L

L

$\alpha$

$0.5 \quad 0.5$

L

L

L

L L

True value

194

84

0.5

0.5

0.5

$\begin{array}{ll}0.5 & 0.5\end{array}$

0.5

Results

$\begin{array}{lcccccccc}\text { \# Quotes set } & 34 & 20 & 34 & 33 & 23 & 27 & 32 & 34 \\ \begin{array}{l}\text { \# Trades } \\ \text { Total }\end{array} & 67 & 59 & 68 & 60 & 292 & 354 & 372 & 452 \\ \quad \text { Inter-dealer } & 0 & 0 & 0 & 0 & 224 & 286 & 311 & 384 \\ \quad \text { Robots } & 67 & 59 & 68 & 60 & 68 & 68 & 61 & 68 \\ \text { Avg. dealer spread } & 18 & 23 & 24 & 24 & 25 & 27 & 27 & 27\end{array}$

Average end-of-round capital ${ }^{1}$

$\begin{array}{lcccccccc}\text { Dealers } & -435 & -19 & -283 & -110 & -286 & -382 & -77 & -513 \\ \text { Robots } & 870 & 38 & 566 & 220 & 572 & 764 & 154 & 1026\end{array}$

Expressed in esquires and excluding the initial amount of capital. 
Table 4.6

Summary Statistics

This table contains summary statistics of trading rounds 9 to 14 for the third group of subjects.

\section{Group 3}

trading round $9-14$

\begin{tabular}{|c|c|c|c|c|c|c|}
\hline Round no. & 9 & 10 & 11 & 12 & 13 & 14 \\
\hline \multicolumn{7}{|l|}{ Settings } \\
\hline Inter-dealer trading & no & no & no & no & yes & yes \\
\hline Pre-trade transparency & L & L & L & L & $\mathrm{L}$ & $\mathrm{L}$ \\
\hline Post-trade transparency & L & L & $\mathrm{L}$ & L & L & L \\
\hline$\alpha$ & 0.5 & 0.5 & 0.5 & 0.5 & 0.5 & 0.5 \\
\hline True value & 156 & 198 & 74 & 141 & 57 & 31 \\
\hline \multicolumn{7}{|l|}{ Results } \\
\hline \# Quotes set & 22 & 48 & 36 & 45 & 32 & 29 \\
\hline \multicolumn{7}{|l|}{$\#$ Trades } \\
\hline Total & 68 & 66 & 53 & 65 & 398 & 225 \\
\hline Inter-dealer & 0 & 0 & 0 & 0 & 346 & 159 \\
\hline Robots & 68 & 66 & 53 & 65 & 52 & 66 \\
\hline Avg. dealer spread & 26 & 28 & 26 & 26 & 29 & 29 \\
\hline \multicolumn{7}{|c|}{ Average end-of-round capital ${ }^{\prime}$} \\
\hline Dealers & -230 & -237 & 2 & -89 & 5 & -217 \\
\hline Robots & 460 & 474 & -4 & 178 & -10 & 434 \\
\hline
\end{tabular}

1 Expressed in esquires and excluding the initial amount of capital. 
Table 4.7

Summary Statistics for Each Trading Mechanism

In this table the summary statistics for individual trading rounds depicted in tables 4.1 through 4.6 are averaged over all three groups to obtain summary statistics for the markets with and without inter-dealer trading.

\begin{tabular}{|c|c|c|}
\hline Variable & $\begin{array}{l}\text { Trading Rounds With } \\
\text { Inter-Dealer Trading }\end{array}$ & $\begin{array}{l}\text { Trading Rounds Without } \\
\text { Inter-Dealer Trading }\end{array}$ \\
\hline Number of quotes set & 27.0 & 35.4 \\
\hline \multicolumn{3}{|l|}{ Number of trades } \\
\hline Total & 218.6 & 54.7 \\
\hline Inter-dealer & 162.8 & 0 \\
\hline Robots & 55.8 & 54.7 \\
\hline \multicolumn{3}{|l|}{ Average spread } \\
\hline Dealers & 21.2 & 20.7 \\
\hline \multicolumn{3}{|c|}{ Average end-of-round spread } \\
\hline Dealers & 22.0 & 20.1 \\
\hline \multicolumn{3}{|c|}{ Average end-of-round capital } \\
\hline Dealers & -333.7 & -339.5 \\
\hline Robots & 667.4 & 679.0 \\
\hline \multicolumn{3}{|l|}{ Price discovery } \\
\hline Time to convergence ' & 200.8 & 184.5 \\
\hline \multicolumn{3}{|l|}{ Percentage price error ${ }^{2}$} \\
\hline after 80 seconds & 0.68 & 0.61 \\
\hline after 160 seconds & 0.48 & 0.40 \\
\hline after 240 seconds & 0.36 & 0.33 \\
\hline
\end{tabular}

1 Average number of seconds until the average quote midpoint for all dealers has converged to less than 5 esquires away from the underlying value.

2 Average price error after $t$ seconds, divided by the average price error after 20 seconds. 
In order to get even better insights into the relative importance of both motives in our experiments, we look at the dispersion of dealer profits in the trading rounds with and without inter-dealer trading. If asymmetric information were dominant in our experiments, we would expect the dispersion of dealer profits to be substantial when inter-dealer trading occurs. Market makers attempt to exploit their private information by trading in the inter-dealer market and dealers who accurately interpret the transaction information are able to make a profit. Because of the fixed-sum characteristic of our experimental market other dealers can then be expected to lose money. If on the other hand risk sharing were the dominant motive, we would expect the dispersion of profits to be small. In this case dealers use the inter-dealer market to redistribute their inventory risk over the other dealers.

\section{Table 4.8}

\section{Distribution of Dealer Profits}

This table shows the distribution of the profits of the market makers, averaged over all rounds. We first ranked the dealers on the basis of profits for every round. We then averaged the highest dealer profits in all rounds in order to obtain an average profit level for the "winner" in each round. We did the same for the second highest, the third highest, and the lowest dealer profits in each round. The number at the bottom of this panel is the standard deviation of the four averages of dealer profits in the same column.

\begin{tabular}{|c|c|c|c|c|c|c|c|c|}
\hline \multirow[b]{2}{*}{ Group } & \multicolumn{4}{|c|}{$\begin{array}{l}\text { Trading Rounds With } \\
\text { Inter-Dealer Trading }\end{array}$} & \multicolumn{4}{|c|}{$\begin{array}{l}\text { Trading Rounds Without } \\
\text { Inter-Dealer Trading }\end{array}$} \\
\hline & 1 & 2 & 3 & $1,2,3$ & 1 & 2 & 3 & $1,2,3$ \\
\hline \multicolumn{9}{|l|}{ Avg. dealer profits } \\
\hline winner & 699.9 & 1394.4 & 2588.2 & 1467.4 & -72.4 & -52.7 & 188.6 & 32.7 \\
\hline second-best & -337.0 & 979.6 & 1582.3 & 665.2 & -361.3 & -136.7 & -49.3 & -178.2 \\
\hline third-best & -656.1 & -152.8 & -1046.3 & -579.5 & -614.1 & -233.7 & -221.0 & -355.7 \\
\hline loser & -1267.4 & -3595.5 & -4103.3 & -2887.4 & -1517.9 & -402.0 & -618.5 & -856.4 \\
\hline \multicolumn{9}{|l|}{ Standard deviation } \\
\hline $\begin{array}{l}\text { of average profits } \\
\text { winner till loser }\end{array}$ & 822.8 & 2264.4 & 2994.2 & 1899.4 & 624.8 & 150.0 & 340.0 & 379.5 \\
\hline
\end{tabular}

In table 4.8 we present information about the distribution of dealer profits. In this table we show the average profits for all groups of dealers and both types of asset markets. We ranked the dealers in each round based on the profits they made in that round. The table presents the average profits of the winners, the second best, the third best, and the worst performing dealers in each trading round for all the subject groups. Winners make 
considerable profits in both markets, but the average profit level of the winners is substantially larger with inter-dealer trading. This is accompanied by a much larger loss for the losers in the inter-dealer market. The standard deviation of these four average profit levels is considerably larger when inter-dealer trading is permitted. These results strongly support our conjecture that information asymmetries are the predominant motive in our experimental multiple-dealer market.

\subsubsection{Price Efficiency}

In this subsection we analyze price efficiency in both markets. As in the previous chapter, we measure price efficiency with price errors. Price errors are again defined as the absolute difference between the average midpoint of the outstanding quotes at time $t$ and the liquidation value of the asset. We have plotted the price errors in figure 4.1. At each point in time, figure 4.1 depicts the average price error over the trading rounds in which inter-dealer trading is allowed and the average price error over the trading rounds in which it is not.

\section{Figure 4.1}

\section{Development of Price Errors}

This figure shows the average development of the price errors in the markets with and without inter-dealer trading. The price error in each trading round is defined as the absolute difference between the underlying value of the asset and the average midquote of all four market makers. The two price error curves in this graph are constructed by averaging the price errors of all individual rounds with the same trading mechanism. The first 20 seconds of each trading round are omitted, as dealers use this time period to enter their first bid and ask quotes.

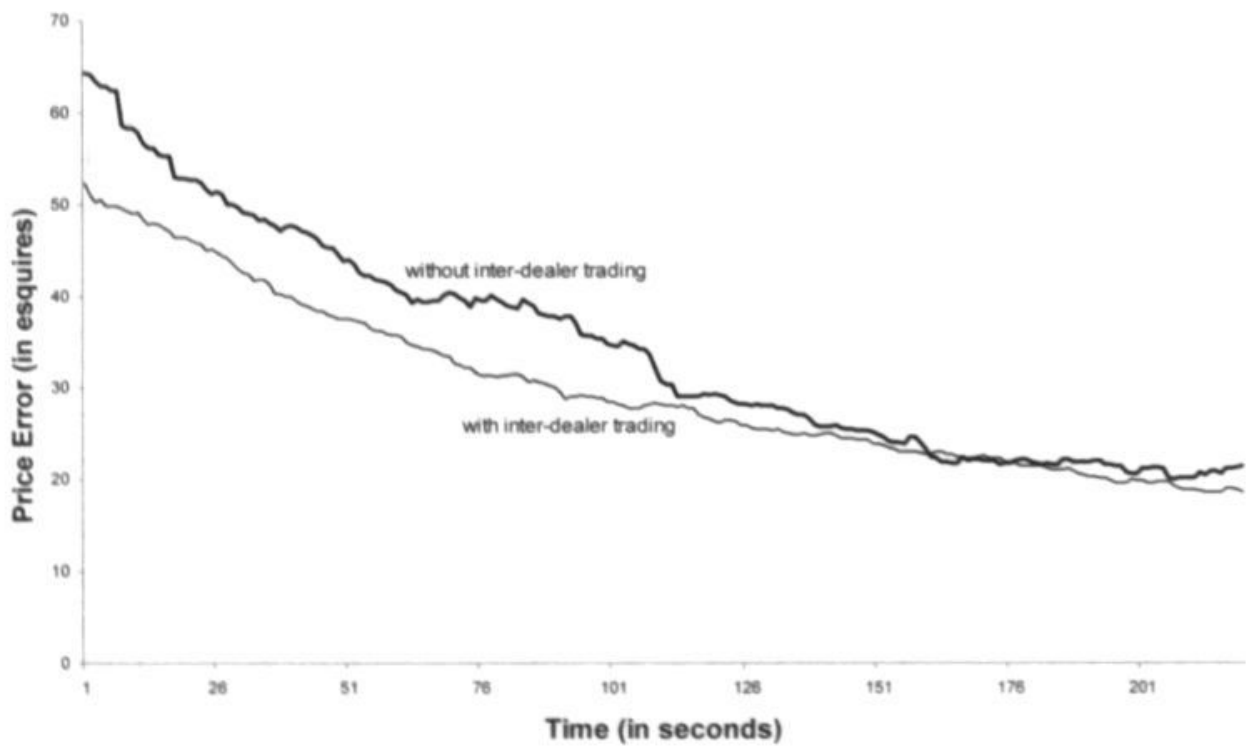


For both microstructures we observe that the price errors decline over time. This reflects the fact that the dealers learn about the liquidation value of the assets through informed robot initiated transactions and that they incorporate this information in their quotes. We also observe that the price errors decline more rapidly in the market without inter-dealer trading than in the market with inter-dealer trading. Allowing for inter-dealer trading thus slows the price discovery process.

These findings are further illustrated by table 4.7. Table 4.7 lists the average price errors for markets with and without inter-dealer trading as a fraction of the pricing error after 20 seconds. These relative price errors decline faster when no inter-dealer trading is possible, especially in the first 160 seconds of a round. Moreover, the average time till convergence of the market price to within 5 esquires of the underlying value is shorter for trading rounds without inter-dealer trading. Quoted prices converge to the underlying value in 10 out of 21 trading rounds without inter-dealer trading, compared to 7 out of 22 rounds with inter-dealer trading.

We estimate the speed of the price discovery in both markets in a formal individual effects panel model. In this model we pool the 43 trading rounds of the three subject groups and correct for individual trading round effects. The model can be expressed as

$$
\mid P_{t r k}-\text { TrueValue }_{r} \mid=\gamma_{0}+\sum_{i=1}^{43} \gamma_{i} I(r=i)+\sum_{j=I-D, \operatorname{mos} I-D} \gamma_{j} I(k=j) t+\eta_{t r k},
$$

where $t$ is time in seconds, $r$ denotes the trading round, $k$ the trading mechanism, $P_{t r k}$ is the average midpoint over all bid and ask quotes at time $t, \mathrm{I}(r=i)$ is a dummy variable for trading round which is equal to 1 if the trading round is equal to $i(i=1, \ldots, 43)$ and zero otherwise, $\mathrm{I}(k=j)$ is a dummy variable for trading mechanism which is equal to 1 if the trading mechanism is equal to $j$ ( $j=$ inter-dealer trading or $j=$ no inter-dealer trading) and zero otherwise, and $\eta_{t r k}$ is an i.i.d. error term. We impose the restriction $\gamma_{l}=0$. As in the previous chapter, we do not use the data from the first 20 seconds of each trading round nor any data points after the convergence of the market price to within 5 esquires of the underlying value.

In table 4.9 we present OLS estimates of the coefficients in equation (4.1) as well as heteroskedasticity robust standard errors. The third column shows the estimates of the slope of the price error curves with and without inter-dealer trading. Both estimates are statistically significant at the 95 percent confidence level. The estimated coefficient is smaller (that is, more negative) for trading rounds in which inter-dealer trading is not possible, indicating faster price discovery. The difference is marginally statistically significant. Hence, our panel model provides evidence for the hypothesis that price efficiency is greater in markets without inter-dealer trading than in markets with inter-dealer trading. 
Table 4.9

Price Efficiency

This table presents the estimated intercept and the coefficients of the trading mechanism dummies from the fixed effects panel model depicted in equation (4.1). Robust standard errors are presented in parentheses. Significance at the 5 percent level is denoted by $\bullet$. The number of data points is 6837 . The R-squared of the regression is equal to 0.901 .

\begin{tabular}{ccc}
\hline Trading Mechanism & Estimated Intercept & Estimated Slope Coefficient \\
\hline with inter-dealer trading & $\eta_{0}: 62.93^{*}$ & $-0.121^{*}$ \\
without inter-dealer trading & $(2.33)$ & $(0.023)$ \\
& & $-0.186^{*}$ \\
\end{tabular}

The findings of our panel analysis, however, may in part be due to the fact that price errors show a small initial increase when inter-dealer trading is not allowed. This is illustrated by table 4.10 , which depicts price errors relative to the price error at the start of the trading round. After 20 seconds, the average absolute pricing error is roughly 7 percent greater than the average difference between the underlying value and the a priori expected value of 100 . There does not seem to be a clear reason for this phenomenon. After 180 seconds, relative price errors are slightly smaller in the rounds without inter-dealer trading. After 240 seconds, price errors in the market with inter-dealer trading are marginally smaller.

We reckon that our results are driven by two effects that work in opposite directions. On the one hand, in the market with inter-dealer trading, information about the underlying value of the asset spreads relatively quickly, because many market participants trade on private information. This results in faster price discovery. On the other hand, market makers tend to focus on exploiting private information in the inter-dealer market. In the market without inter-dealer trading, market makers maximize profits by trying to set the bid quote below and the ask quote above the liquidation value as soon as possible. This speeds up the price discovery process. In the market with inter-dealer trades, dealers can also make profits by initiating trades with other market makers. Dealers filter information about the underlying value from the customer trades and hit the quotes of other market makers in order to exploit their beliefs about the liquidation value of the asset. Therefore, market makers have fewer incentives to set competitive prices. Our observations during the experiments indicated that most dealers believe that profits are maximized by active trading in the inter-dealer market instead of dealing with robots. This is confirmed by the fact that the number of quotes set is over 30 percent higher when inter-dealer trading is not possible. The findings depicted in tables 4.9 and 4.10 suggest that the two effects roughly neutralize each other. 
Table 4.10

Normalized Price Errors

This table presents normalized price errors for trading rounds with and without inter-dealer trading. The normalized price errors are based on the absolute difference between the true value of the security in each round and the average midpoint of all outstanding quotes. These errors are then averaged over all the rounds with a specific trading mechanism. The resulting numbers are corrected for the average initial price error in each transparency regime, to obtain price errors that are directly comparable across trading mechanisms. The initial price error is defined as abs(100 - TrueValue $)$.

\begin{tabular}{ccc}
\hline $\begin{array}{c}\text { Time } \\
\text { (in seconds) }\end{array}$ & $\begin{array}{c}\text { Trading Rounds With } \\
\text { Inter-Dealer Trading }\end{array}$ & $\begin{array}{c}\text { Trading Rounds Without } \\
\text { Inter-Dealer Trading }\end{array}$ \\
\hline 20 & 0.95 & 1.07 \\
60 & 0.72 & 0.78 \\
120 & 0.51 & 0.57 \\
180 & 0.42 & 0.39 \\
240 & 0.34 & 0.36 \\
\hline
\end{tabular}

\subsubsection{Spreads}

In this section we investigate the development of the bid-ask spread in markets with and without inter-dealer trading. As in the previous chapter, the spread at time $t$ is defined as the average of the midpoints of all bid and ask quotes in the market at time $t$. Figure 4.2 presents the average spread size for both the inter-dealer market and the market in which inter-dealer trading is not allowed. The initial spread size is relatively high, but the spread gradually declines over time in the market without inter-dealer trading. As more information is incorporated in market makers' quotes over time, uncertainty about the liquidation value of the traded security decreases and dealers are willing to lower the size of their spreads. In the market with inter-dealer trading, the spread size is fairly constant over the trading round. After around 120 seconds, spreads are considerably wider when inter-dealer trading is allowed. At the end of a trading round the difference amounts to almost 10 percent on average. Hence, transaction costs are considerably smaller in markets without inter-dealer trading. Assuming normality and independence, the mean spread size in the market without inter-dealer trading is significantly smaller than in the market with inter-dealer trading at the 99 percent confidence level. While the recent literature concludes that inter-dealer trading motivated by risk sharing leads to lower execution costs, we find evidence that execution costs are actually increased by inter-dealer trading in an asymmetric information setting. 


\section{Figure 4.2}

\section{Dealer Spreads}

This figure shows the average development of the spreads in the markets with and without inter-dealer trading. The average spread in each trading round is defined as the average size of the spread between the bid and ask quotes of all four market makers. The lines in this graph are constructed by averaging the spreads of all individual rounds with the same trading mechanism. The first 20 seconds of each trading round are omitted from the calculation, as dealers use this time period to enter their first bid and ask quotes.

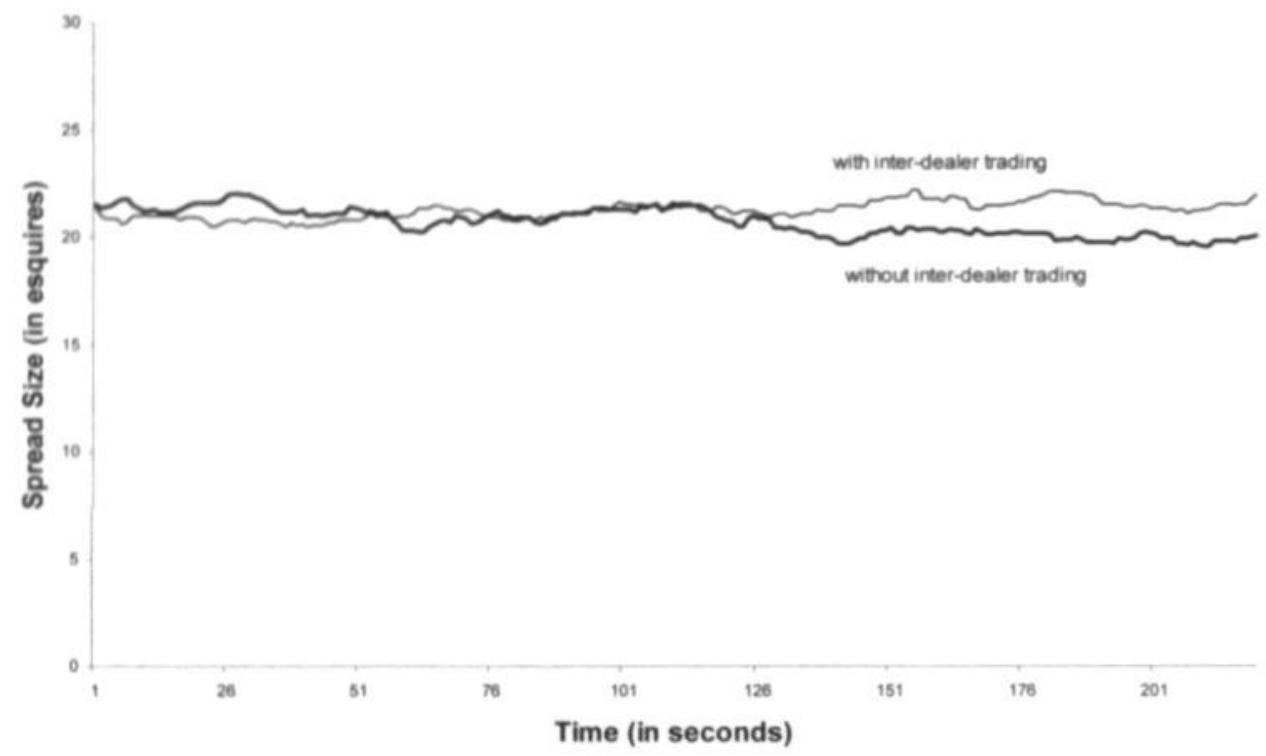

An explanation for this result is that market makers tend to focus on trading with other dealers rather than on trading with external customers, as argued in the previous subsection. Our results can also be interpreted in the context of the well-known trade-off between liquidity and efficiency. When inter-dealer trading is allowed, information spreads relatively quickly. However, adverse-selection costs are higher when dealers are allowed to exploit private information in the inter-dealer market. As the adverse-selection component in spreads is generally considered to be important, this results in a higher spread. Our spread results are also consistent with several empirical studies that find that spreads in dealership markets are higher than in auction markets. ${ }^{19}$ These studies do not examine the effect of inter-dealer trades separately from other microstructural differences, however.

19 See Huang and Stoll (1996), de Jong et al. (1995), and the discussion in Vogler (1997, p. 1630). 


\subsection{Conclusions}

This chapter deals with the consequences of inter-dealer trading in dealership markets. The literature distinguishes two motivations for dealers to trade with each other: risk sharing and asymmetric information. A large part of the recent literature focuses on risk sharing and finds that external investors prefer trading in a market with inter-dealer trading.

We investigate the consequences of inter-dealer trading when asymmetric information is the dominant motive. We obtain our data from an experimental asset market in which financial economics students act as market makers. The experiments are designed in such a way that profiting from information asymmetries is the motivation for trading with other dealers. In total we run the experimental asset market for 43 rounds: 22 rounds of which allow inter-dealer trading, and 21 rounds of which do not allow inter-dealer trading.

We show that the dispersion of dealer profits is dramatically larger in the market with inter-dealer trading than in the market without inter-dealer trading. This supports the idea that information asymmetries are important in our experiments. Dealers obviously use the interdealer market to exploit their beliefs about the underlying value of the asset. As our market is a fixed-sum game, this leads to a much wider variation in the profits of the market makers in each trading round. Secondly, we find that price errors exhibit a small initial increase in the market without inter-dealer trading. This is compensated by a faster decline of the price errors during the rest of the trading round. We argue that there are two opposite effects on price discovery that essentially neutralize each other. On the one hand, inter-dealer trading stimulates price discovery through faster diffusion of information. On the other hand, dealers have fewer incentives to quote competitive prices in the market with inter-dealer trading, because they concentrate on trading with other dealers. Thirdly, we compare the average development of the spread size in the markets with and without inter-dealer trading. Spreads clearly decline faster in the market without inter-dealer trading. At the end of the trading round, the difference is equal to approximately 10 percent on average. A plausible explanation for this finding is that the adverse-selection component of the spread in the market with interdealer trading is larger than in the market without inter-dealer trading. Moreover, market makers tend to focus on trading with other dealers rather than on quoting competitive prices.

Our results indicate that introducing inter-dealer trading in a setting with asymmetric information has considerable consequences on market performance. We show that these consequences are largely unfavorable to external customers of financial asset markets. Notably, bid-ask spreads are relatively wide in markets with inter-dealer trading. This finding sheds new light on the effects of inter-dealer trading as reported in previous studies. We reckon that much more attention should be paid to the asymmetric information motive in both the literature dealing with inter-dealer trading and in public policy discussions. Further research should provide better insights in the relative importance of risk sharing and asymmetric information in real life securities markets. 



\section{PART II}

\section{EXchange Rates AND THE COST OF CAPITAL OF INTERNATIONAL COMPANIES}





\section{Chapter 5}

\section{Introduction to Part II: \\ Puzzles in International Finance}

\subsection{Introduction}

In the past decades, barriers to international investment among developed economies have slowly but steadily diminished. The establishment of the European Monetary Union reinforced this process. Among emerging markets, the number of investment barriers has fallen dramatically. At the start of the $21^{\text {st }}$ century, U.S. and European investors face very few restrictions to buying securities of a large number of foreign countries. Moreover, international goods markets have also become more integrated over time. Most companies realize a growing percentage of their sales and profits abroad. Hence, domestic goods and capital markets seem likely to have become increasingly driven by international factors. Recent empirical international finance literature, however, finds a surprisingly small influence of international events on domestic markets.

We illustrate this point with two examples. First, the benefits of international diversification of investment portfolios are generally considered to be substantial. Standard portfolio theory predicts that stock investors hold the world market portfolio in integrated markets. Recent evidence, however, indicates that investors from numerous European countries invest a remarkably high percentage of their wealth in domestic securities. Cooper and Kaplanis (1994) find that domestic equities accounted for more than 60 percent of the stock portfolios of investors in France, Germany, Italy, and Spain in 1987. Tesar and Werner (1995) present evidence that German investors invested only 10 percent of their wealth abroad in 1990. For the U.K., this percentage was approximately 30 percent. According to Gehrig (1993), the proportion of foreign equity relative to total equity investments in the portfolios of 
banks and mutual funds in Germany and Switzerland amounted to, respectively, 20 and 26 percent in the late 1980 s.

Second, there seems to be little doubt among economists that the value of firms in developed countries is meaningfully affected by fluctuations in international exchange rates. Recent empirical studies nevertheless find surprisingly little evidence in favor of significant exchange rate exposure for European corporations. Martinez-Solano (1998) analyzes 67 nonfinancial Spanish companies over the period 1992-1997 and finds that slightly more than 20 percent of the firms are significantly exposed to exchange rates. Nydahl (1999) concludes that approximately 25 percent of 47 Swedish firms exhibit significant exposure over the period 1990-1997. The evidence for the Netherlands is mixed. Dutch firms are without a doubt engaged in many international activities. Roughly 80 percent of the sales of the 27 multinationals with the highest market capitalization is realized abroad, while on average fewer than 20 percent of their employees work in the Netherlands (see Het Financieele Dagblad (1998)). Moreover, an analysis of the annual reports of 14 Dutch companies by de Jong and Ligterink (1992) shows that firms often point out important exchange rate exposure effects on earnings. The authors suggest, however, that companies have an incentive to attribute disappointing results to exchange rate fluctuations. Kool and Schweitzer (1997) find an insignificant effect of the real dollar/guilder rate on the stock returns of six Dutch multinational firms in the period 1975-1995, after correcting for movements in the Dutch stock market index. ${ }^{20}$ In a study of 30 Dutch multinational firms over the period 1984-1996, de Jong and Dassen (1997) conclude that the exposure to the U.S. dollar is sizeable. However, de Jong and Dassen do not report the statistical significance of their results. In an unreported, exploratory investigation of the monthly stock returns of the 50 Dutch firms with the highest market capitalization over the period 1980-1999, we find that the exposure to eight foreign currencies is jointly significant for only 8 companies.

An important part of the recent literature is dedicated to puzzles in international finance. Besides the home bias puzzle and the foreign exchange exposure puzzle described above, well-known enigmas concern uncovered interest parity, purchasing power parity, and country versus industry diversification. In part II of this thesis we present three empirical studies on several of these controversies. Chapter 6 analyzes purchasing power parity in a panel of 17 countries. Our panel methodology is invariant to the choice of the benchmark or numeraire currency. We allow for individual country effects in the relation between exchange rates and prices, which allows us to identify the individual currency pairs for which purchasing power parity holds. In chapter 7 we investigate whether international and domestic versions of the capital asset pricing model yield a different estimate of the cost of capital for a large sample of firms. We also analyze the exposure of these companies to fluctuations in

20 Kool and Schweitzer find significant exposure in a regression of stock returns on real dollar/guilder rate returns only. However, recent tests of exchange rate exposure do incorporate the domestic market portfolio as a dependent variable (see e.g. Bartov and Bodnar (1994) and $\mathrm{He}$ and $\mathrm{Ng}$ (1998)). 
foreign currencies. In chapter 8 we consider a sample of firms with foreign equity listings. We conjecture that international and domestic asset pricing models lead to a different estimate of the cost of capital for companies with international cross-listings. Moreover, cross-listed firms can be expected to exhibit significant exchange rate exposure.

This introductory chapter presents a concise review of the recent literature on five puzzles in international finance: the uncovered interest parity puzzle, the purchasing power parity puzzle, the equity home bias puzzle, the country versus industry diversification puzzle, and the foreign exchange exposure puzzle. In section 5.2 we attempt to provide a summary of the recent empirical findings as well as a number of possible explanations offered for each puzzle. In section 5.3 we briefly discuss the set-up of the studies included in part II of this thesis. Section 5.4 offers a conclusion.

\subsection{Puzzles in International Financial Markets}

\subsubsection{The Uncovered Interest Parity Puzzle}

It is generally accepted that arbitrage between spot and forward foreign exchange markets ensures that covered interest parity (CIP) holds. The CIP condition states that the return on investing a unit of domestic currency in a domestic deposit is equal to the return of converting the domestic currency into foreign currency, investing it in a foreign deposit and converting the proceeds back into domestic currency at the forward exchange rate. Many studies investigate the validity of a related fundamental hypothesis in international economics: uncovered interest parity (UIP). If UIP holds, the ex ante expected home currency return on foreign deposits in excess of the home currency return on domestic deposits is zero (assuming the proceeds of the foreign deposits are converted back into the domestic currency at the future realized spot exchange rate).

As market expectations of future exchange rates are very hard to observe, UIP is generally jointly tested with the assumption of rational expectations. That is, the future realization of the exchange rate is assumed to be equal to the expected exchange rate plus a white-noise error term. This joint hypothesis is often referred to as the unbiasedness hypothesis. In standard tests of the unbiasedness hypothesis, the change in the spot exchange rate is regressed on the forward premium. Under the null-hypothesis of UIP and rational expectations, the slope coefficient in this regression is equal to one.

A large number of articles report rejections of the unbiasedness hypothesis. Lewis (1995), for example, analyzes the U.S. dollar exchange rates against the Deutschmark, the British pound, and the Japanese yen over the period 1975-1989 and strongly rejects the nullhypothesis at the one-month horizon. The slope coefficients are not only significantly different from one, they are even significantly negative for all exchange rates in the sample. Lewis also shows that predictable excess returns exhibit a lot of variation over time. These results are typical of the empirical literature on the unbiasedness hypothesis. 
Lewis reviews the literature and examines two potential explanations for the rejection of UIP. First, predictable excess returns may arise from a (time-varying) foreign exchange risk premium. Second, the assumption of rational expectations may be violated due to (systematic) forecast errors. These expectational errors can be caused by irrational traders as well as by peso problems or other difficulties in measuring expectations in a given sample. Lewis concludes that while both issues can partly account for the predictability of excess returns, they cannot explain the high variability in these returns.

Huisman, Koedijk, Kool, and Nissen (1998) focus on the small sample problems of bilateral time-series tests. They test the unbiasedness hypothesis in a panel model that is invariant to the choice of the numeraire currency. The authors analyze monthly returns of the British pound against 14 OECD currencies over the period 1979:01-1996:03. Although the slope coefficients are significantly smaller than one, they are significantly different from zero and approximately equal to 0.5 . This implies that the rejection of the unbiasedness hypothesis is not as severe as commonly found. Huisman, Koedijk, Kool, and Nissen subsequently distinguish between "normal" periods and periods in which the average forward premium is large. They find that the unbiasedness hypothesis cannot be rejected in periods with large forward premia. They argue that this result may be due both to inactivity bands in which no arbitrage takes place and to peso problems.

Meredith and Chinn (2000) apply a slightly different methodology for testing the unbiasedness hypothesis. They test the null-hypothesis that the slope coefficient equals unity in a regression of the change in the spot exchange rate on the difference between the domestic and the foreign interest rate. ${ }^{21}$ Meredith and Chinn examine the unbiasedness hypothesis for both short and long horizons in a sample of the G-7 exchange rates against the U.S. dollar in the period 1980:1-2000:1. The average slope coefficient at the 3-, 6-, and 12-month horizon is equal to approximately -0.8 . At the 10 -year horizon, however, all slope coefficients are positive and the null-hypothesis is rejected in only three cases.

\subsubsection{The Purchasing Power Parity Puzzle}

The theory of purchasing power parity (PPP) states that national price levels should tend to be equal when expressed in a common currency. This proposition is based on the idea that goods market arbitrage enforces domestic and foreign prices of a broad range of individual goods to be equal once converted to a common currency. While at short horizons tariffs and non-tariff barriers (such as government regulations and information costs) may prevent goods arbitrage from taking place, most economists strongly believe that PPP should hold in the long run under a floating exchange rates regime.

The traditional test of (relative) PPP is to examine whether real exchange rates contain a unit root. A large majority of studies of post-1973 floating rate data fail to reject the

21 This testing methodology is equivalent to the standard test employed by e.g. Lewis (1995) if CIP holds. 
hypothesis that real exchange rates follow a random walk. A major objection to these studies is that unit root tests lack power. Rogoff (1996) reviews the literature and discusses two distinct ways in which researchers respond to this power problem. First, several studies attempt to enhance the power of the unit root test by looking at long time-series of real exchange rates. For instance, Lothian and Taylor (1996) analyze annual data on the exchange rates between the British pound and the U.S. dollar over the period 1791-1990 and between the pound and the French franc over the period 1803-1990. Lothian and Taylor reject the unit root hypothesis for both exchange rates over the full sample period. Estimates of a first-order autoregression model indicate that the half-life of real exchange rate shocks is approximately six years for the pound/dollar rate and three years for the pound/franc rate. Other long-horizon PPP studies find similar half-lives for real exchange rates. An important caveat of these studies is that the data spans different exchange rate regimes. Lothian and Taylor state that over the past 200 years, the United States has experienced no less than 12 separate exchange rate regimes.

A second way to deal with the power problem is to use real exchange rate data for a cross-section of countries. An example of such a panel data study is Frankel and Rose (1996). They analyze annual exchange rate data for 150 countries over the period 1948 to 1992 . The authors find evidence that PPP holds, even for post-1973 data. The estimated half-life of PPP deviations amounts to roughly four years, which resembles the findings of other panel studies. A recent paper by O'Connell (1998) raises an important problem with panel tests of PPP. O'Connell argues that real exchange rates of different currencies against a common numeraire exhibit cross-sectional dependence. They contain two common components, namely, independent variation in the value of the numeraire currency and independent variation in the price index of the numeraire country. This cross-sectional dependence adversely affects the size and the power of the panel unit root tests. O'Connell shows that the size bias can be considerable. The true size may be as high as 50 percent when the nominal size is equal to 5 percent. This size bias can be accompanied by significant drops in the power of the test. The loss in power can be avoided by using generalized least squares (GLS) estimation.

\subsubsection{The Home Bias in Equities Puzzle}

According to standard portfolio theory, investors should hold a combination of the risk-free asset and the world market portfolio in integrated capital markets. This implies that U.S. investors should invest a considerable part of their wealth in foreign assets in order to optimally exploit diversification opportunities. Recent studies (e.g. Bohn and Tesar (1996)) estimate the average share of foreign equities in U.S. portfolios at only around 8 percent. This is widely regarded as suboptimal with any set of preferences. Similar percentages are reported for European countries (see e.g. Cooper and Kaplanis (1994)). This phenomenon has been called the "equity home bias". Lewis (1999) provides an extensive review of the literature on the home bias. 
Lewis examines the home bias for U.S. investors in the period January 1970 to December 1996. She uses the S\&P 500 as a proxy for the U.S. stock market portfolio. Returns on the non-U.S. world stock market index are measured by monthly dollar returns on the Morgan Stanley "Europe, Australia, and Far East" index. The mean return as well as the standard deviation are smaller for the domestic index as compared to the foreign index. The correlation between the indices is equal to 0.48 , suggesting large potential diversification benefits from investing abroad. The author shows that in a CAPM framework the share of foreign assets in the minimum variance portfolio is about 40 percent. Depending on risk aversion, most U.S. investors should place an even higher percentage of their portfolio in foreign assets. As the observed foreign portfolio share is only 8 percent, Lewis $(1999$, p. 578$)$ concludes: "Clearly, no degree of risk intolerance can justify such a low level of foreign portfolio allocation."

Lewis examines three explanations for the home bias in equities. First, domestic assets may provide a better hedge against domestic country-specific risks. For example, domestic equities can possibly be used as a hedge against domestic inflation. The CAPM model that the author employs for analyzing the home bias in the U.S. abstracts from deviations from purchasing power parity. However, as reported in section 5.2.2, evidence in favor of PPP is weak at short horizons. Recent empirical studies reject the hypothesis that the home bias can be explained by inflation hedge motives. Another objection to the CAPM framework is that a considerable part of an investor's wealth is non-marketable. Hence, the market portfolio is mismeasured. An important example of non-marketable wealth is human capital. As human capital returns can be shown to be highly correlated with domestic stock market returns but not with foreign stock returns, however, incorporating human capital in the analysis only worsens the home bias puzzle. An additional argument is that U.S. investors may not need to hold foreign assets for diversification purposes. Investing in U.S. multinationals may yield returns that depend on international factors. Lewis finds little evidence for this explanation. The stocks of multinationals are highly correlated with the domestic market index. And, as outlined in section 5.2.4, diversification across countries within an industry is much more effective than diversification across industries within a country. A recent study by Errunza, Hogan, and Hung (1999), however, shows that U.S. investors can mimic foreign market indices with domestically traded assets, such as American Depositary Receipts (ADRs) and closed-end country funds.

Second, the gains of international diversification may not outweigh the costs. The costs of diversifying internationally consist of taxes, transaction costs, and information costs. Lewis claims that, in the CAPM framework in her paper, the benefits of international diversification lie in the range of 20 percent to almost 100 percent of lifetime consumption, depending on assumptions about risk aversion. Although the costs are hard to measure, they are unlikely to exceed the benefits. The huge flows of capital in international equity transactions suggest that the costs of foreign investment are relatively minor. 
Third, a number of recent articles argue that the high degree of uncertainty in the estimates of the mean and the variance of domestic and foreign market portfolios implies that the improvement in an investor's stock portfolio stemming from international diversification is not statistically significant. Lewis concludes that the empirical evidence is mixed. This is an interesting direction for future research.

\subsubsection{The Country versus Industry Diversification Puzzle}

It is well documented that correlations between international equity markets are low. As indicated in the previous subsection, the correlations between the stock market indices of G-7 countries are typically much smaller than one and often smaller than 0.5 . Even estimates of the correlation between the equity markets of economically strongly integrated countries like the Netherlands and Germany rarely exceed 0.7 . Rouwenhorst (1999) offers three possible explanations for these low correlations. First, as discussed in the previous subsection a disproportionate part of investor portfolios consists of domestic stocks. If this implies that the marginal investor in the market portfolio of a certain country is from that country, country portfolios may reflect the particular sentiment of the domestic investors. Second, the correlation between country indices may be low due to differences in industrial composition. Part of the benefits of international diversification are then derived from industrial diversification. Third, firms in different countries may be subject to country-specific economic shocks or may react differently to global economic shocks.

Several recent empirical studies show that the low correlations between international equity markets mainly arise from country-specific factors. Differences in industrial composition account for only a small amount of the return variation in country indices. Heston and Rouwenhorst (1994) analyze monthly data on 829 stocks from 12 European countries in the period 1978 to 1992 . Each firm in the sample is assigned to one of seven broad industries. Heston and Rouwenhorst decompose the return on the country indices in excess of the value-weighted European market index into a pure country effect and seven industry effects. They show that on average only 7 percent of the variance of the excess return on a country index can be explained by industry factors. This result is especially puzzling because European countries exhibit both strong economic integration and large differences in industrial composition.

Griffin and Karolyi (1998) use a database covering 25 countries and 66 industries over the period 1992 to 1995 to examine the relative importance of country and industry effects. As this paper also investigates non-European countries, country effects can be expected to be even more dominant. Griffin and Karolyi find that the ratio of the variance of the cumulative industry effects to the variance of the weekly excess returns on the country indices amounts to approximately 4 percent. This confirms the results of Heston and Rouwenhorst.

The fact that differences in international country indices can primarily be attributed to country-specific factors has important implications for international diversification strategies. Griffin and Karolyi demonstrate that diversification across industries within a country can 
reduce the variance to roughly 22 percent of the variance of an average individual stock. Diversification across countries within an industry leads to a reduction in variance of more than 90 percent. Diversification across countries and industries only yields an additional reduction in variance of 1 percent. Rouwenhorst (1999) updates the Heston and Rouwenhorst study and concludes that geographical diversification remains more important than industrial diversification.

\subsubsection{The Exchange Rate Exposure Puzzle}

Exchange rates are generally considered to be a major source of financial uncertainty for firms in industrialized countries. Many multinationals realize a high percentage of their sales abroad. A large number of companies are dependent on the import of raw materials. Moreover, purely domestic corporations that sell goods competing with imports are also likely to be exposed to exchange rates. Several recent empirical studies, however, report a remarkably weak link between the value of companies and movements in the domestic currency relative to foreign currencies.

Exchange rate exposure is often measured by the slope coefficient in a regression of the (excess) return on a stock on percentage change in a trade-weighted exchange rate index. A drawback of this approach is that individual firms within a country may be differently exposed to different foreign currencies. Jorion (1990) estimates the exposure of 287 U.S. multinationals to fluctuations in a U.S. dollar exchange rate index against 15 foreign currencies. The sample period starts in January 1971 and ends in December 1987. Jorion finds significant exposure for only 15 firms in the sample. The exposure coefficients vary widely across multinational firms and often change over time. A second result is that exposure is positively related to the ratio of foreign to total sales.

Bartov and Bodnar (1994) offer two explanations for the weak evidence for exchange rate exposure. First, the results may be caused by the sample selection procedure used. For example, firms with extensive foreign operations can probably hedge exchange rate exposure at relatively low cost. Bartov and Bodnar select firms that report substantial gains (losses) as a result of a depreciating (appreciating) dollar in their annual financial statements. Second, investors may make systematic errors in the assessment the relation between currency fluctuations and the value of a firm. Bartov and Bodnar correct for possible mispricing by incorporating lagged exchange rate returns in the regression. The authors estimate exchange rate exposure in a pooled regression for 208 U.S. firms over the period 1978 to 1990. Excess stock returns over a 60-trading-day interval are not significantly correlated to contemporaneous exchange rate changes. Lagged changes in the dollar, however, do have a significant effect on stock returns at the 99 percent confidence level. This suggests that the effect of changes in the dollar is not instantaneously incorporated into stock prices. A simple trading strategy based on the lagged relation yields an annualized abnormal return of 4 percent. 
$\mathrm{He}$ and $\mathrm{Ng}(1998)$ analyze a sample of 171 Japanese multinationals that have export ratios of at least 10 percent over the period 1979:01-1993:12. Their main results indicate that changes in the trade-weighted exchange rate index of the yen against nine other currencies have a significant impact on the excess stock return for approximately 25 percent of the firms in the sample. For most corporations, an appreciation of the yen adversely affects the stock price. In a cross-sectional analysis, $\mathrm{He}$ and $\mathrm{Ng}$ find that exchange rate exposure is positively related to a firm's size and export ratio and negatively related to variables that are proxies for a firm's hedging incentives, such as leverage.

\subsection{Outline of Part II}

In part II of this thesis we take another empirical look at several of the puzzles in international finance discussed in the previous section. In chapter 6 we employ a panel data methodology to examine absolute and relative purchasing power parity for 17 countries over the period 1973:1-1996:3. Our methodology constitutes a straightforward way of dealing with the issue of cross-sectional dependence addressed by O'Connell (1998). As discussed in section 5.2.2, O'Connell shows that real exchange rates relative to a common numeraire currency are highly correlated. This leads to potentially very large biases in the size and power of panel data tests. We deal with the cross-sectional dependence by applying a GLS estimation technique that makes our results invariant to the choice of the numeraire currency. We also concentrate on the common assumption in panel data studies that PPP is equally valid for every currency. We argue that PPP may well hold for some currencies, but not for others. For example, goods arbitrage is relatively more effective for countries that are geographically proximate. Our approach allows for an evaluation of PPP for each currency pair separately. We find substantive evidence in favor of relative PPP for currencies related to the German mark. The evidence for PPP is much weaker for the U.S. and Canada.

In chapter 7 we build on a paper by Stulz (1995b). Stulz explores the question whether a domestic asset pricing model yields a different estimate of a firm's cost of capital than an international model. Stulz investigates whether the domestic CAPM and the single factor ICAPM of Grauer, Litzenberger and Stehle (1976) lead to a different estimate of the beta of the Swiss multinational Nestlé. He derives an expression for this so-called "pricing error" and finds that the domestic CAPM yields a substantially larger estimate of Nestlé's cost of capital than the ICAPM. Chapter 7 provides three extensions to the analysis of Stulz. First, we examine a multifactor ICAPM including both the global market portfolio and exchange rate risk premia. Second, we develop statistical tests for the significance of the pricing error. Third, we evaluate the pricing error for almost 3,300 stocks from nine different countries over the period 1980:02-1999:06. We detect a significant pricing error for only around 5 percent of the companies in our sample. A variance decomposition analysis suggests that this "pricing error puzzle" may be attributed to strong country factors in the data, consistent with the 
evidence discussed in section 5.2.4. This finding is possibly related to what De Ménil (1999) calls lack of real capital market integration due to cyclical, structural, and institutional country-specific factors. These closely tie together the fortunes of all firms operating in the same country. Our pricing error testing methodology closely resembles the standard tests for exchange rate exposure. We show how both tests are related and investigate to what extent the firms in our sample are exposed to currency fluctuations. Our results confirm the conclusions of the recent literature, as reviewed in section 5.2.5. Exchange rate exposure is significant for only a limited number of stocks. The strong country factors in our data, however, indicate that firms within a country share a joint exposure to global factors. When we adjust our testing methodology for this phenomenon, we find significant exposure for more than $\mathbf{4 5}$ percent of the firms in our sample.

We analyze the cost of capital of cross-listed firms in chapter 8 . Several studies show that companies with foreign equity listings are generally large multinationals with a strong international orientation. As these firms probably exhibit substantial exposure to global factors, the multifactor ICAPM may well yield a different estimate of their cost of capital than the domestic CAPM. Therefore, we expect to find a considerable pricing error for cross-listed corporations. We analyze monthly stock returns of 336 firms with international listings from nine countries over the period 1980-1999. We find a significant pricing error for roughly 12 percent of the firms. The size of the implied cost of capital differential is approximately 50 basis points for the U.S. and around 75 basis points for the U.K. Our results provide little support for our hypothesis that the pricing error is significant for cross-listed stocks. More than 80 percent of the firms with cross-border listings are significantly exposed to exchange rate fluctuations, however. We also estimate the pricing error and foreign exchange exposure for a benchmark sample of 2,957 companies without international listings. Approximately 4.4 percent of these domestic firms displays a significant pricing error, while 40 percent exhibits significant exchange rate exposure.

\subsection{Conclusions}

Since World War II we have observed a gradual convergence to economic integration between both international financial markets and international goods markets. Although a number of investment barriers still exist, notably among emerging and less developed countries, international factors seem to have gained in importance for domestic goods and capital markets. The recent finance literature, however, has identified a number of issues on which international events have a remarkably small impact. These include the well-known home bias puzzle and the foreign exchange exposure puzzle. Part II of this thesis re-examines several of the puzzles in international finance. 


\section{Chapter 6}

\section{The Re-Emergence of PPP in the 1990s}

\subsection{Introduction}

The theory of purchasing power parity (PPP) is one of the central tenets in international economics. When exchange rates started to float world-wide in 1973 , it was widely believed that PPP would provide an accurate description of movements in exchange rates. The following years of very high exchange rate volatility quickly destroyed that idea. The demise of PPP was confirmed through formal econometric tests in the late 1970 s and early $1980 \mathrm{~s}$. At the beginning of the $1980 \mathrm{~s}$, it seemed as if the theory of PPP had collapsed completely.

Tests of PPP have often taken the form of unit root tests of the real exchange rates. As is well-known (see e.g. the review by Edison, Gagnon, and Melick, 1997), these tests suffer form extremely low power. This may well be the reason that the unit root in real exchange rates is hardly ever rejected. Several researchers cope with the power problems by using longhorizon data. Well-known studies with long data spans are Edison (1987) and Lothian and Taylor (1996). These studies find that real exchange rates exhibit slow but significant mean reversion, suggesting that PPP is valid in the long run.

Another way to circumvent the low power of the traditional tests is the use of panel data. Examples of panel data studies of PPP are Abuaf and Jorion (1990) and, more recently, Jorion and Sweeney (1996), and Frankel and Rose (1996). Pooling data for different exchange rates against the U.S. dollar, these papers find relatively strong evidence in favor of PPP. On the basis of long-horizon and panel data results, it is generally perceived that PPP has risen from its ashes in the past few years. In his review of the empirical literature, Rogoff (1996, pp. 657-658) concludes: 
"Overall, while there are some limitations to both the long-horizon and cross-section results on convergence to PPP, the recent literature has reached a surprising degree of consensus: PPP deviations tend to damp out, but only at the slow rate of roughly $15 \%$ per annum."

However, the panel results of PPP are questioned in a recent study by O'Connell (1998), who shows that calculating all real exchange rates relative to the U.S. dollar leads to cross-sectional dependence in panel data. Adjusting for this problem makes it much more difficult to reject the random walk in real exchange rates.

In this chapter we consider PPP using a panel data methodology that explicitly deals with the numeraire effect that causes the cross-sectional dependence. Our panel model extends the four country model of Koedijk and Schotman (1990). The parameter estimates in the PPP equations are invariant to the choice of the numeraire currency.

The focus of this chapter is also on another assumption that is typical in the panel literature. The relatively high power of the panel studies is partly achieved by assuming that PPP holds equally well for every currency. This implies that all mean reversion parameters are equal in the Abuaf and Jorion (1990) and Frankel and Rose (1996) studies. Individual currency effects are treated as constant terms (fixed or random effects), while the slope coefficients are equal across equations. An alternative position is that (long-run) PPP holds for some currency pairs, but not for others. For each country we investigate whether the value of its currency moves proportionally to the price level (or inflation) in that country.

The difference between our approach and other panel data studies can be explained by the following example. Consider a panel with three countries: the United States, Germany, and the Netherlands. Suppose that PPP holds between the mark and the guilder, but not between the dollar and these currencies. No matter which currency is used as the numeraire, PPP is always rejected in this panel. With the dollar as the numeraire the rejection is correct, but with the guilder as the numeraire the rejection is due only to the dollar/guilder rate, and not the mark/guilder rate. Nevertheless, in small samples it would appear that rejection of PPP is stronger with the U.S. dollar as the numeraire than with the guilder as the numeraire. This is exactly the conclusion of Papell and Theodoridis (1998), who compare panel unit root tests with the mark and the dollar as alternative numeraires. In our approach, we estimate the price parameters simultaneously for all currencies. In the three-country example, we would find that prices and currencies move proportionally in the Netherlands and Germany, while they do not in the United States.

The plan of the chapter is as follows. In section 6.2 we discuss our numeraire invariant panel methodology, while section 6.3 contains the results. Section 6.4 concludes. 


\subsection{Methodology}

The general framework for empirical tests of absolute PPP is to compare consumer price indices expressed in a common numeraire currency. This absolute consumption-based PPP relates the logarithm of the exchange rate between currencies $i$ and $j$ to the logarithm of the consumer price indices in countries $i$ and $j$ :

$$
q_{i j}(t)=s_{i j}(t)+p_{i}(t)-p_{j}(t)=\left(c_{i}-c_{j}\right)+\beta_{i} p_{i}(t)-\beta_{j} p_{j}(t)+v_{i j}(t),
$$

where $s_{i j}$ is the logarithm of the nominal exchange rate (the price of currency $i$ in units of currency $j), q_{i j}$ is the real exchange rate, and $p_{i}$ denotes the logarithm of the consumer price index for country $i$. Absolute PPP is said to hold in the long run if the following three conditions are fulfilled: (i) $\beta_{i}=\beta$ (symmetry), (ii) $\beta_{i}=0$ (proportionality), and (iii) the error term $v_{i j}(t)$ is stationary. Most empirical tests simply impose the first two conditions. Under these restrictions the null-hypothesis most often tested is that the real exchange rate $q_{i j}(t)$ contains a unit root, against the alternative hypothesis that the real exchange rate is stationary. 22

The emphasis in this chapter is, in contrast, on the first two conditions. Equation (6.1) is estimated simultaneously as a system of $N$ equations for $N$ exchange rates $(i=1, \ldots, N)$ against the common numeraire currency $j=0$. We test the null-hypothesis $\beta_{i}=0$ for each of the $N+1$ currencies under the maintained hypothesis that the error term $v_{i j}(t)$ is stationary (although probably highly auto-correlated). In order to minimize the risk of spurious regression, we consider an augmented version of equation (6.1) with a linear trend included

$$
q_{i j}(t)=\left(c_{i}-c_{j}\right)+\left(\delta_{i}-\delta_{j}\right) t+B_{i} p_{i}(t)-\beta_{j} p_{j}(t)+v_{i j}(t) .
$$

The constant terms $c_{j}$ and the trend coefficients $\delta$ are not identified. Without loss of generality we can normalize these parameters using $c_{0}=0$ and $\delta_{0}=0$. Under the null-hypothesis of longrun PPP the remaining trend coefficients $\delta(\mathrm{i}=1, \ldots, N)$ should be equal to zero, as any other trending explanatory variable.

For ease of interpretation we report the results for the transformed, but equivalent presentation

$$
q_{i 0}(t)=\left(\tilde{c}_{i}-\tilde{c}_{0}\right)+\left(\tilde{\delta}_{i}-\tilde{\delta}_{0}\right) t+B_{i} \tilde{p}_{i}(t)-B_{0} \tilde{p}_{0}(t)+v_{i 0}(t)
$$

where

$$
\begin{gathered}
\tilde{p}_{i}(t)=p_{i}(t)-\psi_{0 i}-\psi_{H} t \text { and } \\
\tilde{p}_{0}(t)=p_{0}(t)-\psi_{00}-\psi_{10} t
\end{gathered}
$$

Incidentally, this null-hypothesis is contrary to the usual methodology of hypothesis testing. The theory should hold under the null and be rejected under the alternative. In the unit root tests the hypotheses are reversed. See Schotman and Van Dijk (1991) for a Bayesian analysis of the unit root hypothesis in real exchange rates, in which null and alternative are treated symmetrically. 
are the detrended price series defined as the residuals of the regression of $p_{i}(t)$, respectively $p_{0}(t)$, on a constant and a linear trend, so that

$$
\begin{aligned}
& \tilde{c}_{i}-\tilde{c}_{0}=c_{i}-c_{0}+\beta_{i} \psi_{0 i}-\beta_{0} \psi_{00}, \\
& \tilde{\delta}_{i}-\tilde{\delta}_{0}=\delta_{i}-\delta_{0}+B_{i} \psi_{l i}-\beta_{0} \psi_{l 0} .
\end{aligned}
$$

Note that the coefficients $\beta_{i}$ and $\beta_{0}$ on the price variables are the same in equations (6.2) and (6.3), but regression (6.3) has the advantage that prices have been orthogonalized from the trend component. In the extended model, any effect of the detrended prices on the real exchange rate is due to price variability and does not come about through a missing trend in the real exchange rate. In the transformed model, the null-hypothesis remains unchanged.

The levels tests have some serious defects. Because exchange rates and prices might have unit roots (i.e., a stochastic instead of a deterministic trend), the test statistics may not have a standard asymptotic distribution. Even if the explanatory variables do not have an exact unit root, the results of Stock (1996) indicate that tests based on standard asymptotic theory could be unreliable. In order to circumvent unit root and spurious regression problems, we also consider the hypothesis of relative PPP. The relative version of PPP requires that the percentage change in the bilateral exchange rate equals the inflation differential between the domestic and the foreign country. The hypothesis does not specify the horizon over which inflation differentials and exchange rate changes should be equal. Taking $k$-period differences of equation (6.1), the test equation for relative PPP becomes

$$
\Delta_{k} q_{i j}(t)=B_{i} \Delta_{k} p_{i}(t)-B_{j} \Delta_{k} p_{j}(t)+v_{i j}(t),
$$

where $\Delta_{k}$ denotes the $k$-period difference operator $\Delta_{k} y(t)=y(t)-y(t-k)$, and where the error term $v_{i j}(t)$ is possibly auto-correlated due to overlapping observations. For the model with trends in equation (6.2), the differencing operation leads to an augmented version of equation (6.4) with a constant term.

Estimation and testing is carried out on a full panel of $N+1$ currencies. Suppose we have a sample with currencies numbered $i=0,1, \ldots, N$. For the actual estimation we only need data relative to one particular numeraire currency, say currency 0 . Simply subtracting the equations for exchange rates $q_{i 0}$ and $q_{j 0}$ yields the implied regression model for the cross exchange rate $q_{i j}$, which automatically has explanatory variables $\Delta_{k} p_{i}$ and $\Delta_{k} p_{j}$, while $\Delta_{k} p_{0}$ drops out.

Since all exchange rates in the regression are expressed in the same numeraire currency 0 , the error terms $v_{i 0}(t)(i=1, \ldots, N)$ are likely to be positively correlated due to the strong common numeraire effect. This implies that, although the cross-sectional ordinary least squares (OLS) estimator is consistent, it is not efficient. More efficient estimates can be obtained by applying generalized least squares (GLS), which requires assumptions about the error terms. As a model for the cross-sectional dependence we assume the decomposition of Mahieu and Schotman (1994)

$$
v_{p}(t)=v_{i}(t)-v_{0}(t)
$$


The decomposition states that the error term in the exchange rate equation is the difference between an error term $v_{i}(t)$ for country $i$ and an error term for the numeraire currency 0 , which appears in $N$ equations of the system. In the panel literature this specification is referred to as the random time effects model (see Baltagi (1995)). We assume that the country specific shocks are mutually uncorrelated and have a common variance equal to $1 / 2 \sigma^{2}$. Under these assumptions the covariance matrix for the vector $v_{0}=\left(v_{10}, \ldots, v_{N 0}\right)^{\prime}$ takes the form

$$
\Sigma=1 / 2 \sigma^{2}\left(\boldsymbol{I}+u^{\prime}\right),
$$

where $I$ is the $(N \times N)$ identity matrix and $t$ denotes the $(N \times 1)$ vector of ones. This covariance structure imposes the condition that all exchange rates have equal variance and that the correlation between exchange rates is $1 / 2$. Since $\Sigma$ is completely specified, the GLS estimator is directly applicable.

The covariance structure in equation (6.6) not only deals with the positive crosssectional correlations, but as Koedijk and Schotman (1990) show, it also ensures that all results are completely invariant with respect to the choice of the numeraire currency. Whether we express all exchange rates against the U.S. dollar, the Japanese yen, the Deutschmark, or any other currency has no effect on the estimates of the parameters $\beta$, and $\delta$.

We use the Newey-West procedure to calculate standard errors. Application of the Newey-West estimator provides standard errors that are robust against heteroskedasticity and auto-correlation in the residuals. Moreover, since the Newey-West estimator does not employ the cross-sectional covariance structure in equation (6.6), it is also robust against possible misspecification of the covariance matrix $\Sigma$ in the panel model. Even if the covariance structure is more complicated than in equation (6.6), the GLS estimator remains consistent, though no longer efficient.

\subsection{Results}

The data is quarterly and cover a period of 24 years (1973:1-1996:3). Nominal exchange rates and consumer prices have been collected for 17 countries: Australia, Austria, Belgium, Canada, Denmark, Finland, France, Germany, Italy, Japan, the Netherlands, Norway, Spain, Sweden, Switzerland, the United Kingdom, and the United States. The nominal exchange rate and the consumer price index (CPI) are available from the International Financial Statistics (IFS) tape (lines ae and 64).

All series are converted to logarithms. Real exchange rates against the U.S. dollar are constructed as $s_{i 0}-p_{0}+p_{i}$, where $s_{i 0}$ is the logarithm of the nominal exchange rate against the U.S. dollar, $p_{i}$ denotes the logarithm of the consumer price index in country $i$, and $p_{0}$ denotes the logarithm of the price index in the United States. 
Table 6.1

Absolute PPP Regression Results

\begin{tabular}{|c|c|c|c|c|c|}
\hline Country & $\beta_{i}$ & Country & $\beta$ & Country & $\beta_{i}$ \\
\hline Australia & $\begin{array}{c}0.20 \\
(0.28)\end{array}$ & France & $\begin{array}{c}0.07 \\
(0.05)\end{array}$ & Spain & $\begin{array}{l}-0.06 \\
(0.04)\end{array}$ \\
\hline Austria & $\begin{array}{c}-0.11 \\
(0.08)\end{array}$ & Germany & $\begin{array}{c}0.15 \\
(0.11)\end{array}$ & Sweden & $\begin{array}{c}0.15^{*} \\
(0.05)\end{array}$ \\
\hline Belgium & $\begin{array}{c}0.15^{*} \\
(0.07)\end{array}$ & Italy & $\begin{array}{c}-0.01 \\
(0.04)\end{array}$ & Switzerland & $\begin{array}{l}-0.28^{*} \\
(0.10)\end{array}$ \\
\hline Canada & $\begin{array}{c}0.19^{*} \\
(0.06)\end{array}$ & Japan & $\begin{array}{l}-0.53^{*} \\
(0.10)\end{array}$ & United Kingdom & $\begin{array}{c}-0.03 \\
(0.05)\end{array}$ \\
\hline Denmark & $\begin{array}{c}0.01 \\
(0.05)\end{array}$ & Netherlands & $\begin{array}{c}0.13 \\
(0.09)\end{array}$ & United States & $\begin{array}{c}0.08 \\
(0.06)\end{array}$ \\
\hline Finland & $\begin{array}{l}-0.02 \\
(0.06)\end{array}$ & Norway & $\begin{array}{c}0.04 \\
(0.05)\end{array}$ & & \\
\hline Pooled & $\begin{array}{c}0.05 \\
(0.03)\end{array}$ & & & & \\
\hline
\end{tabular}

Table 6.1 refers to the system of levels regressions in equation (6.1). Under the nullhypothesis of PPP, all the $\beta_{i}$ must be equal to zero. The pooled estimate shows that for these 17 countries taken together we cannot reject the PPP hypothesis, since the level of the real exchange rate is not related to relative prices. However, the pooling restriction $\beta_{i}=\beta$, for all $i$ $=1, \ldots, N$, is rejected. A Wald test based on the unrestricted parameter estimates rejects with a P-value less than 0.001 . The parameter estimates for the individual currencies indeed show much variation. The PPP hypothesis is rejected for five countries: Belgium, Canada, Japan, Sweden, and Switzerland. 
Table 6.2

Augmented Absolute PPP Regression Results

This table presents numeraire invariant estimates of the effect of the price level on the real exchange rate in regression (6.3). The $\delta$ parameters reflect the coefficient of the quarterly trend variable under the identifying restriction $\delta_{t s}=0$. Newey-West standard errors are reported in parentheses. Significance at the 5 percent level is denoted by ${ }^{*}$. The sample period is 1972:1-1996:3.

\begin{tabular}{|c|c|c|c|c|c|}
\hline Country & $\beta_{i}$ & $\tilde{\delta}_{i}$ & Country & $\beta_{i}$ & $\tilde{\delta}_{i}$ \\
\hline Australia & $\begin{array}{l}-0.36^{*} \\
(0.07)\end{array}$ & $\begin{array}{c}0.24^{*} \\
(0.04)\end{array}$ & Japan & $\begin{array}{l}-0.26^{*} \\
(0.10)\end{array}$ & $\begin{array}{l}-0.73^{*} \\
(0.04)\end{array}$ \\
\hline Austria & $\begin{array}{l}-0.34^{*} \\
(0.16)\end{array}$ & $\begin{array}{l}-0.27^{*} \\
(0.05)\end{array}$ & Netherlands & $\begin{array}{l}-0.34^{*} \\
(0.11)\end{array}$ & $\begin{array}{l}-0.02 \\
(0.05)\end{array}$ \\
\hline Belgium & $\begin{array}{l}-0.01 \\
(0.17)\end{array}$ & $\begin{array}{c}0.01 \\
(0.06)\end{array}$ & Norway & $\begin{array}{l}-0.49^{*} \\
(0.06)\end{array}$ & $\begin{array}{l}-0.07 \\
(0.04)\end{array}$ \\
\hline Canada & $\begin{array}{l}-0.69^{*} \\
(0.22)\end{array}$ & $\begin{array}{l}0.18^{*} \\
(0.02)\end{array}$ & Spain & $\begin{array}{l}-0.17^{*} \\
(0.08)\end{array}$ & $\begin{array}{l}-0.33^{*} \\
(0.05)\end{array}$ \\
\hline Denmark & $\begin{array}{c}-0.06 \\
(0.08)\end{array}$ & $\begin{array}{l}-0.17^{*} \\
(0.05)\end{array}$ & Sweden & $\begin{array}{r}-0.16 \\
(0.17)\end{array}$ & $\begin{array}{c}0.12^{*} \\
(0.04)\end{array}$ \\
\hline Finland & $\begin{array}{l}-0.56^{*} \\
(0.12)\end{array}$ & $\begin{array}{l}-0.15^{*} \\
(0.04)\end{array}$ & Switzerland & $\begin{array}{l}-0.99^{*} \\
(0.30)\end{array}$ & $\begin{array}{l}-0.39^{*} \\
(0.07)\end{array}$ \\
\hline France & $\begin{array}{c}-0.06 \\
(0.05)\end{array}$ & $\begin{array}{l}-0.05 \\
(0.05)\end{array}$ & United Kingdom & $\begin{array}{l}-0.50^{*} \\
(0.11)\end{array}$ & $\begin{array}{l}-0.18^{*} \\
(0.03)\end{array}$ \\
\hline Germany & $\begin{array}{l}-0.02 \\
(0.21)\end{array}$ & $\begin{array}{c}-0.05 \\
(0.05)\end{array}$ & United States & $\begin{array}{l}-0.99^{*} \\
(0.23)\end{array}$ & $(-)$ \\
\hline Italy & $\begin{array}{c}-0.20 \\
(0.13)\end{array}$ & $\begin{array}{l}-0.18^{*} \\
(0.04)\end{array}$ & & & \\
\hline
\end{tabular}

Table 6.2 repeats the PPP test with a linear trend added to the explanatory variables as in equation (6.2). With a trend included the hypothesis $\beta_{i}=0$ is rejected much more often. For example, for the United States the parameter estimate $\beta_{U S}=-0.99$ implies that the coefficient on the nominal U.S. dollar exchange rates would be only 0.01 . In other words, the covariance between the nominal dollar exchange rate and the U.S. price level in deviation of a trend is almost zero, suggesting that nominal U.S. dollar exchange rates are not affected at all by consumer prices. The same holds for Switzerland, and to a lesser extent for Canada, Finland, and Norway. The countries for which we cannot reject the null-hypothesis $\beta_{i}=0$ are Belgium, 
Denmark, France, Germany, Italy, and Sweden. As the parameter $\beta_{i}$ is negative for all currencies, exchange rates do not fully adjust to (permanent) price increases.

When prices do not explain the trends in the nominal exchange rates, the linear trend terms must account for them. In order to interpret the trend coefficient consider for example Australia. The parameter estimate of 0.24 relative to the U.S. dollar means that the real Australian dollar has been depreciating against the U.S. dollar at a rate of approximately 1 percent per year $(0.24 \times 4$ quarters $)$, but at a much slower rate of $4 \times(0.24-0.18) \approx 1 / 4$ percent against the Canadian dollar. At a rate of almost 3 percent per year (against the U.S. dollar), the Japanese yen is the strongest appreciating currency in the system.

\section{Table 6.3}

\section{Relative PPP Regression Results}

This table presents numeraire invariant estimates of the effect of the inflation on the real exchange rate changes in regression (6.4). The column headings indicate whether or not the regression contains a constant term (normalized using $c_{\theta}=0$ ). Newey-West standard errors are reported in parentheses. Significance at the 5 percent level is denoted by ${ }^{\bullet}$. The sample period is 1972:1-1996:3.

\begin{tabular}{|c|c|c|c|c|c|c|c|c|}
\hline \multirow{3}{*}{ Country } & \multicolumn{8}{|c|}{ Horizon (quarters) } \\
\hline & \multicolumn{2}{|l|}{1} & \multicolumn{2}{|l|}{4} & \multicolumn{2}{|l|}{8} & \multicolumn{2}{|l|}{12} \\
\hline & $c=0$ & $c \neq 0$ & $c=0$ & $c \neq 0$ & $c=0$ & $c \neq 0$ & $c=0$ & $c \neq 0$ \\
\hline Australia & $\begin{array}{c}-0.22 \\
(0.29)\end{array}$ & $\begin{array}{c}0.20 \\
(0.53)\end{array}$ & $\begin{array}{l}-0.05 \\
(0.32)\end{array}$ & $\begin{array}{c}-0.04 \\
(0.41)\end{array}$ & $\begin{array}{c}0.00 \\
(0.32)\end{array}$ & $\begin{array}{l}-0.33 \\
(0.32)\end{array}$ & $\begin{array}{c}0.01 \\
(0.28)\end{array}$ & $\begin{array}{l}-0.42 \\
(0.31)\end{array}$ \\
\hline Austria & $\begin{array}{c}-0.98^{*} \\
(0.25)\end{array}$ & $\begin{array}{l}-0.87^{*} \\
(0.33)\end{array}$ & $\begin{array}{l}-0.50 \\
(0.34)\end{array}$ & $\begin{array}{c}-0.33 \\
(0.51)\end{array}$ & $\begin{array}{l}-0.38 \\
(0.28)\end{array}$ & $\begin{array}{l}-0.27 \\
(0.47)\end{array}$ & $\begin{array}{l}-0.37 \\
(0.26)\end{array}$ & $\begin{array}{c}-0.38 \\
(0.36)\end{array}$ \\
\hline Belgium & $\begin{array}{l}-0.68^{*} \\
(0.24)\end{array}$ & $\begin{array}{l}-0.67^{*} \\
(0.31)\end{array}$ & $\begin{array}{c}-0.21 \\
(0.27)\end{array}$ & $\begin{array}{l}-0.12 \\
(0.37)\end{array}$ & $\begin{array}{l}-0.10 \\
(0.25)\end{array}$ & $\begin{array}{l}-0.03 \\
(0.36)\end{array}$ & $\begin{array}{l}-0.09 \\
(0.26)\end{array}$ & $\begin{array}{l}-0.06 \\
(0.35)\end{array}$ \\
\hline Canada & $\begin{array}{c}-0.69 \\
(0.36)\end{array}$ & $\begin{array}{l}-1.78^{*} \\
(0.61)\end{array}$ & $\begin{array}{c}-0.15 \\
(0.41)\end{array}$ & $\begin{array}{l}-1.11^{*} \\
(0.53)\end{array}$ & $\begin{array}{c}-0.07 \\
(0.44)\end{array}$ & $\begin{array}{l}-1.10^{*} \\
(0.51)\end{array}$ & $\begin{array}{c}-0.06 \\
(0.40)\end{array}$ & $\begin{array}{l}-1.11^{*} \\
(0.49)\end{array}$ \\
\hline Denmark & $\begin{array}{l}-0.68^{*} \\
(0.16)\end{array}$ & $\begin{array}{l}-0.73^{*} \\
(0.18)\end{array}$ & $\begin{array}{c}-0.24 \\
(0.19)\end{array}$ & $\begin{array}{l}-0.14 \\
(0.22)\end{array}$ & $\begin{array}{c}-0.15 \\
(0.17)\end{array}$ & $\begin{array}{c}-0.07 \\
(0.23)\end{array}$ & $\begin{array}{c}-0.12 \\
(0.15)\end{array}$ & $\begin{array}{r}-0.07 \\
(0.21)\end{array}$ \\
\hline Finland & $\begin{array}{l}-0.68^{*} \\
(0.16)\end{array}$ & $\begin{array}{l}-1.00^{*} \\
(0.25)\end{array}$ & $\begin{array}{c}-0.33 \\
(0.23)\end{array}$ & $\begin{array}{l}-0.67^{*} \\
(0.33)\end{array}$ & $\begin{array}{c}-0.25 \\
(0.21)\end{array}$ & $\begin{array}{c}-0.63 \\
(0.37)\end{array}$ & $\begin{array}{c}-0.21 \\
(0.16)\end{array}$ & $\begin{array}{l}-0.65^{*} \\
(0.31)\end{array}$ \\
\hline France & $\begin{array}{c}-0.44^{*} \\
(0.20)\end{array}$ & $\begin{array}{c}-0.23 \\
(0.28)\end{array}$ & $\begin{array}{c}-0.13 \\
(0.23)\end{array}$ & $\begin{array}{c}-0.01 \\
(0.26)\end{array}$ & $\begin{array}{c}-0.06 \\
(0.21)\end{array}$ & $\begin{array}{c}-0.02 \\
(0.23)\end{array}$ & $\begin{array}{l}-0.06 \\
(0.18)\end{array}$ & $\begin{array}{l}-0.05 \\
(0.19)\end{array}$ \\
\hline Germany & $\begin{array}{l}-0.98^{*} \\
(0.34)\end{array}$ & $\begin{array}{c}-0.88 \\
(0.49)\end{array}$ & $\begin{array}{l}-0.36 \\
(0.46)\end{array}$ & $\begin{array}{c}-0.21 \\
(0.67)\end{array}$ & $\begin{array}{c}-0.16 \\
(0.39)\end{array}$ & $\begin{array}{c}0.07 \\
(0.55)\end{array}$ & $\begin{array}{c}-0.05 \\
(0.38)\end{array}$ & $\begin{array}{c}0.01 \\
(0.40)\end{array}$ \\
\hline
\end{tabular}




\section{Table 6.3 - continued \\ Relative PPP Regression Results}

This table presents numeraire invariant estimates of the effect of the inflation on the real exchange rate changes in regression (6.4). The column headings indicate whether or not the regression contains a constant term (normalized using $c_{\theta}=0$ ). Newey-West standard errors are reported in parentheses. Significance at the 5 percent level is denoted by ${ }^{*}$. The sample period is 1972:1-1996:3.

\begin{tabular}{|c|c|c|c|c|c|c|c|c|}
\hline \multirow{3}{*}{ Country } & \multicolumn{8}{|c|}{ Horizon (quarters) } \\
\hline & \multicolumn{2}{|l|}{1} & \multicolumn{2}{|l|}{4} & \multicolumn{2}{|l|}{8} & \multicolumn{2}{|l|}{12} \\
\hline & $c=0$ & $c \neq 0$ & $c=0$ & $c \neq 0$ & $c=0$ & $c \neq 0$ & $c=0$ & $c \neq 0$ \\
\hline \multirow[t]{2}{*}{ Italy } & $-0.33^{*}$ & -0.36 & -0.10 & -0.20 & -0.05 & -0.21 & -0.05 & -0.23 \\
\hline & $(0.16)$ & $(0.25)$ & $(0.15)$ & $(0.27)$ & (0.15) & $(0.28)$ & (0.13) & $(0.27)$ \\
\hline \multirow[t]{2}{*}{ Japan } & $-0.83^{*}$ & $-0.58^{*}$ & -0.43 & -0.18 & -0.37 & -0.08 & -0.43 & -0.08 \\
\hline & $(0.25)$ & $(0.28)$ & $(0.24)$ & $(0.26)$ & $(0.23)$ & $(0.20)$ & $(0.22)$ & $(0.18)$ \\
\hline \multirow[t]{2}{*}{ Netherlands } & $-0.89 *$ & $-0.88^{*}$ & -0.35 & -0.36 & -0.23 & -0.32 & -0.23 & -0.40 \\
\hline & $(0.26)$ & $(0.31)$ & $(0.33)$ & $(0.37)$ & $(0.28)$ & $(0.33)$ & $(0.26)$ & $(0.24)$ \\
\hline \multirow[t]{2}{*}{ Norway } & $-0.68^{*}$ & $-1.03^{*}$ & -0.27 & $-0.58^{*}$ & -0.18 & $-0.63^{*}$ & -0.16 & $-0.64^{*}$ \\
\hline & $(0.20)$ & $(0.24)$ & $(0.25)$ & $(0.24)$ & $(0.23)$ & $(0.23)$ & $(0.18)$ & $(0.17)$ \\
\hline \multirow[t]{2}{*}{ Spain } & $-0.43^{*}$ & -0.44 & -0.20 & -0.17 & -0.15 & -0.21 & -0.15 & -0.25 \\
\hline & $(0.22)$ & $(0.43)$ & $(0.19)$ & $(0.27)$ & $(0.16)$ & $(0.27)$ & $(0.13)$ & $(0.24)$ \\
\hline \multirow[t]{2}{*}{ Sweden } & $-0.47^{*}$ & $-0.66^{*}$ & -0.08 & -0.21 & -0.02 & -0.48 & 0.00 & -0.45 \\
\hline & $(0.23)$ & $(0.31)$ & $(0.26)$ & $(0.45)$ & $(0.23)$ & $(0.50)$ & $(0.18)$ & $(0.43)$ \\
\hline \multirow[t]{2}{*}{ Switzerland } & $-1.17^{*}$ & -0.79 & $-0.77^{*}$ & -0.54 & $-0.63^{*}$ & -0.40 & $-0.60^{*}$ & -0.29 \\
\hline & $(0.36)$ & $(0.54)$ & $(0.31)$ & $(0.52)$ & $(0.29)$ & $(0.55)$ & $(0.29)$ & $(0.55)$ \\
\hline \multirow[t]{2}{*}{ United Kingdom } & $-0.59^{*}$ & $-0.89^{*}$ & -0.26 & $-0.63^{*}$ & -0.18 & -0.52 & -0.18 & -0.51 \\
\hline & $(0.17)$ & $(0.27)$ & $(0.23)$ & $(0.28)$ & $(0.25)$ & $(0.34)$ & $(0.24)$ & $(0.34)$ \\
\hline \multirow[t]{2}{*}{ United States } & -0.64 & -1.11 & -0.24 & 0.92 & -0.16 & -0.92 & -0.17 & -0.98 \\
\hline & $(0.35)$ & $(0.61)$ & (0.37) & $(0.49)$ & $(0.41)$ & $(0.54)$ & $(0.39)$ & $(0.50)$ \\
\hline \multirow[t]{2}{*}{ Pooled } & $-0.43^{*}$ & $-0.64^{*}$ & -0.10 & -0.33 & -0.04 & -0.31 & -0.03 & -0.32 \\
\hline & $(0.15)$ & $(0.16)$ & $(0.16)$ & $(0.19)$ & $(0.16)$ & $(0.21)$ & $(0.13)$ & $(0.21)$ \\
\hline
\end{tabular}

Table 6.3 reports results for the tests on changes in exchange rates. The results are reported both with and without a constant term in each equation. As for the level regressions, the slope coefficients are much closer to zero for most currencies when the constant terms are left out. The constants are often jointly significant, however, indicating that some real 
exchange rates have a non-zero drift. For panel unit root tests of long-run PPP this implies that a trend $\delta, t$ cannot be omitted from the test regression.

For the one quarter differences, relative PPP is strongly rejected. For most currencies the inflation coefficient is significantly different from zero. For the 12 quarter differences, there are only three statistical rejections: Canada, Finland, and Norway. The test might not be very powerful, however, as standard errors are large. Equality of all slopes is always rejected, so the pooled estimate should be interpreted with care.

The most remarkable results are for Japan. For the yen the inclusion of the constant term brings the inflation effect much more in line with relative PPP. Since the constant term represents a trend in the real exchange rate, a trend-like variable is clearly missing. But apart form the trend, the marginal effect of inflation on the exchange rate is fully consistent with PPP. The trend in the Japanese yen is often attributed to the sharp postwar increase in productivity in Japan. Rogoff (1996, p. 661) calls the yen/dollar exchange rate the "canonical time series example of the Balassa Samuelson effect." Chinn and Johnston (1996) conduct an extensive panel cointegration study for 14 countries and conclude that the productivity variable greatly improves the fit for the yen/dollar exchange rate, but much less so for the other exchange rates against the dollar.

Interestingly, we find that many of the slope parameters jump upward at the fourquarter horizon. Notice, for instance, the shift in pooled estimate, which increases from -0.43 to -0.10 from the one quarter to the one year horizon. This could mean that some of the statistical difficulties in finding evidence in favor of PPP are due to seasonal measurement errors in price indices. The price data we use is seasonally adjusted, but in the regressions we always find a large difference between the one-quarter and the one-year regressions. The estimates for eight and twelve quarters are almost identical and close to those of for the four quarters.

Whatever way we run the regression (levels or differences), we consistently find that for the group of currencies related to the Deutschmark, PPP seems a reasonable hypothesis, as there are no trends and as the slope coefficients are consistent with PPP. We do not find any relation between prices and nominal exchange rates for the U.S. and Canada. For Japan, and to a lesser extent for Switzerland, an additional trend is missing.

\subsection{Conclusions}

In the past 20 years the PPP pendulum has swung from total collapse in the early 1980 s to complete resurrection in the 1990s. The evidence supporting PPP comes especially from longhorizon and panel data studies. However, the panel methodology is questioned by O'Connell (1998), who shows that the standard practice of calculating real exchange rates relative to the U.S. dollar can lead to cross-sectional dependence in time series panel data. 
In this chapter we investigate PPP among 17 currencies in the period 1972-1996 using a panel framework that explicitly deals with the numeraire effect that causes the crosssectional dependence. Our results are independent of the specific characteristics of the chosen benchmark currency. We find that for a system of multiple exchange rates PPP provides an accurate description of exchange rate fluctuations. This hold especially at horizons longer than one year. The extent to which relative PPP holds differs, however, from currency to currency or from currency bloc to currency bloc. Hence, we find that the selection of the sample is crucial in PPP research.

Our evidence in favor of PPP is strongest for the German mark and relatively weak for the U.S. dollar. Lothian (1998) has recently suggested that the difficulty of finding evidence of PPP with the dollar as the numeraire currency is caused by the period 1980-1987, during which the dollar initially strongly depreciated, but later strongly appreciated. For Japan, we find little evidence in favor of PPP, as a trending variable is omitted from the regression equation.

On the basis of our findings we conclude that there is substantive evidence that PPP holds for many currencies. For the currency bloc around Germany the evidence in favor of PPP is very strong, but we find little evidence supporting PPP for the U.S./Canada currency bloc. Therefore, we argue that, instead of concentrating on the general validity of PPP, researchers should focus on the question why it holds within several currency blocs and not between them. Potential explanations are the fact that goods arbitrage is more effective between, for instance, various European countries due to their geographical proximity and the lower volatility of their currencies. 



\section{Chapter 7}

\section{The Cost of Capital in International Financial Markets: Local versus Global Beta}

\subsection{Introduction}

Theory suggests the use of an international CAPM (ICAPM) for computing a firm's cost of equity capital in a financially integrated world. In practice, however, a wide variety of asset pricing models is used to compute the cost of capital. This is indicated by a recent survey by Keck, Levengood, and Longfield (1998), which shows that practitioners often perform cost of capital computations in a way that is inconsistent with the theoretical foundations of international valuation. This phenomenon may, among other things, be related to the fact that even though the ICAPM is theoretically preferable to the domestic CAPM, a firm's expected stock return calculated using the domestic CAPM does not necessarily provide an incorrect estimate of the cost of capital. The two asset pricing models could lead to the same cost of (equity) capital if the local stock market portfolio contains all the information that is relevant in order to price domestic assets internationally. We refer to Stulz (1998) for an overview of the literature on globalization, asset pricing, and the cost of capital.

The purpose of this chapter is to empirically examine whether international and domestic asset pricing models lead to a different estimate of the cost of capital. A partial answer is given by Stulz (1995b), who derives an expression for the difference in the estimation of a firm's beta when computed with the domestic CAPM as compared to the single factor ICAPM of Grauer, Litzenberger, and Stehle (1976). Stulz refers to this difference as the pricing error, which is linearly related to the computed cost of capital differential. He uses data on the Swiss multinational Nestlé and finds a sizeable pricing error. 
We generalize the analysis of Stulz (1995b) in three ways. First, we employ the multifactor ICAPM of Solnik (1983) and Sercu (1980) including both the global market portfolio and exchange rate risk premia. ${ }^{23}$ Second, we derive statistical tests for the significance of the pricing error. Third, we use data on 3,293 stocks from nine different countries to investigate the difference between each of these models empirically. ${ }^{24} \mathrm{We}$ analyze the sample period 1980:02-1999:06.

We find that the pricing error in terms of the cost of capital computed with either the domestic CAPM or the multifactor ICAPM of Solnik-Sercu is marginal. Only for about 5 percent of all firms in our sample the domestic CAPM yields a statistically significantly different cost of capital than the multifactor ICAPM at the 95 percent confidence level. We show that the absolute difference in the cost of capital amounts to about 50 basis points for the US, about 75 basis points for Germany and Japan and similar amounts for the other countries in our sample. We argue that our findings can possibly be attributed to strong country factors in the individual stock returns, consistent with the evidence of Heston and Rouwenhorst (1994) and Griffin and Karolyi (1998). A tentative explanation of this finding is a lack of real

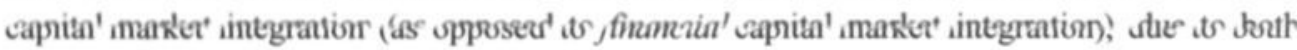
cyclical and structural, and institutional country-specific factors. These closely tie together the fortunes of all firms operating in the same country.

Testing for a pricing error turns out to be very similar to testing for exchange rate exposure. We show how both methodologies are related and how pricing error tests can shed light on the well-known puzzle that firms from a variety of data sets show little exposure to exchange rate fluctuations. ${ }^{25}$

The chapter is set up as follows. In section 7.2 we review the international CAPM and the domestic CAPM and derive testable hypotheses. In section 7.3, the data is described and summary statistics are discussed. Empirical results are presented in section 7.4. Section 7.5 explores the results using a variance decomposition technique. We elaborate on the link between the pricing error tests and the foreign exchange exposure literature in section 7.6. Summary and conclusions are presented in section 7.7 .

23 In the benchmark ICAPM that Stulz (1995b) uses, exchange rate factors are omitted, as PPP is assumed to hold. However, evidence abounds that substantial PPP-deviations exist at a monthly horizon, see e.g. Abuaf and Jorion (1990), Frankel and Rose (1995), and chapter 6. Several recent studies, e.g. Dumas and Solnik (1995) and De Santis and Gérard (1998), present evidence that currency risk is priced for firms from a variety of countries.

24 Such wide coverage of firms and countries stands in contrast to most of the empirical literature, see for example Harvey (1991), Ferson and Harvey (1993), and Dumas and Solnik (1995).

25 See Jorion (1990), Amihud (1994), Bodnar and Gentry (1993), Bartov and Bodnar (1994), and $\mathrm{He}$ and $\mathrm{Ng}$ (1998). 


\subsection{The International CAPM and the Domestic CAPM}

In this section we develop tests to evaluate whether the domestic CAPM yields a significantly different cost of capital than the multifactor ICAPM. The starting point for the rest of this chapter is the Solnik-Sercu version of the multifactor ICAPM. ${ }^{26}$ In this model the systematic risk factors are the global market portfolio and exchange rates. Assume a world with $N+1$ countries (currencies). The ICAPM has $N+1$ systematic risk factors: the global market portfolio and $N$ exchange rates. The model can be expressed as

$$
E\left[R_{i}\right]=r_{0}+E\left[R_{G}-r_{0}\right] d_{i}+E\left[S+r-\imath r_{0}\right]^{\prime} d_{i 2},
$$

where $R_{i}$ and $R_{G}$ are the return of asset $i$ and the global market, respectively, expressed in the numeraire currency. The numeraire currency is the home currency 0 of asset $i$. $S$ represents the vector of nominal exchange rate returns of the other $l=1, \ldots, N$ countries against currency 0 . The vector $r$ denotes the nominal returns on the risk-free asset in country $l(l=1, \ldots, N), r_{0}$ is the risk-free rate in the numeraire (home) country, and $t$ is a vector of ones. For a derivation of equation (7.1) we refer to Sercu and Uppal (1995). The global market beta and the exchange rate betas are defined as the regression coefficients $d_{i 1}$ and $d_{i 2}$ in

$$
R_{i}=\alpha_{1 i}+Z^{\prime} d_{i}+u_{i}=\alpha_{1 i}+R_{G} d_{i 1}+S^{\prime} d_{i 2}+u_{i},
$$

where $Z=\left[R_{G}, S\right]$ and $\alpha_{l i}=r_{0}\left(1-d_{i l}\right)+\left(r-v r_{0}\right) d_{i 2}$ is a constant. The specific risk $u_{i}$ is orthogonal to $Z$. This version of the ICAPM is the maintained hypothesis for the rest of this chapter.

In order to estimate $d_{i}$ we assume that the regression parameters are constant within a particular sample period. The risk premia on the global market and the currency factors may be time-varying though (see for example Dumas and Solnik (1995)) Our empirical tests will be formulated in terms of hypotheses on the factor loadings $d_{i}$ for individual stocks relative to the global factors.

We follow Stulz (1995b) and consider the domestic CAPM as an alternative model

$$
E\left[R_{i}\right]=r_{0}+E\left[R_{L}-r_{0}\right] b_{i},
$$

where $R_{L}$ is the return of the local market index expressed in the numeraire currency 0 . The beta of the CAPM can be estimated in the regression

$$
R_{i}=\alpha_{2 i}+R_{L} b_{i}+e_{i},
$$

The domestic CAPM posits a different decomposition into systematic and specific risk than the ICAPM. In order to compare the two models, we need to relate $R_{L}$ to the global factors $Z$. Since equation (7.2) applies to every individual stock, it also applies to the local market portfolio of every country. Applying (7.2) to $R_{L}$ we get

$$
R_{L}=\alpha_{L}+Z^{\prime} d_{L}+u_{L} \text {, }
$$

\footnotetext{
26 Differences between the international asset pricing models of Solnik $(1974,1983)$, Grauer, Litzenberger, and Stehle (1976), Sercu (1980), Stulz (1981), and Adler and Dumas (1983) mainly arise from different assumptions about the role of exchange rates and inflation. See Stulz (1995a) for an overview of the literature.
} 
where $u_{L}$ is orthogonal to $Z$. Substituting equation (7.5) into (7.4) yields

$$
R_{i}=\alpha_{3 i}+Z^{\prime} d_{L} b_{i}+u_{L} b_{i}+e_{i},
$$

where $\alpha_{3 i}=\alpha_{2 i}+b_{i} \alpha_{t}$.

Equations (7.2) and (7.6) lead to the same decomposition of systematic and specific risk if the local specific risk $e_{i}$ in equation (7.4) is orthogonal to $Z$. In that case, the composite specific risk term $u_{L} b_{i}+e_{i}$ is orthogonal to $Z$ and equations (7.2) and (7.6) are identical. But then the parameters in equations (7.2) and (7.6) must be the same too, implying

$$
d_{i}=d_{L} b_{i} \text {. }
$$

If the restrictions in equation (7.7) hold, no pricing error results from using the domestic CAPM instead of the ICAPM. We call a test for this null-hypothesis a "Pricing Error" test. It tests the orthogonality between the global factors and the residuals from the domestic CAPM regression (7.4). A simple way to implement the test is to add the global instruments $Z$ to the domestic CAPM regression,

$$
R_{i}=\alpha_{4 i}+R_{L} \beta_{i}+Z^{\prime} \delta_{i}+\zeta_{i} .
$$

and test the null hypothesis $\mathrm{H}_{0}: \delta=0$. If the restriction holds, the specific risk according to the domestic CAPM does not contain any systematic global risk factors. Consequently, the domestic market portfolio contains all the information that is relevant to price assets. On the other hand, if specific risk as indicated by the domestic CAPM does contain additional systematic risk related to the global factors, the domestic CAPM incorrectly ignores such risk. The ICAPM will require a risk premium, however. In that case, the domestic CAPM leads to a different cost of capital than the ICAPM.

Rejection of (7.7) can be due to either the condition on the beta of the global market portfolio $\left(d_{i 1}=d_{L 1} b_{i}\right)$, the exchange rate betas $\left(d_{i 2}=d_{L 2} b_{i}\right)$, or both. If rejection occurs because of violation of the exchange rate restrictions $d_{i 2}=d_{L 2} b_{i}$, the impact on the estimated cost of capital might nevertheless be zero if required foreign exchange risk premia $\mathrm{E}\left[S+r-t r_{0}\right]$ are zero. $^{27}$ Therefore, whether only the first restriction in equation (7.7) is violated within the framework of the multifactor ICAPM is of interest under the assumption that exchange rate risk premia are zero. In appendix 7.A we show that the pricing error vector $p_{i}=d_{L} b_{i}-d_{i}$ can be written as a linear combination of the parameter $\delta$ in equation (7.8)

$$
p_{i}=\left(\mathrm{I}+\frac{d_{L} d_{L}^{\prime} \Omega}{\sigma_{L}^{2}}\right)^{-1} \delta_{i}=\Lambda \delta_{i},
$$

where $\Omega$ is the covariance matrix of $Z$ and $\sigma_{L}{ }^{2}$ is the variance of residuals $u_{L}$ in equation (7.5). We test the null-hypothesis that the first element of $p_{i}$ is equal to zero. We call this the "Global Beta" test. If the null-hypothesis is rejected, the direct ICAPM beta $d_{i l}$ will differ significantly from the indirect beta $d_{L /} b_{i}$. Table 7.1 presents a brief summary of the hypotheses underlying the different tests.

27 For a review of the literature on exchange rate risk we refer to Dumas and Solnik (1995) and Engel (1996). 
Table 7.1

Summary of Null-Hypotheses, Purposes, and Underlying Model Structures of the Test Statistics

\begin{tabular}{|c|c|c|c|}
\hline Test & Regression Model & $\mathrm{H}_{0}$ & Issue \\
\hline Pricing Error & $R_{i}=\alpha_{4 i}+R_{L} B_{i}+Z \delta_{i}+\zeta_{i}$ & $\delta=0$ & $\begin{array}{l}\text { pricing error of domestic } \\
\text { CAPM vs. ICAPM }\end{array}$ \\
\hline Global Beta & $R_{i}=a_{u i}+R_{L} \theta_{i}+Z^{\prime} \delta_{i}+\zeta_{i}$ & $\begin{array}{l}1^{\text {st }} \text { element } \\
\text { of } \Lambda \delta=0\end{array}$ & $\begin{array}{l}\text { beta error of domestic } \\
\text { CAPM vs. ICAPM }\end{array}$ \\
\hline Exposure & $R_{i}=\gamma_{i 0}+R_{L} \gamma_{i 1}+S^{\prime} \gamma_{i 2}+\varepsilon_{i}$ & $\gamma_{2}=0$ & $\begin{array}{l}\text { e.r. exposure controlled } \\
\text { for local market return }\end{array}$ \\
\hline Total Exposure & $\begin{array}{l}R_{G}=c_{i}+S^{\prime} f_{G S}+\eta_{G} \\
R_{L}=c_{2}+R_{G} f_{L G}+S f_{L S}+\eta_{L} \\
R_{i}=c_{i b}+S^{\prime} c_{i t}+\eta_{G} c_{i 2}+\eta_{L} c_{i s}+v_{i}\end{array}$ & $c_{i l}=0$ & $\begin{array}{l}\text { e.r. exposure controlled } \\
\text { for orthogonalized local } \\
\text { and global market return }\end{array}$ \\
\hline Currency Betas & $R_{i}=\alpha_{1 i}+R_{G} d_{i l}+S^{\prime} d_{i 2}+u_{i}$ & $d_{i 2}=0$ & $\begin{array}{l}\text { e.r. exposure controlled } \\
\text { for global market return }\end{array}$ \\
\hline
\end{tabular}

Our analysis concerns the potential differences between expected returns implied by ICAPM and those implied by the standard domestic betas. We will not test hypotheses on the cross-section of $\alpha_{i}$ 's. For the domestic CAPM it has been well documented that betas cannot explain the cross-section of expected returns, and that $\alpha_{i}$ differs systematically from zero for portfolios sorted on market capitalization size or book-to-market ratio. Fama and French (1998) show that these empirical results hold both for the U.S. and many other countries. Our tests can be interpreted as an examination of the issue whether international risk factors imply different expected returns than the local market factor and could consequently be used in explaining the asset pricing anomalies of the domestic CAPM.

\subsection{Data}

In the empirical analysis we use monthly data for nine industrialized countries: Australia, Canada, France, Germany, Japan, the Netherlands, Switzerland, United Kingdom, and the United States. Nominal exchange rates for all countries are taken from the International Financial Statistics (IFS) tape (line ae). In the empirical application we consider the period 1980:02-1999:06. 
Table 7.2

Summary Statisties (returns in \% per month)

This table presents summary statistics for the domestic market index in local currency and in U.S. dollars, the nominal exchange rate and the global market index denoted in local currency for each of the nine countries in our sample. The first two columns contain the mean return and standard deviation of the MSCl country indices expressed in local currency. The third and the fourth column present the mean and standard deviation of exchange rate returns against the U.S. dollar. Columns five and six reflect the mean return and standard deviation of the MSCl country indices expressed in U.S. dollar. Finally, the last two columns depict the mean return and standard deviation of the $\mathrm{MSCl}$ world index expressed in local currency. The sample period is 1980:02-1999:06. Data on domestic and global market indices is obtained from MSCI. Nominal exchange rates are taken from the International Financial Statistics (IFS) tape.

\begin{tabular}{lcccccccc}
\hline & \multicolumn{2}{c}{$\begin{array}{c}\text { Local MSCI } \\
\text { (in local currency) }\end{array}$} & $\begin{array}{c}\text { FX-return } \\
\text { (against US\$) }\end{array}$ & $\begin{array}{c}\text { Local MSCI } \\
\text { (in US\$) }\end{array}$ & $\begin{array}{c}\text { Global MSCI } \\
\text { (in local currency) }\end{array}$ \\
\cline { 2 - 8 } Country & Mean & StDv & Mean & StDv & Mean & StDv & Mean & StDv \\
\hline Australia & 1.04 & 6.20 & -0.22 & 2.88 & 0.82 & 7.53 & 1.40 & 4.60 \\
Canada & 0.81 & 4.96 & -0.10 & 1.32 & 0.71 & 5.60 & 1.28 & 3.94 \\
France & 1.30 & 5.96 & -0.19 & 3.29 & 1.11 & 6.43 & 1.37 & 4.77 \\
Germany & 1.11 & 5.74 & -0.04 & 3.32 & 1.07 & 6.14 & 1.21 & 4.76 \\
Japan & 0.63 & 5.74 & 0.29 & 3.52 & 0.92 & 6.96 & 0.89 & 4.55 \\
Netherlands & 1.51 & 5.09 & -0.05 & 3.32 & 1.46 & 5.10 & 1.22 & 4.74 \\
Switzerland & 1.14 & 5.06 & 0.02 & 3.65 & 1.16 & 5.51 & 1.16 & 5.04 \\
United Kingdom & 1.40 & 4.99 & -0.16 & 3.28 & 1.24 & 5.68 & 1.33 & 4.54 \\
United States & 1.36 & 4.32 & - & - & 1.36 & 4.32 & 1.18 & 4.17 \\
\hline
\end{tabular}

Table 7.2 presents summary statistics for local and global stock market (MSCI) returns, and exchange rate returns. Returns are measured as logarithmic differences and given in percentages per month. The average domestic market return in local currency ranges from 0.63 for Japan to 1.51 for the Netherlands. Corresponding standard deviations vary between 6.20 for Australia and 4.32 for the U.S. Columns seven and eight contain summary statistics of the MSCI world market portfolio expressed in local currency. Again, Japan is an outlier with an exceptionally low average return due to a substantial appreciation of the yen. 
Table 7.3

\section{Composition of MSCI Index and Sample}

This table presents an overview of the composition of the MSCI World index in July, 1994 (source: Morgan Stanley Capital International Perspective, Third Quarter 1994) and of the composition of our sample of individual stocks. The sample period is 1980:02-1999:06. The first subsample consists of the period 1980:021989:12. The second subsample is the period 1990:01-1999:06.

\begin{tabular}{lccccc}
\hline Country & $\begin{array}{c}\text { weight in } \\
\text { MSCI world } \\
\text { index }\end{array}$ & $\begin{array}{c}\text { \# stocks } \\
\text { in sample }\end{array}$ & $\begin{array}{c}\text { weight in } \\
\text { sample }\end{array}$ & $\begin{array}{c}\text { \# stocks in } 1^{\text {st }} \\
\text { subsample }\end{array}$ & $\begin{array}{c}\text { \# stocks in } 2^{\text {nd }} \\
\text { subsample }\end{array}$ \\
\hline Australia & 2.3 & 108 & 3.3 & 118 & 244 \\
Canada & 2.2 & 219 & 6.7 & 231 & 345 \\
France & 3.7 & 127 & 3.9 & 130 & 500 \\
Germany & 3.8 & 178 & 5.4 & 181 & 432 \\
Japan & 28.7 & 829 & 25.2 & 734 & 1,755 \\
Netherlands & 2.1 & 123 & 3.7 & 126 & 160 \\
Switzerland & 2.7 & 129 & 3.9 & 136 & 264 \\
United Kingdom & 9.4 & 1,051 & 31.9 & 1,118 & 1,245 \\
United States & 35.6 & 529 & 16.1 & 557 & 749 \\
& & & & & 5,694 \\
\hline
\end{tabular}

The market-weighted local equity indices and the market-weighted global market index are from Morgan Stanley Capital International (MSCI). Table 7.3 shows that the nine countries jointly account for approximately 90 percent of the MSCI market-weighted world index in July 1994. Australia, Canada, France, Germany, the Netherlands, and Switzerland are each less than 4 percent of the MSCI market-weighted world index. The United States take approximately 36 percent of the index.

Data on individual stocks in this study is obtained from Datastream. We have downloaded stock prices, dividend yields, and dividends of firms that are included in the Datastream equity lists. If dividends are unavailable, the dividend yield is used. If neither dividends nor dividend yields are available, the stock is excluded from the sample. We also exclude stocks that have not been continuously listed over the whole period and stocks that are denominated in a currency different from the local currency of the country where they are listed. Furthermore, the data is filtered for data errors; stocks with outlier observations are 
excluded from the sample. ${ }^{28}$ Using stocks with a long time series history increases the power of our time series tests on regression coefficients. It also introduces survivorship bias that would invalidate a cross-sectional asset pricing test on the intercepts $\alpha_{i}$. We believe that this bias only marginally affects our results. This is indicated by the fact that results only slightly vary over different subperiods.

The second column of table 7.3 reports the number of stocks included for each country after the selection procedures. The total sample consists of 3,293 stocks with a complete series of returns for the period 1980:02-1999:06. The third column of table 7.3 shows the weight of each country in our world sample. The weight is computed by dividing the number of stocks in the country by the total number of stocks in the sample. Columns five and six of table 7.3 show the number of stocks in our sample for two subperiods, 1980:02-1989:12 and 1990:011999:06. ${ }^{29}$ Tests on these additional stocks over the subsamples will help us to assess possible sample selection problems.

\subsection{Empirical Results}

In this section we discuss the main results obtained by applying the testing methodology introduced in section 7.2 to the sample of 3,293 stocks. Throughout, we assume that the MSCI world and local indexes are good proxies for the global and local market portfolios respectively. We apply the Pricing Error and Global Beta tests as discussed in section 7.2 to each individual firm in order to assess the magnitude and significance of the pricing error made by the domestic CAPM as compared to the multifactor ICAPM. A summary of the test results is reported country-wise in table 7.4 for the full sample period. All tests in this chapter are robust to heteroskedasticity.

Column 1 of table 7.4 presents the rejection percentage of the Pricing Error test per country. That is, this column shows the percentage of stocks per country for which the CAPM yields a significant cost of capital differential with $95 \%$ confidence compared to the ICAPM. The hypothesis of a zero pricing error is rejected very infrequently for each country. The highest rejection percentage is 7.32 percent for the Netherlands, while the lowest is 3.10 percent for Switzerland. For the total sample of 3,293 firms, the Pricing Error test rejects in only 5.16 percent of the cases (170 companies). The fourth column of table 7.4 shows the rejection percentage of the Global Beta test per country. This test evaluates the significance of the first element of the pricing error vector $d_{L} b_{i}-d_{i}$. The total percentage of firms for which the hypothesis that the first element of this vector is equal to zero is rejected is 2.95 percent (97 firms). Individual countries such as Australia, the U.K., and the U.S. show even lower percentages. Table 7.4 also displays rejection frequencies of the Pricing Error test and the

\footnotetext{
28 These are stocks with average annual returns larger than 200 percent, stocks with a local beta smaller than 0.1 , and infrequently traded stocks which have a zero return for more than twenty percent of the observations.

29

Estimation results for subperiods are qualitatively similar.
} 
Global Beta test for two subperiods. For the period 1980:02-1989:12, the Pricing Error test rejects for 3.63 percent of the 3,331 firms in the sample and the rejection frequency of the Global Beta test is equal to 5.95 percent. The hypothesis of no pricing error is rejected for 195 out of 5,694 companies in the subperiod 1990:01-1999:06. The Global Beta test rejects for 6.23 percent of the firms.

Table 7.4

Pricing Error Test Results

This table contains the rejection frequencies for two tests for each of the nine countries in our sample. The Pricing Error test examines whether a pricing error exists between the domestic CAPM and the multifactor ICAPM. The Global Beta test is similar to the Pricing Error test but focuses on the beta error of the domestic CAPM versus the multifactor ICAPM. All test statistics are Chi-squared distributed and robust to heteroskedasticity. Rejection frequencies are defined as the percentage of firms in a country for which the nullhypothesis is rejected at the $5 \%$ significance level. "Average" depicts a weighted average of the percentages of firms in each individual country for which the null-hypothesis is rejected. The weights of the rejection frequencies are the weights of each country in the sample as shown in the third column of table 7.3. The sample period is 1980:02-1999:06. This table also shows the rejection frequencies for both tests for two subsamples. The first subsample consists of the period 1980:02-1989:12. The second subsample is the period 1990:01-1999:06. Data on individual stocks is obtained from the Datastream equity lists. Stocks with incomplete price or dividend data, stocks with outlier observations, and illiquid stocks have been removed from the dataset.

Country

Pricing Error Test

percentage rejections
Global Beta Test

percentage rejections

\begin{tabular}{lcccccc}
\hline & $1980-1999$ & $1980-1989$ & $1990-1999$ & $1980-1999$ & $1980-1989$ & $1990-1999$ \\
\hline Australia & 4.63 & 4.24 & 2.87 & 1.85 & 4.24 & 9.02 \\
Canada & 4.11 & 3.46 & 3.77 & 6.85 & 6.93 & 8.41 \\
France & 5.51 & 1.54 & 2.20 & 4.72 & 6.15 & 9.20 \\
Germany & 6.74 & 3.87 & 2.55 & 2.25 & 4.42 & 3.01 \\
Japan & 5.79 & 2.73 & 3.82 & 3.98 & 9.54 & 7.18 \\
Netherlands & 7.32 & 0.79 & 1.88 & 4.88 & 4.76 & 6.25 \\
Switzerland & 3.10 & 7.35 & 3.41 & 0.78 & 10.29 & 1.89 \\
United Kingdom & 4.19 & 4.11 & 2.97 & 1.43 & 3.94 & 4.82 \\
United States & 6.05 & 3.95 & 4.94 & 2.84 & 4.85 & 5.87 \\
& & & & & & 6.23 \\
Average & 5.16 & 3.63 & 3.42 & 2.95 & 5.94 & 6.23 \\
\hline
\end{tabular}


The evidence from table 7.4 indicates that the domestic CAPM generally does not lead to a significantly different cost of capital than the multifactor ICAPM. On average, rejection of the null-hypothesis that this differential is equal to zero only occurs for about 5 percent of the firms in our sample. That is, the risk of a firm in our sample that is specific according to the domestic CAPM very rarely contains any additional systematic risk in the global market. As rejection frequencies for subperiods are very similar, we reckon that possible survivorship bias in our sample as well as the assumption that betas are not time-varying have little influence on our results.

Figures 7.1 through 7.9 contain additional information on the pricing error tests for each country. The top panel of the figures provides a scatter plot of each firm's "direct beta" versus its "indirect beta". The direct beta is the firm's multifactor ICAPM beta $d_{i l}$, while the indirect estimate of a firm's global beta can be calculated by multiplying the global beta of the local market as represented by the first element of the vector $d_{L}$ and the firm's CAPM beta $b_{i}$. For each country, the dots in the graph are centered around the line with a slope of unity. ${ }^{30}$ For firms on this line, the estimated cost of capital is invariant to the use of the CAPM or ICAPM, if exchange rate risk is not priced. Firms that plot below the line have a higher cost of capital using the ICAPM than using the CAPM. The difference reflects a premium for risk that is specific according to the domestic CAPM but contains additional systematic risk related to the global factors. On the other hand, firms that lie above the line have a lower cost of capital according to the ICAPM as compared to the CAPM, suggesting the presence of risk that the domestic CAPM indicates to be systematic, but that can be diversified in the global market. Although for each country several firms plot off the straight line, the differences are generally very small. ${ }^{31}$ The bottom panel of figures 7.1 through 7.9 presents a histogram of the beta errors of all individual firms for each country. These histograms show that the distribution of beta errors is centered around zero. For each country, a very large majority of firms exhibits an absolute beta error smaller than 0.2 .

This is supported by the summary statistics, which are presented in table 7.5. They show that the equally weighted average of the differences between the indirect and the direct betas is close to zero for all countries, as expected (see footnote 30). The absolute pricing error in terms of betas within each country is more interesting. This number varies from 0.076 (Germany and the US) to 0.123 (France) and is thus relatively small in beta terms.

\footnotetext{
30 The value-weighted sum of the ICAPM betas equals unity. Also, each local market is priced correctly by the ICAPM. By construction the market-weighted average pricing error is equal to zero. This means that for an individual firm the CAPM and the ICAPM might give different cost of capital but on average, (value-weighted) domestic pricing provides the correct cost of capital. Note that the above characteristics only hold in a world where both local and global market indexes are measured perfectly including all individual stocks. In our empirical work, non-zero average pricing errors arise first because we do not use all stocks included in the local and global MSCl-indices, and second because we present equally weighted averages.
}

31 If exchange rate risk is priced, differences in the estimated cost of capital may be larger because of differences in the directly and indirectly estimated coefficients on the exchange rate factors. 


\section{Figure 7.1}

\section{Australia: The Cross-Section of Alternative Beta Estimates}

The top panel of this figure depicts a scatter plot of the "direct" ( $x$-axis) versus the "indirect" beta ( $y$-axis) for 108 companies. Direct betas are obtained from the multifactor ICAPM and are equal to the OLS estimate of $d_{l \prime}$ in regression (7.2). Indirect betas are calculated as the product of $b_{i}$ from the domestic CAPM as displayed in regression (7.4) and the estimate of $d_{L I}$ of the domestic market portfolio priced with the multifactor ICAPM in regression (7.5). The line in the graph reflects the $45^{\circ}$ line. The bottom panel shows a histogram of the beta errors for all Australian firms. The beta error is defined as the difference between the indirect and the direct beta. The sample period is 1980:02-1999:06.

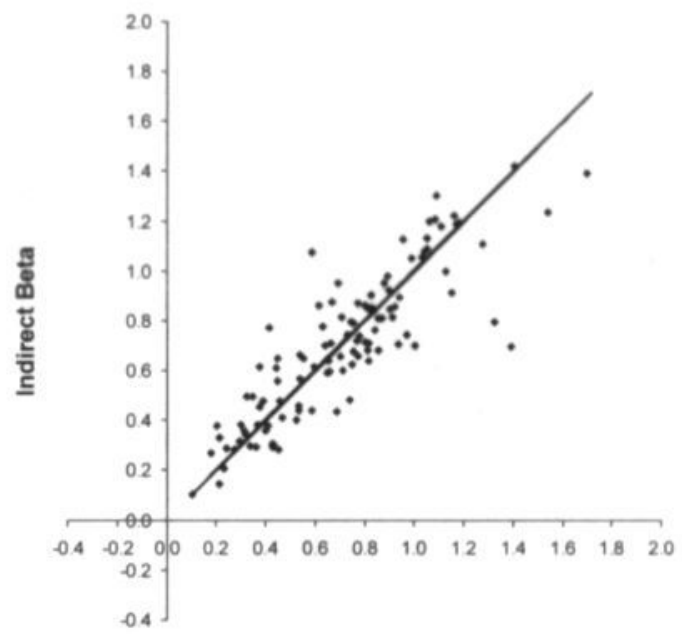

Direct Beta

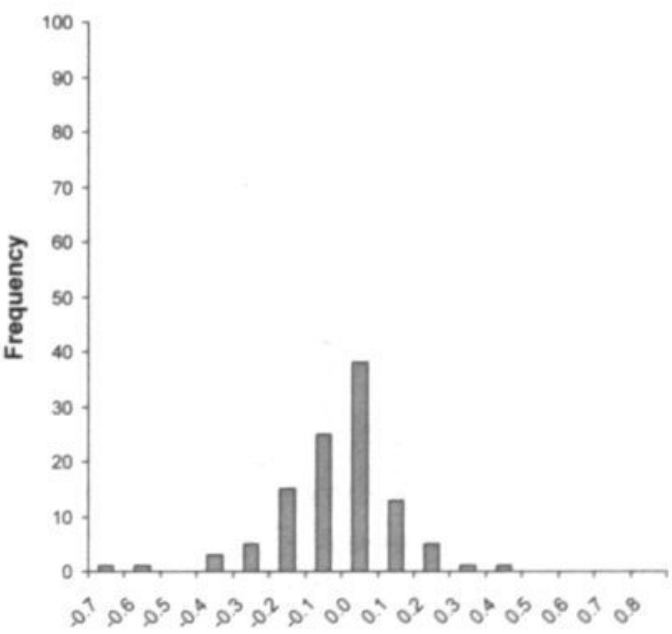

Beta Error 


\section{Figure 7.2}

\section{Canada: The Cross-Section of Alternative Beta Estimates}

The top panel of this figure depicts a scatter plot of the "direct" ( $x$-axis) versus the "indirect" beta ( $y$-axis) for 219 companies. Direct and indirect beta estimates can be estimated as described in figure 7.1. The line in the graph reflects the $45^{\circ}$ line. The bottom panel shows a histogram of the beta errors for all Canadian firms. The beta error is defined as the difference between the indirect and the direct beta. The sample period is 1980:021999:06.

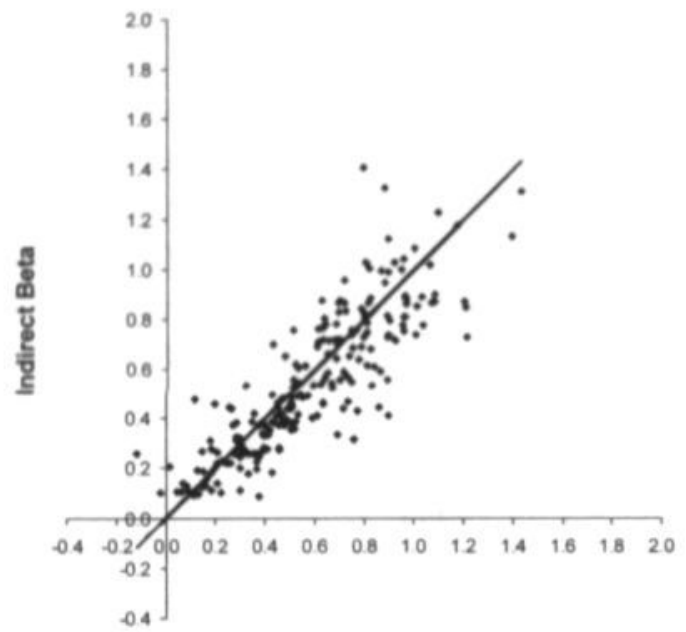

Direct Beta

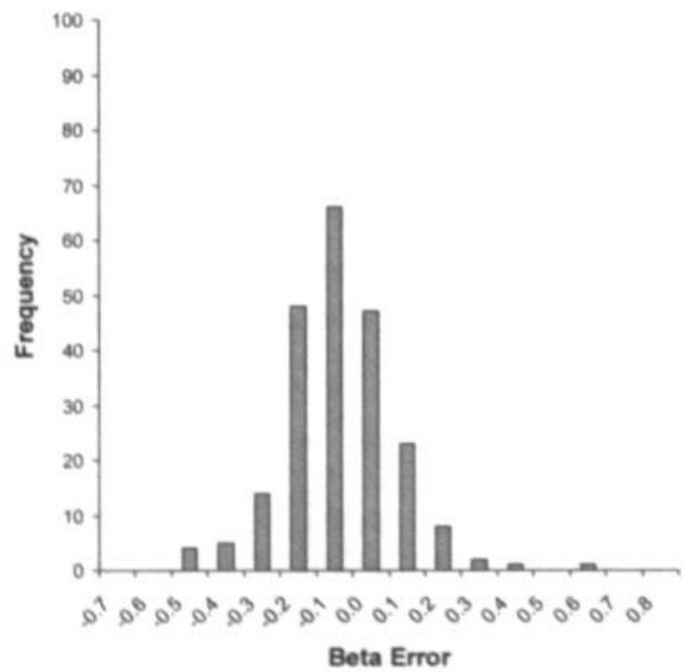


Figure 7.3

\section{France: The Cross-Section of Alternative Beta Estimates}

The top panel of this figure depicts a scatter plot of the "direct" ( $x$-axis) versus the "indirect" beta ( $y$-axis) for 127 companies. Direct and indirect beta estimates can be estimated as described in figure 7.1. The line in the graph reflects the $45^{\circ}$ line. The bottom panel shows a histogram of the beta errors for all French firms. The beta error is defined as the difference between the indirect and the direct beta. The sample period is 1980:02-1999:06.

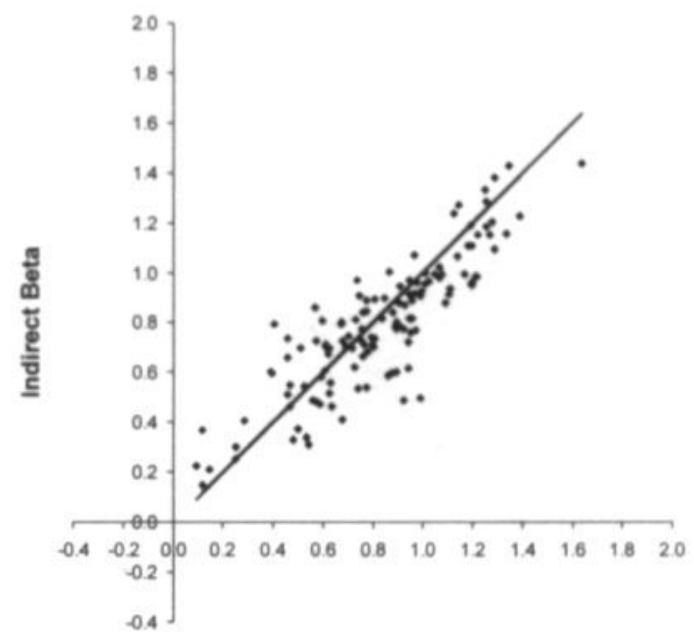

Direct Beta

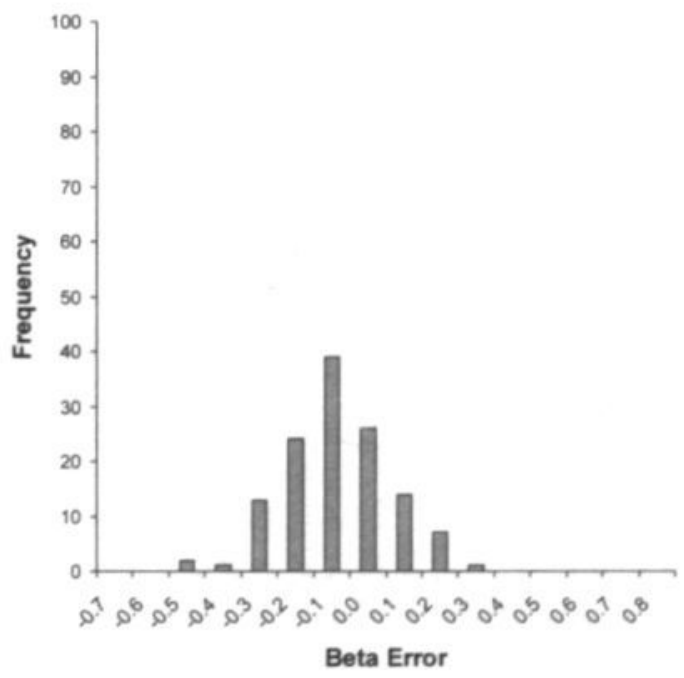


Figure 7.4

\section{Germany: The Cross-Section of Alternative Beta Estimates}

The top panel of this figure depicts a scatter plot of the "direct" ( $x$-axis) versus the "indirect" beta ( $y$-axis) for 178 companies. Direct and indirect beta estimates can be estimated as described in figure 7.1. The line in the graph reflects the $45^{\circ}$ line. The bottom panel shows a histogram of the beta errors for all German firms. The beta error is defined as the difference between the indirect and the direct beta. The sample period is 1980:02-1999:06.
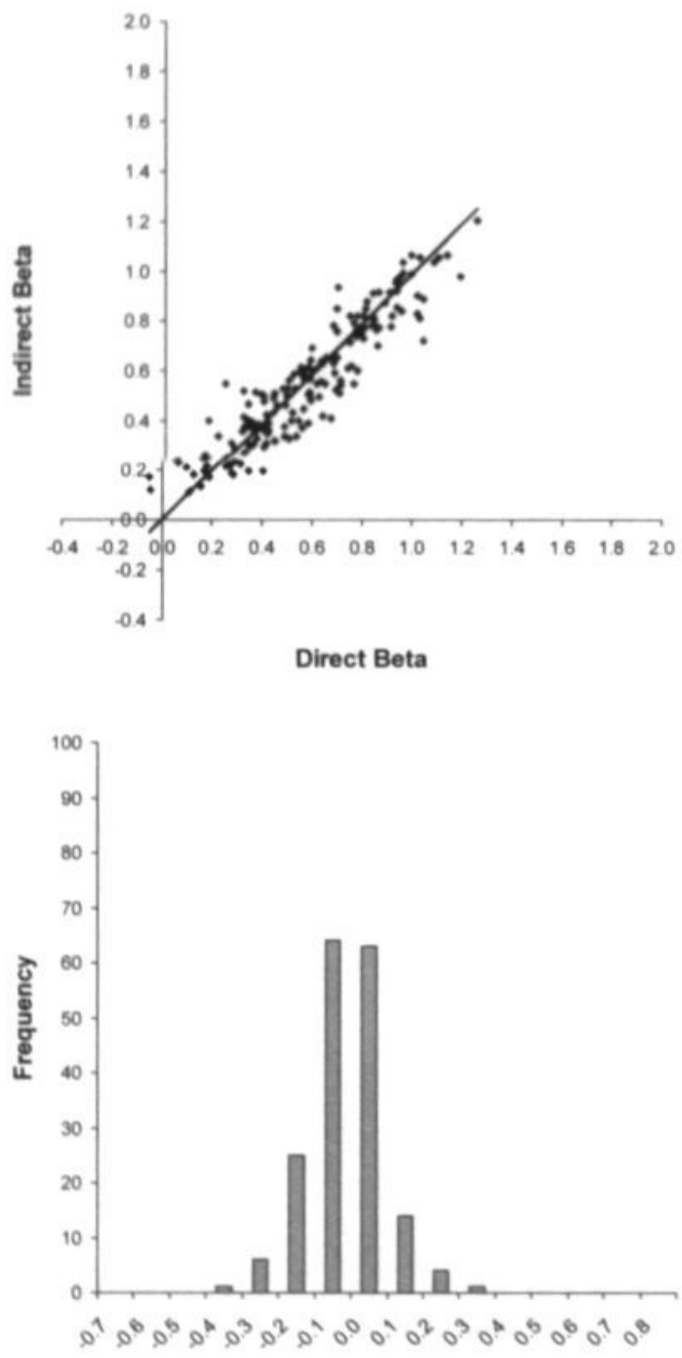

Beta Error 
Figure 7.5

\section{Japan: The Cross-Section of Alternative Beta Estimates}

The top panel of this figure depicts a scatter plot of the "direct" ( $x$-axis) versus the "indirect" beta ( $y$-axis) for 829 companies. Direct and indirect beta estimates can be estimated as described in figure 7.1. The line in the graph reflects the $45^{\circ}$ line. The bottom panel shows a histogram of the beta errors for all Japanese firms. The beta error is defined as the difference between the indirect and the direct beta. The sample period is 1980:021999:06.
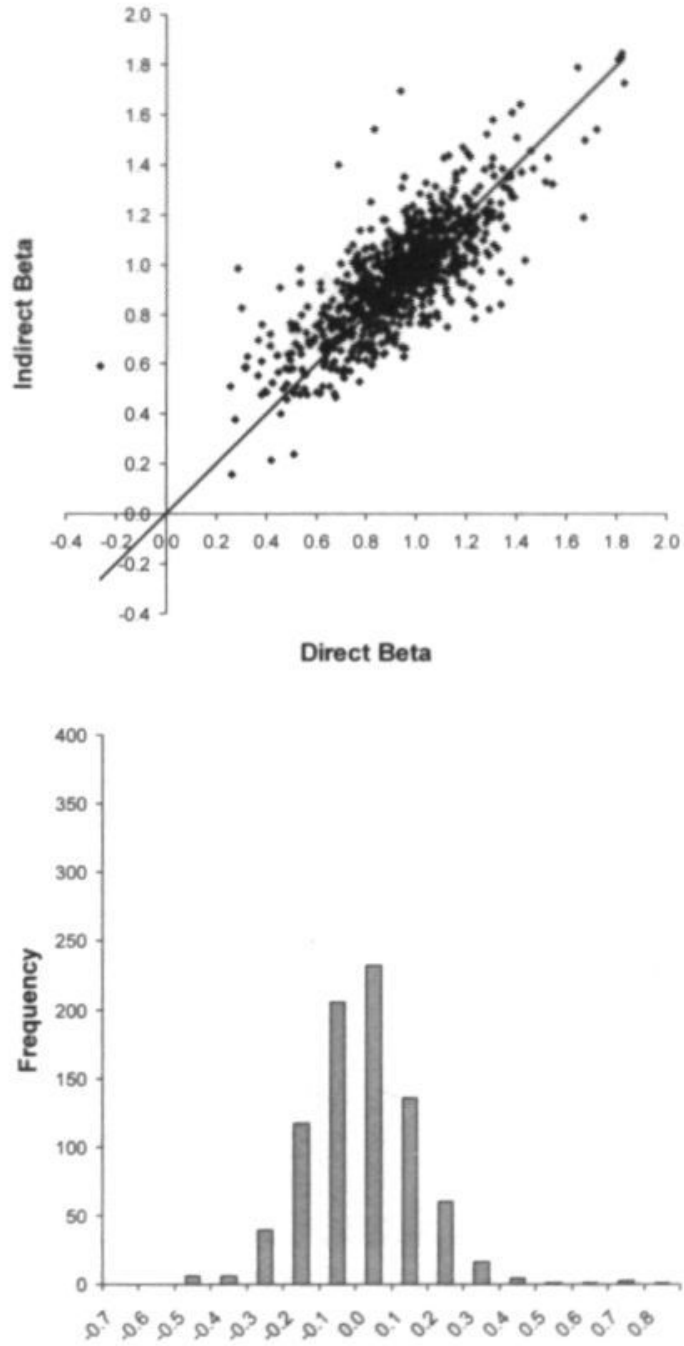

Beta Error 


\section{Figure 7.6}

\section{The Netherlands: The Cross-Section of Alternative Beta Estimates}

The top panel of this figure depicts a scatter plot of the "direct" ( $x$-axis) versus the "indirect" beta ( $y$-axis) for 123 companies. Direct and indirect beta estimates can be estimated as described in figure 7.1. The line in the graph reflects the $45^{\circ}$ line. The bottom panel shows a histogram of the beta errors for all Dutch firms. The beta error is defined as the difference between the indirect and the direct beta. The sample period is 1980:02-1999:06.

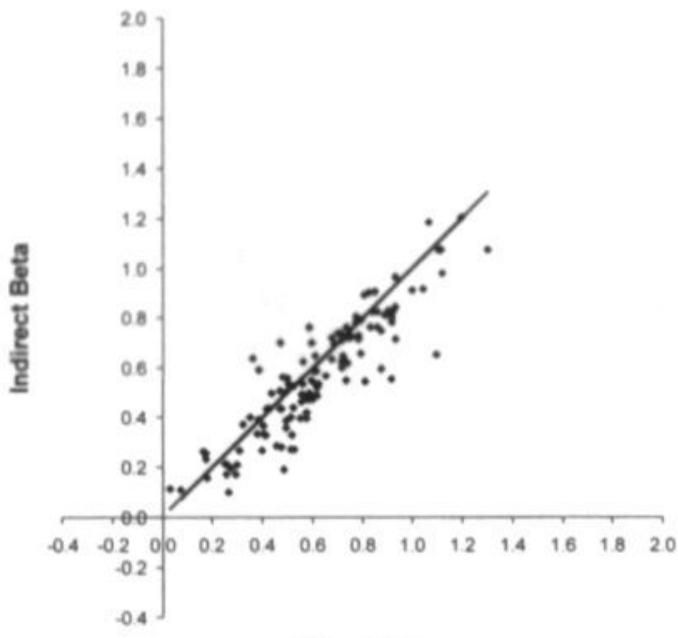

Direct Beta

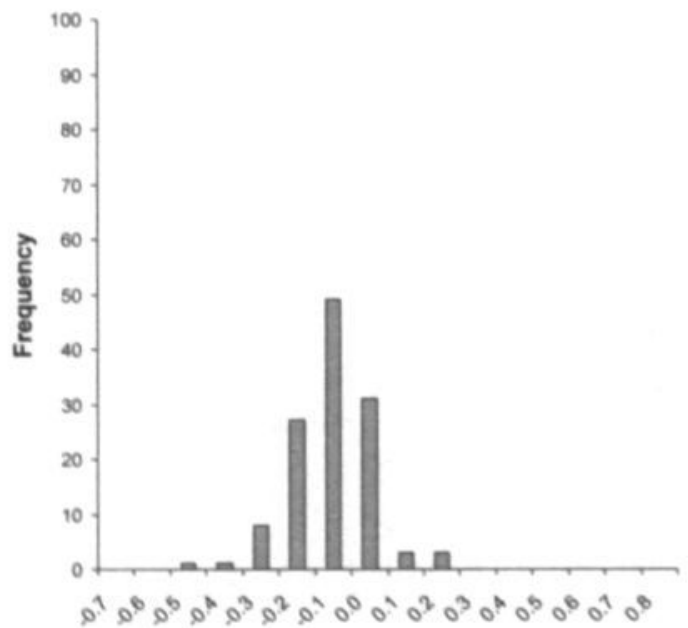

Beta Error 


\section{Figure 7.7}

\section{Switzerland: The Cross-Section of Alternative Beta Estimates}

The top panel of this figure depicts a scatter plot of the "direct" ( $x$-axis) versus the "indirect" beta ( $y$-axis) for 129 companies. Direct and indirect beta estimates can be estimated as described in figure 7.1. The line in the graph reflects the $45^{\circ}$ line. The bottom panel shows a histogram of the beta errors for all Swiss firms. The beta error is defined as the difference between the indirect and the direct beta. The sample period is 1980:02-1999:06.

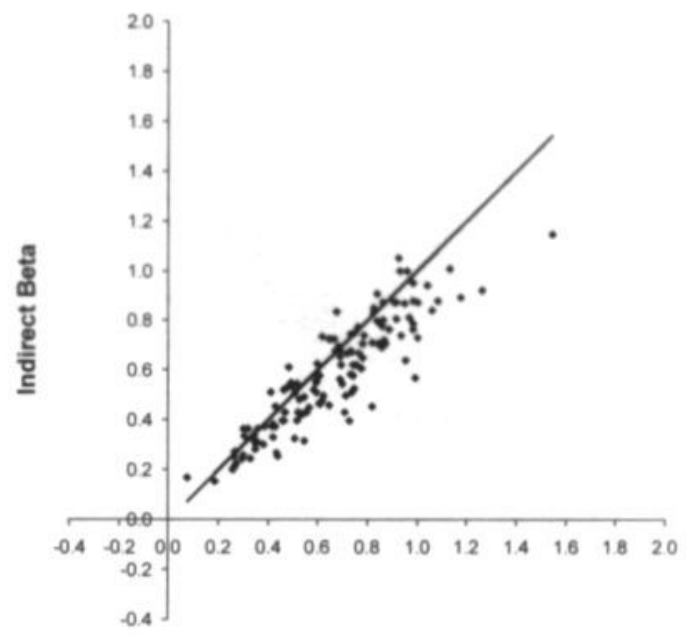

Direct Beta

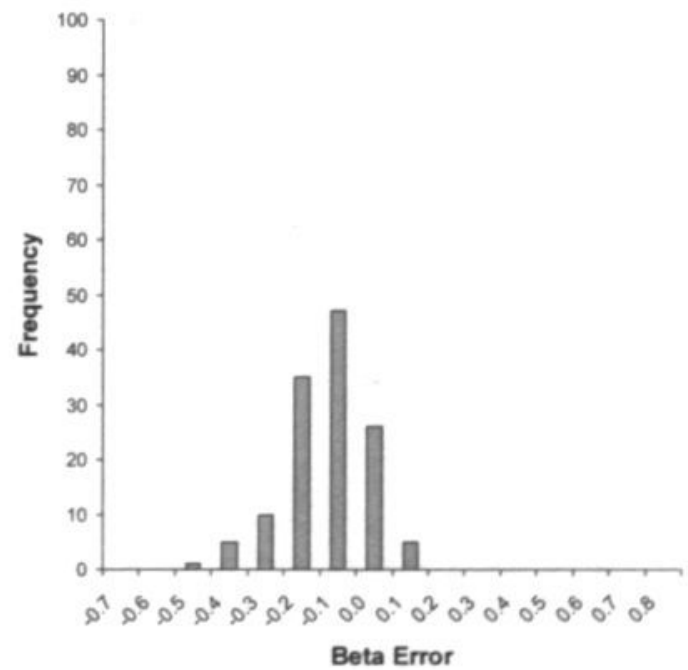




\section{Figure 7.8}

\section{United Kingdom: The Cross-Section of Alternative Beta Estimates}

The top panel of this figure depicts a scatter plot of the "direct" ( $x$-axis) versus the "indirect" beta ( $y$-axis) for 1,051 companies. Direct and indirect beta estimates can be estimated as described in figure 7.1. The line in the graph reflects the $45^{\circ}$ line. The bottom panel shows a histogram of the beta errors for all U.K. firms. The beta error is defined as the difference between the indirect and the direct beta. The sample period is 1980:02-1999:06.
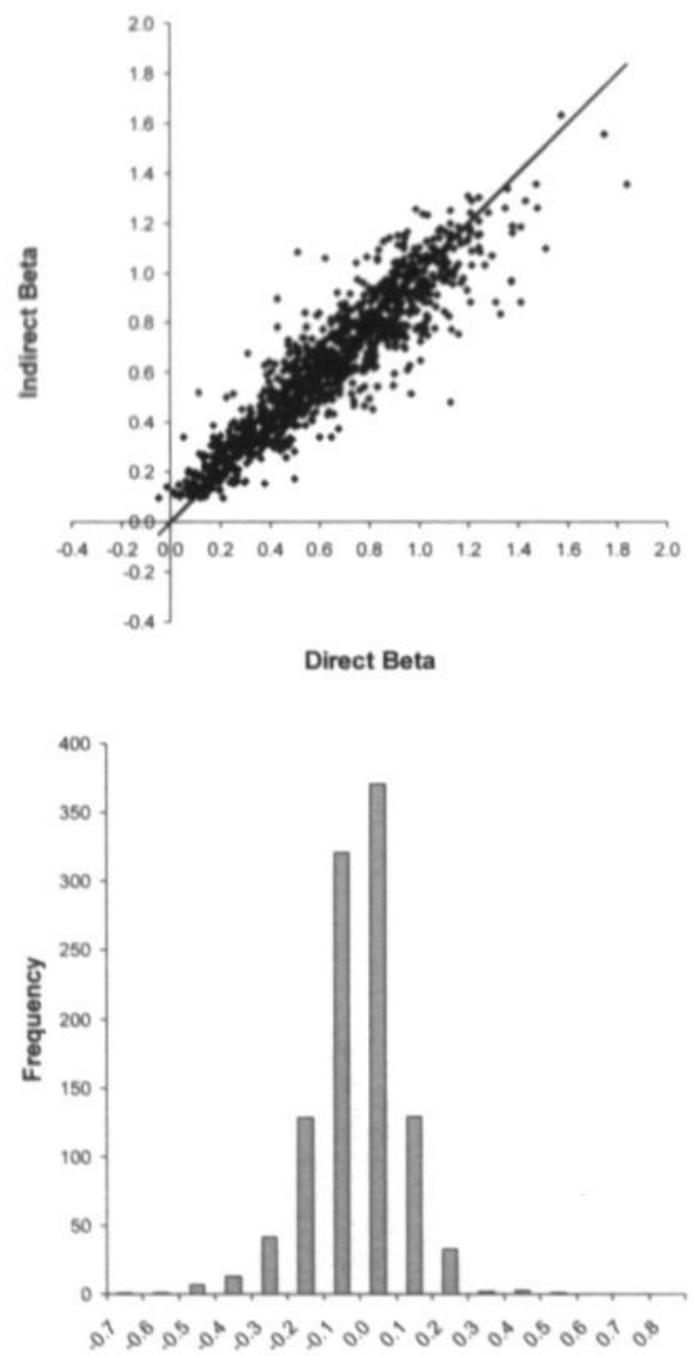

Beta Error 


\section{Figure 7.9}

\section{United States: The Cross-Section of Alternative Beta Estimates}

The top panel of this figure depicts a scatter plot of the "direct" ( $x$-axis) versus the "indirect" beta ( $y$-axis) for 529 companies. Direct and indirect beta estimates can be estimated as described in figure 7.1. The line in the graph reflects the $45^{\circ}$ line. The bottom panel shows a histogram of the beta errors for all U.S. firms. The beta error is defined as the difference between the indirect and the direct beta. The sample period is 1980:02-1999:06.

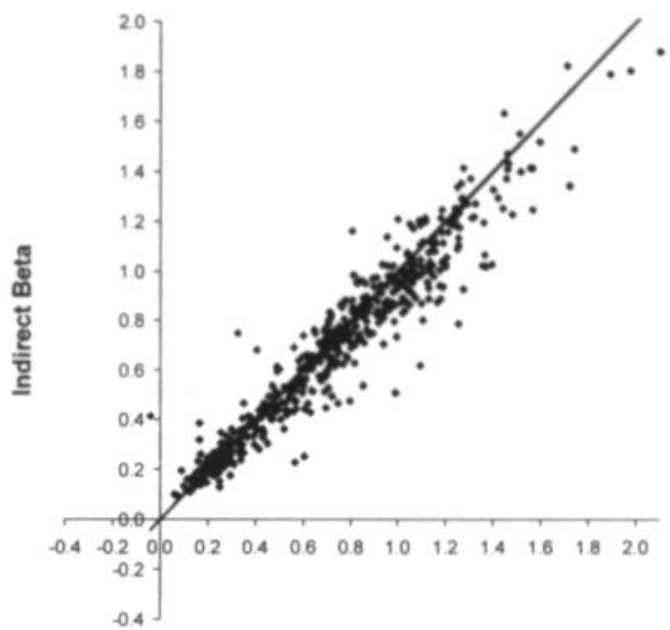

Direct Beta

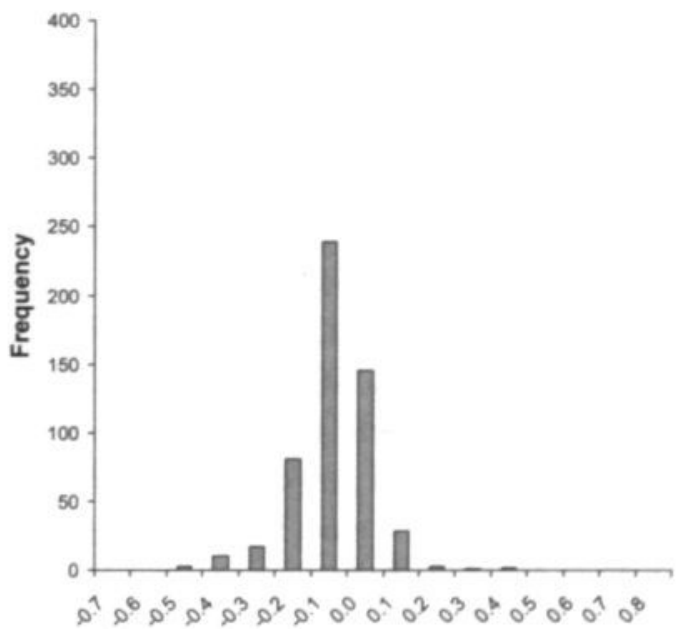

Beta Error 
Table 7.5

Summary Statistics of the Beta Error

\begin{tabular}{|c|c|c|c|c|c|}
\hline Country & Mean & Abs & StDv & Min & Max \\
\hline Australia & -0.010 & 0.116 & 0.160 & -0.693 & 0.487 \\
\hline Canada & -0.037 & 0.121 & 0.155 & -0.489 & 0.616 \\
\hline France & -0.038 & 0.123 & 0.149 & -0.497 & 0.384 \\
\hline Germany & -0.014 & 0.076 & 0.099 & -0.310 & 0.306 \\
\hline Japan & 0.018 & 0.118 & 0.155 & -0.495 & 0.853 \\
\hline Netherlands & -0.057 & 0.097 & 0.111 & -0.441 & 0.276 \\
\hline Switzerland & -0.080 & 0.104 & 0.110 & -0.426 & 0.158 \\
\hline United Kingdom & -0.004 & 0.091 & 0.123 & -0.642 & 0.577 \\
\hline United States & -0.037 & 0.076 & 0.105 & -0.478 & 0.457 \\
\hline
\end{tabular}

In the absence of currency risk premia (and in the absence of deviations from the restriction $\left.\alpha_{l i}=\alpha_{2 i}+b_{i} \alpha_{L}\right)$ the expression $\left(d_{L} b_{i}-d_{i}\right) E\left[R_{G}-r_{0}\right]$ would give an estimate of the cost of capital difference between the domestic and the international CAPM. The (discrete) return on the global market portfolio over the sample period 1980-1999 was 15.2 percent annually when expressed in U.S. dollars. Over the same period, the average domestic onemonth risk free rate was 7.8 percent, resulting in an excess market return of 7.4 percent. Consequently, the implied cost of capital difference between the two models amounts to 0.56 percent on average for U.S. firms. For Germany, the excess return on the global market in local currency equals 9.4 percent, yielding a pricing error in terms of cost of capital of 0.71 percent. For Japan, the implied cost of capital differential is equal to 0.78 percent, while for France the difference is equal to 1.01 percent per year in local currency.

Figures 7.1 through 7.9 and table 7.5 show that the pricing error in terms of beta is not only not statistically significant but also relatively unimportant in economic terms. Most firms plot fairly close to the line with a slope of unity in the scatter plots. The summary statistics and the histograms show that the absolute beta error between the CAPM and the multifactor ICAPM is remarkably small for all countries. In cost of capital terms, these differences generally amount to less than one percent on average. 
While we acknowledge that changing the cost of equity capital by 1 percent could have a substantial impact on capital budgeting decisions, we argue that a pricing error of 1 percent is relatively small in light of the large uncertainties in estimating the cost of equity capital for an individual firm. Fama and French (1997) show that standard errors of more than 3 percent per year are typical when the single factor domestic CAPM is used to estimate the cost of equity capital for 48 U.S. industries. Cost of capital estimates for individual firms are likely to be even less accurate. The large standard errors arise because of imprecise estimates of both factor risk premia and risk loadings. Moreover, Fama and French (1997) also show that pricing errors of 2 percent between the single factor domestic CAPM and the three-factor model of Fama and French (1993) per year are common. Griffin (2002) reports pricing errors between domestic and world Fama-French three-factor models ranging between 6.1 percent and 9.4 percent per year for Canada, Japan, the U.K., and the U.S.

\subsection{Local, Global, and Currency Factors: A Variance Decomposition}

This section further explores our finding that the pricing error is rarely statistically significant in our sample of almost 3,300 international stocks. We investigate how much of the risk that is specific from a local country perspective is systematic from a global perspective. For this we use a variance decomposition metric that allows for an assessment of the respective contributions of the local market, the global market and the vector of exchange rate changes to an individual asset $i$ 's return.

The decomposition starts from the domestic CAPM and investigates how much global market and currency factors add to the local market index as a measure of systematic risk. We consider the regression

$$
R_{i}=\alpha_{5 i}+R_{L} b_{i}+\eta_{z}{ }^{\prime} h_{i}+\xi_{i},
$$

where $\eta_{Z}$ represents the residual vector from regressing $Z$ on $R_{L}$. This way the marginal contribution of the global factors to the explanatory power of the regression conditional on the local market contribution can be measured. Under the null-hypothesis of a zero cost of capital differential, all the global risk factors are accounted for by the local market index. Equation (7.10) is a simple reparametrization of equation (7.8). However, equation (7.10) immediately yields the actual contribution of the global factors $Z$. Taking the variance of both the left and the right hand side of equation (7.10), the variance decomposition of stock $i$ can be expressed as

$$
\omega_{i}^{2}=b_{i}^{2} \omega_{L}^{2}+h_{i}\left(\Omega+\frac{\Omega d_{L} d_{L}^{\prime} \Omega}{\omega_{L}^{2}}\right) h_{i}+\sigma_{i}^{2} .
$$

In equation (7.11) the total variance of stock $i$ (denoted by $\omega_{i}{ }^{2}$ ) is decomposed into systematic local market risk (related to the variance $\omega_{L}{ }^{2}$ of the local market return), additional global risk in $Z$ that is orthogonal to the local market (related to the covariance matrix $\Omega$ of $Z$ ), and specific risk $\sigma_{i}{ }^{2}$. Note that the contribution of the global factors should be zero under the null- 
hypothesis that the domestic CAPM does not yield a different cost of capital than the multifactor ICAPM. That is, the estimate of $h_{i}$ must equal zero under the null-hypothesis.

In figure 7.10 , the average variance decomposition according to equation (7.11) is given for each country. The figure provides information on the explanatory power of the local and the orthogonalized global factors in a regression of individual stock returns. From the graph, it is clear that the marginal contribution of the global factors $Z$ across firms in one country is negligible on average. Obviously, the choice between domestic CAPM and the multifactor ICAPM does not matter a great deal for the computation of the cost of capital. ${ }^{32}$ Our results provide support for the existence of important country effects in asset pricing, consistent with De Ménil (1999), Heston and Rouwenhorst (1994), Rouwenhorst (1999), Griffin and Karolyi (1998), and Griffin (2002), who show that the cross-section of returns and their variations across international equity markets are caused by large country-specific components, and not industrial structure.

Figure 7.10 suggests that most firms within one country share a common exposure to international currency and stock market factors. Since such average exposure is captured in the international pricing of the local stock market index, this index in turn is a sufficient statistic against which to measure an individual firm's sensitivity to global factors. This means that even in integrated markets the pricing error is relatively small for most firms, because the local market factor can serve as a proxy for the omitted global factors in the domestic CAPM. The domestic CAPM induces a pricing error only for firms that have significantly deviating exposure from the local market.

Our results point to the fact that a firm's risk profile is closely connected to the country from which it operates. This holds for the large majority of firms. A tentative explanation of this finding is related to what De Ménil (1999) calls lack of real capital market integration. De Ménil (1999) finds that both cyclical and structural, and institutional countryspecific factors significantly contribute to the explanation of cross-country differences in ROA for large non-financial firms. More in particular, he finds significant effects for the level of capital deepening and for the regulatory environment. With respect to the latter, De Ménil points to labor market regulation and product market regulation as significant determinants of firm performance. Clearly, all firms within the same national jurisdiction face similar constraints and opportunities in this respect. Similarly, Koedijk and Kremers (1996) show that differences in medium-term macroeconomic growth across the European Union are negatively related to market regulation.

\footnotetext{
32 The extent to which formal rejection of a pricing error is possible, can be shown to depend on the overall explanatory power of the ICAPM. In other words, the power of the test depends on the performance of the model. Unreported results are available from the author to illustrate this point.
} 
Figure 7.10

\section{Average Pricing Error Decomposition}

This figure presents the variance decomposition described in section 7.5. The general idea behind this decomposition is that the orthogonalized global market factor and the currency risk factors are added to the CAPM regression, as depicted in equation (7.10). Equation (7.11) shows that the variance of firm $i$ can then be expressed as the sum of systematic local market risk, additional global risk in the global factors that is orthogonal to the local market, and specific risk. With this metric we are able to estimate to what extent the global market and the exchange rate risk factors add explanatory power to the domestic CAPM. Under the null-hypothesis of no pricing error, the global factors should have no contribution to the total variance. The variance decomposition for a country is equal to the weighted average of all decompositions of individual firms in that country with $\left(1 / \sigma_{i}^{2}\right)\left(\Sigma 1 / \sigma_{i}^{2}\right)$ as weights. The vertical axis depicts the explanatory power of each of the factors in terms of the percentage of the total variance of a stock which can be explained by that factor. The sample period is 1980:021999:06.

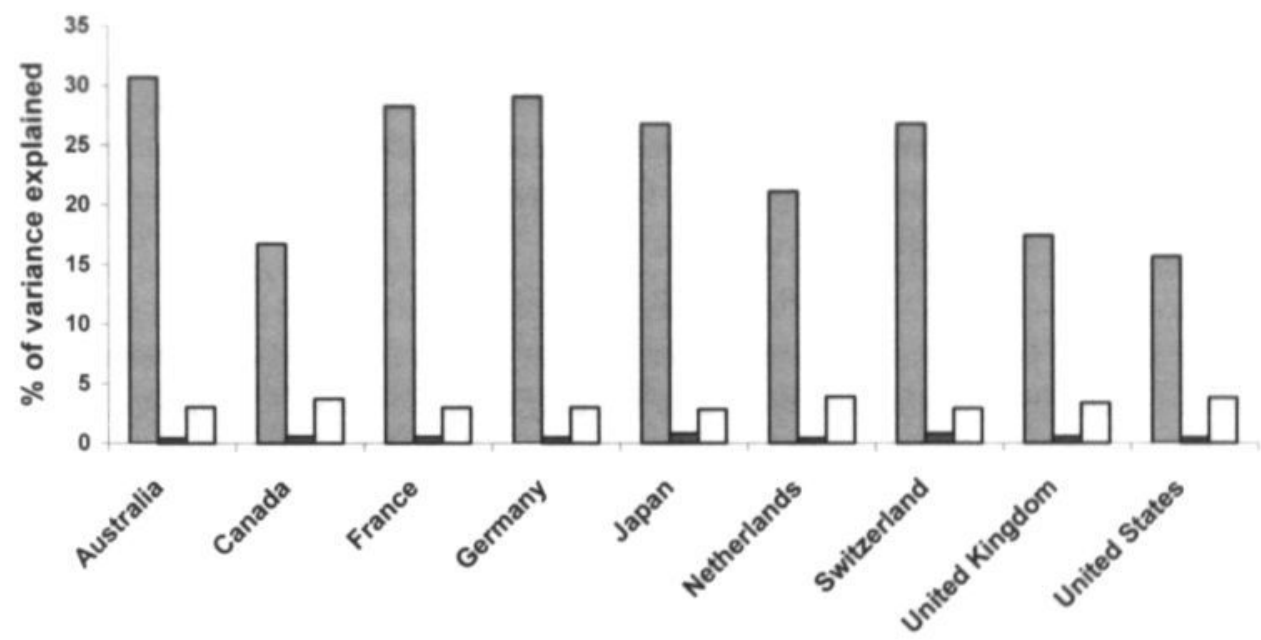

口Local $\square$ Global $\square$ Currency

In short, with a lack of real capital market integration and substantial cross-country differences in market regulation, a country's fortunes and the fortunes of the firms operating in this country are closely tied together. It may be true that certain firm characteristics such as size and degree of international activity play a role in explaining the deviating exposure of a firm relative to the local market. Further research is required to examine this issue. Chapter 8 of this thesis examines whether companies with international cross-listing display a pricing error.

Increasing harmonization of regulatory policies as is happening in the EU will reduce these structural differences. In the same vein, increasing real integration will reduce cyclical 
differences. For the time being, substantial differences remain between countries and firms across countries. Note that the lack of real integration is separate from the issue of financial integration. Because we take the ICAPM as the null-hypothesis, we implicitly assume that stock markets are fully integrated. Consequently, our results have no implications for the financial integration of international capital markets.

\subsection{Exchange Rate Exposure}

In section 7.2 we showed that in general testing for a pricing error can be implemented by examining the statistical significance of a set of instrumental variables in a time series regression of the stock return of an individual firm on an intercept and the domestic market return (see equation (7.8)). These pricing error tests are very similar to the well-known tests for exchange rate exposure. In this section we perform several exchange rate exposure tests and show that the results of section 7.5 can shed light on the well-known puzzle that companies show hardly any exposure to exchange rate fluctuations

Adler and Dumas (1984) define foreign exchange exposure as the impact of exchange rate movements on the value of a firm. Recent papers in the field, e.g. Jorion (1990), Bartov and Bodnar (1994), and $\mathrm{He}$ and $\mathrm{Ng}$ (1998), test for currency exposure of individual companies using a version of the time-series regression

$$
R_{i}=\gamma_{i 0}+R_{L} \gamma_{i 1}+f(S)^{\prime} \gamma_{i 2}+\varepsilon_{i},
$$

where $f(S)$ is a function of the nominal exchange rate returns expressed in the home currency of firm $i$. The null-hypothesis of the test for currency exposure can be formulated as $H_{0}: \gamma_{i 2}=$ 0 . This test can also be interpreted as a pricing error test as it analyzes whether any systematic (currency) risk can be filtered out from the risk of a firm that is diversifiable according to the domestic CAPM.

Several versions of regression (7.12) have been used in the literature. Most studies use a trade-weighted exchange rate index for $f(S)$. A disadvantage of that specification is that firms within a country may be differently exposed to various exchange rates. An alternative would be to define $f(\cdot)$ to be a linear projection. In this chapter the latter test is called the "Exposure" test. It uses a subset of the orthogonality conditions in equation (7.8). A brief description of the Exposure test is presented in table 7.1.

We suspect that foreign currency exposure as estimated in equation (7.12) may (in part) be captured by the domestic market factor. In order to control for this effect we also run the alternative regression

$$
R_{i}=c_{i 0}+S^{\prime} c_{i t}+\eta_{G} c_{i 2}+\eta_{L} c_{i 3}+v_{i},
$$

where $\eta_{G}$ is the residual vector from regressing $R_{G}$ on an intercept and $S$. Similarly, $\eta_{L}$ is the residual vector from regressing $R_{L}$ on an intercept, $R_{G}$, and $S$. By orthogonalizing $R_{L}$, we want to accomplish that the coefficient on $S$ does not merely reflect the deviating exposure of firm $i$ 
from the average currency exposure of all firms in the country. The test of $c_{i l}=0$ is called the "Total Exposure" test.

An alternative way to estimate exchange rate exposure is in a regression of a stock return on the global market return and exchange rate returns. It is unlikely that most of the joint currency exposure would also be captured by the global stock market, which contains a much more diverse population of firms. The appropriate regression to run is the following

$$
R_{i}=\alpha_{1 i}+R_{G} d_{i 1}+S^{\prime} d_{i 2}+u_{i}
$$

Note that equation (7.14) is the same as equation (7.2). This regression looks for significant "Currency Betas". A short description of the hypotheses underlying the Total Exposure and the Currency Betas tests is presented in table 7.1.

Table 7.6

\section{Exchange Rate Exposure Test Results}

This table presents rejection frequencies for three tests for each of the nine countries in our sample. The Exposure test tests for exchange rate exposure of individual stocks when controlled for the local market index. The Total Exposure test tests for exchange rate exposure when controlled for fluctuations in the local and global market indices that are orthogonal to all exchange rates. The Currency Betas test tests for exposure of individual firms when the global market return is included in the regression. All test statistics are Chi-squared distributed and robust to heteroskedasticity. Rejection frequencies are defined as the percentage of firms in a country for which the null-hypothesis is rejected at the 5 percent significance level. "Average" depicts a weighted average of the percentages of firms in each individual country for which the null-hypothesis is rejected. The weights of the rejection frequencies are the weights of each country in the sample as shown in the third column of table 7.3. The sample period is 1980:02-1999:06.

\begin{tabular}{lccc}
\hline Country & $\begin{array}{c}\text { Exposure Test } \\
\text { percentage rejections }\end{array}$ & $\begin{array}{c}\text { Total Exposure Test } \\
\text { percentage rejections }\end{array}$ & $\begin{array}{c}\text { Currency Betas Test } \\
\text { percentage rejections }\end{array}$ \\
\hline Australia & 12.04 & 74.07 & 74.07 \\
Canada & 12.79 & 47.03 & 51.14 \\
France & 14.96 & 50.39 & 46.46 \\
Germany & 20.22 & 48.88 & 46.07 \\
Japan & 16.16 & 52.47 & 73.22 \\
Netherlands & 17.07 & 53.66 & 20.33 \\
Switzerland & 6.98 & 57.36 & 34.88 \\
United Kingdom & 11.23 & 36.44 & 27.02 \\
United States & 14.74 & 38.56 & 39.70 \\
& & & 45.67 \\
Average & 13.85 & 45.43 & \\
\hline
\end{tabular}


The first column of table 7.6 depicts the percentage of firms in each individual country for which the null-hypothesis of no currency exposure in regression (7.12) is rejected at the 95 percent confidence level. Consistent with the literature we find that significant exposure exists on average for about 14 percent of the firms in our sample. As mentioned in section 7.5 , the variance decomposition in figure 7.10 shows that most firms within a country have a joint exposure to the global market and exchange rates. Therefore, the evidence in column 1 of table 7.6 does not necessarily imply that the value of a firm is not affected by changes in exchange rates. The exposure may at least partly be captured by the domestic market factor

The rejection percentages for the Total Exposure test as depicted in column 2 of table 7.6 are considerably higher than those of the Exposure test. On average about 45 percent of the firms exhibit significant currency exposure. The highest rejection percentage is 74.07 percent for Australia, while the lowest is 36.44 percent for the U.K. The results for the Currency Betas test are very similar to these findings. This corroborates our results. Our exchange rate exposure results could possibly be affected by survivorship bias in our data set, especially because firms that have large currency exposures may well face relatively great bankruptcy risks. As test results for subperiods (unreported) are qualitatively similar, we do not expect this to be an important issue.

\subsection{Conclusions}

While theory suggest the use of an international CAPM in integrated capital markets, the domestic CAPM does not necessarily imply an inadequate estimate of the cost of capital. In this chapter we examine to what extent international and domestic asset pricing models imply a different estimate of the cost of capital for a sample of monthly data for 3,293 firms from nine major industrialized countries from 1980 to 1999 . We distinguish between: (i) the multifactor ICAPM of Solnik-Sercu including both the global market portfolio and exchange rate risk premia, and (ii) the single factor domestic CAPM. Our analysis allows for an assessment of what is important in cost of capital computations and what is not.

The main results of this chapter stem from two time series regressions we run for each individual stock in the sample. First, when we run a regression of the return on andividual stock on the return on the world market index and several exchange rates, we find that a large number of companies are exposed to fluctuations in exchange rates. Foreign exchange exposure is statistically significant for more than 45 percent of the firms in our sample. Second, when we incorporate the domestic market index in this regression, the exposure to exchange rates dissolves for most firms. In fact, both the global market index and the exchange rate factors become insignificant for the vast majority of corporations. The global factors are jointly significant for only approximately 5 percent of the firms in our sample.

We draw the following conclusions from this analysis. Firms are exposed to global risk factors, validating an international finance approach to measuring the cost of equity 
capital. Corporations within a country by and large exhibit a joint exposure to international risk factors. For a large majority of companies, this joint exposure is fully captured in the international pricing of the domestic market index. That is, stock returns are generally dominated by an index of their local currency domestic market index. This finding is corroborated by a variance decomposition analysis. As a result, the systematic risk of a stock implied by the single factor domestic CAPM is very infrequently significantly different from the systematic risk implied by the multifactor ICAPM. The implied cost of capital differential is also remarkably small in economic terms, particularly when we take into consideration the large uncertainties in estimating factor risk premia and risk loadings. The difference in the estimate of a firm's systematic risk amounts to around 50 basis points on average for the U.S., roughly 75 basis points for Germany and Japan, and approximately 100 basis points for France. Independent of the issue whether international capital markets are fully integrated, the domestic CAPM rarely leads to a different estimate of the cost of capital than the multifactor ICAPM. A tentative explanation of this finding is a lack of real capital market integration, due to both cyclical and structural, and institutional country-specific factors. 


\section{Appendix 7.A}

In this appendix we show that the pricing error of the CAPM as compared to the multifactor ICAPM of Solnik-Sercu can be expressed as a linear combination of the parameter $\delta$ in the regression

$$
R_{i}=\alpha_{4 i}+R_{L} \beta_{i}+Z^{\prime} \delta_{i}+\zeta_{i}
$$

This is equation (7.8). The moment conditions of equation (A1) can be written as

$$
\left(\begin{array}{cc}
\omega_{L}^{2} & d_{L}^{\prime} \Omega \\
\Omega d_{L} & \Omega
\end{array}\right)\left(\begin{array}{l}
\beta_{i} \\
\delta_{i}
\end{array}\right)=\left(\begin{array}{c}
\omega_{L}^{2} b_{i} \\
\Omega d_{i}
\end{array}\right),
$$

where $\Omega$ is the $(N+1) \times(N+1)$ covariance matrix of $Z, \omega_{L}^{2}$ is the variance of $R_{L}$, and $d_{L}$ is the vector of regression parameters in regression (7.5)

$$
R_{L}=\alpha_{L}+Z^{\prime} d_{L}+u_{L},
$$

for the local market portfolio. The covariance between $Z$ and $R_{L}$ is therefore equal to $\Omega d_{L}$ Solving for $\delta$ from the second line of (A2) we get

$$
\delta=d=d r R
$$

Substituting this expression into the first line of equation (A2) gives

$$
\beta_{i}=\frac{\omega_{L}^{2} b_{i}-d_{i} \Omega d_{i}}{\omega_{L}^{2}-d_{L} \Omega d_{L}}=b_{i}-\frac{d_{L} \Omega p_{i}}{\sigma_{L}^{2}},
$$

where $p_{i}=d_{L} b_{i}-d_{i}$ is the pricing error and $\sigma_{L}{ }^{2}$ is the variance of residuals $u_{L}$. Substituting this expression for $\beta_{i}$ back into equation (A4) yields

$$
\delta_{i}=\left(\mathrm{I}+\frac{d_{L} d_{L}^{\prime} \Omega}{\sigma_{L}^{2}}\right) p_{i} .
$$

Equation (A6) can be rewritten as

$$
p_{i}=\left(\mathrm{I}+\frac{d_{L} d_{L} \Omega}{\sigma_{L}^{2}}\right)^{-1} \delta_{i} .
$$

Note that $d_{L}, \Omega$, and $\sigma_{L}{ }^{2}$ are unrelated to asset $i$ and are treated as exogenous. 


\section{Chapter 8}

\section{The Cost of Capital of Cross-Listed Firms}

\subsection{Introduction}

As many companies have recently become considerably more internationally oriented, foreign equity listings have gained importance as a strategic management tool. The number of international cross-listings in the U.S. has increased in recent years. Since 1993, the total number of non-U.S. listed companies at NYSE has more than quadrupled to 470 as of May 31,2002 . The number of international stocks at NASDAQ has increased from 261 at the end of 1992 to more than 459 at August 31, 2001. Since 1996, the number of cross-listed firms at AMEX has about doubled to 51 as of May 31, 2002.

The literature on international cross-listings focuses on two main issues. First, many studies have examined the effects of a cross-border listing of a stock in terms of excess returns, liquidity, and the cost of capital. Foerster and Karolyi (1993) investigate Canadian stocks that list in the U.S. and find a positive pre-listing abnormal return, while the 100-day post-listing abnormal return is negative. The liquidity of the stocks increases and the beta's decrease on average. Werner and Kleidon (1996) also find that liquidity increases for a sample of U.K stocks that have a cross-listing at the NYSE. The authors find no effect for the risk of the stocks. Jorion and Schwartz (1986) compare the cost of capital and the risk of 94 Canadian stocks that are dually listed in the U.S. with a benchmark sample of 655 Canadian stocks not listed at an exchange in the U.S. They find that the cross-listed companies have a lower cost of capital, but a higher sensitivity to U.S. market risk than the benchmark firms. More recently, Doukas and Switzer (2000) find a significantly positive stock market reaction to the announcement of a listing in the U.S. by 79 Canadian firms in the period 1977-1997. This is consistent with the hypothesis that international listings lead to a decrease in the risk 
premium of firms operating in mildly segmented markets. In an extensive survey of studies on cross-listings, Karolyi (1998) concludes that the evidence indicates a favorable short-term stock price reaction to the listing, an improvement in liquidity, and a considerably lower cost of equity capital. The evidence on longer term post-listing stock price performance is mixed.

Second, the characteristics of companies that list their shares abroad have been studied extensively, as well as the motivations for cross-listing their stock at a foreign exchange. Saudagaran (1988) examines a sample of 223 companies that obtain a dual listing in Canada, Europe, Japan, or the U.S. and finds that large firms with a high percentage of sales abroad are relatively likely to list abroad. Similarly, Pagano, Röell, and Zechner (2002) find that companies that list abroad are relatively large and have a high level of foreign sales and R\&D spending. Biddle and Saudagaran (1989) conclude that firms are relatively unlikely to list at overseas exchanges with stricter disclosure regulations than the home market. Karolyi (1998) reviews the recent evidence and concludes that stringent disclosure requirements are the main obstacle to overseas listings. Fuerst (1998), on the other hand, argues that companies could use a cross-listing at an exchange with strict regulations for signaling quality.

We focus on the cost of capital of interlisted stocks. The purpose of this chapter is to shed light on the question whether international and domestic asset pricing models lead to a different estimate of the cost of capital for a firm with at least one listing abroad. In chapter 7 we derived statistical tests for the so-called pricing error between the domestic CAPM and the multifactor ICAPM of Solnik (1983) and Sercu (1980) including both the global market portfolio and exchange rate risk premia. We showed that the pricing error is an affine function of the estimated cost of capital differential. We analyzed a sample of almost 3,300 companies over the period 1980:02-1999:06 and found a significant pricing error for only 5 percent of the firms. This result is probably related to strong country factors in the data.

In this chapter we separate our sample of 3,293 securities into firms interlisted at a foreign stock market and firms that are not. Our hypothesis is that firms with at least one international listing exhibit a relatively large pricing error. As mentioned above, several studies have shown that companies with overseas listings have a large market capitalization and a high percentage of sales abroad. These firms show a clear international orientation and may therefore well exhibit exposure to global factors that deviates from the other firms within their country. This would imply that the local market index cannot serve as a proxy for the omitted global factors in the domestic CAPM. Hence, we suspect that international listings can be used as a characteristic that distinguishes firms with large pricing errors from low pricing error companies. In chapter 7 we expressed a need for such a characteristic.

We find a significant pricing error between the domestic CAPM and the multifactor ICAPM for only 12 percent of the 336 interlisted firms. The absolute difference in the cost of capital for cross-listed companies amounts to about 50 basis points for the U.S., 55 basis points for Germany, 80 basis points for the U.K., and 90 basis points for Japan. Hence, we find limited evidence supporting our hypothesis that the pricing error is large for firms with international cross-listings. We show that these findings could again be explained by strong 
country factors in the data. A potential explanation for this finding is a lack of real capital market integration. As discussed in chapter 7, De Ménil (1999) presents evidence that these country-specific factors play a significant role in explaining cross-country differences in ROA for large non-financial firms Europe.

As a benchmark for our results for firms with foreign listings we use the sample of 2,957 companies that do not have international listings. Around 4.4 percent of these "purely domestic" firms shows a significant pricing error. The estimated cost of capital differential amounts to 80 basis points on average for domestic stocks.

This chapter is organized as follows. In section 8.2 we briefly review our pricing error testing methodology from chapter 7 . Section 8.3 provides a description of the data. We discuss our empirical results for interlisted stocks in section 8.4. Section 8.5 presents the results for our benchmark sample of domestic stocks. Section 8.6 summarizes and concludes.

\subsection{Methodology}

This section briefly discusses our testing methodology for a pricing error between the domestic CAPM and the multifactor ICAPM from chapter 7. We assume a world with $N+1$ countries. The starting point of the derivation in section 7.2 is formed by three regressions. The first regression is based on the Solnik-Sercu version of the multifactor ICAPM and relates the return of an individual stock to the global market portfolio and exchange rate factors

$$
R_{i}=\alpha_{1 i}+Z^{\prime} d_{i}+u_{i}=\alpha_{1 i}+R_{G} d_{i 1}+S^{\prime} d_{i 2}+u_{i},
$$

where $R_{i}$ and $R_{G}$ denote the return of asset $i$ and the global market expressed in the numeraire currency 0 of asset $i, S$ is the vector of nominal exchange rate returns of the other $l=1, \ldots, N$ countries against currency 0 , and $Z=\left[R_{G}, S\right]$. This equation is equal to equation (7.2).

The second regression uses the local market portfolio as the systematic risk factor and can be used to estimate the beta of the domestic CAPM

$$
R_{i}=\alpha_{2 i}+R_{L} b_{i}+e_{i},
$$

where $R_{L}$ is the return of the local market index expressed in the numeraire currency 0 . In order to determine the pricing error between the domestic CAPM and the multifactor ICAPM, we apply the ICAPM to the local market index

$$
R_{L}=\alpha_{L}+Z^{\prime} d_{L}+u_{L} .
$$

In the previous chapter we showed that the pricing error can then be expressed as

$$
p_{i}=d_{L} b_{i}-d_{i} \text {. }
$$

We developed two different pricing error tests. The first test examines $\mathrm{H}_{0}: \delta_{1}=0$ in the regression

$$
R_{i}=\alpha_{4 i}+R_{L} \beta_{i}+Z^{\prime} \delta_{i}+\zeta_{i} .
$$

This test is called the "Pricing Error" test. Note that equation (8.5) is the same as equation (7.8). If the restriction holds, risk that is specific according to the domestic CAPM 
does not contain additional systematic risk related to the global factors. The second pricing error test examines only the first element of the pricing error (also referred to as the beta error), which is relevant when exchange rate risk is not priced. In appendix 7.A we demonstrated that the pricing error vector in equation (8.4) can be written as a linear combination of the parameter $\delta$ in regression (8.5)

$$
p_{i}=\left(\mathrm{I}+\frac{d_{L} d_{L}^{\prime} \Omega}{\sigma_{L}^{2}}\right)^{-1} \delta_{i}=\Lambda \delta_{i},
$$

where $\Omega$ is the covariance matrix of $Z$, and $\sigma_{L}{ }^{2}$ is the variance of the residuals $u_{L}$ in equation (8.3). We call the test for the null-hypothesis that the first element of $p_{i}$ is equal to zero the "Global Beta" test.

\subsection{Data}

The data we use in this chapter is the same as in the previous chapter. In this section we only discuss the source of the data. For more information we refer to section 7.3. We employ monthly data for nine countries: Australia, Canada, France, Germany, Japan, the Netherlands, Switzerland, United Kingdom, and the United States. The sample period is 1980:02-1999:06. Nominal exchange rates are from International Financial Statistics (IFS). The marketweighted local equity indices and the market-weighted global equity index are obtained from Morgan Stanley Capital International (MSCI). Data on individual stocks is taken from Datastream.

The first and second columns of table 8.1 show the number of cross-listed companies, respectively the number of purely domestic stocks with a complete series of returns over the sample period for each country. Our sample consists of more than 300 companies with crosslistings and almost 3,000 domestic firms. The other four columns of table 8.1 depict the number of interlisted and domestic stocks for two subperiods, 1980:02-1989:12 and 1990:011999:06. The number of interlisted stocks is roughly the same for all sample periods, which is probably related to the fact these firms are relatively large and well-established. The total amount of domestic stocks varies widely, however. Our main empirical analysis focuses on cross-listed stocks. We use our sample of domestic stocks as a benchmark in order to assess to what extent the pricing error and the foreign exchange exposure of cross-listed stocks diverge from those of domestic companies. 


\section{Table 8.1}

\section{Sample Composition}

This table presents the number of domestic and interlisted firms for different countries in three different sample periods. Columns one and two depict the number of companies in the sample period 1980:02-1999:06. The third and the fourth columns show how many stocks the sample contains in the first subperiod 1980:02-1989:12. The number of corporations in each country for the second subperiod 1990:01-1999:06 are reflected in the last two columns.

\begin{tabular}{|c|c|c|c|c|c|c|}
\hline \multirow[b]{2}{*}{ Country } & \multicolumn{2}{|c|}{$\begin{array}{c}\text { \# stocks } \\
\text { in whole sample } \\
1980: 02-1999: 06\end{array}$} & \multicolumn{2}{|c|}{$\begin{array}{c}\text { \# stocks } \\
\text { in } 1^{\text {st }} \text { subsample } \\
1980: 02-1989: 12\end{array}$} & \multicolumn{2}{|c|}{$\begin{array}{c}\text { \# stocks } \\
\text { in } 2^{\text {nd }} \text { subsample } \\
\text { 1990:01-1999:06 }\end{array}$} \\
\hline & Interlisted & Domestic & Interlisted & Domestic & Interlisted & Domestic \\
\hline Australia & 24 & 84 & 24 & 94 & 23 & 221 \\
\hline Canada & 29 & 190 & 29 & 202 & 29 & 316 \\
\hline France & 22 & 105 & 22 & 108 & 22 & 478 \\
\hline Germany & 24 & 154 & 24 & 157 & 24 & 408 \\
\hline Japan & 127 & 702 & 126 & 608 & 127 & 1,628 \\
\hline Netherlands & 26 & 97 & 26 & 100 & 26 & 134 \\
\hline Switzerland & 14 & 115 & 14 & 122 & 14 & 250 \\
\hline United Kingdom & 17 & 1,034 & 17 & 1,101 & 17 & 1,228 \\
\hline United States & 53 & 476 & 53 & 504 & 52 & 697 \\
\hline Total & 336 & 2,957 & 335 & 2,996 & 334 & 5,360 \\
\hline
\end{tabular}

\subsection{Empirical Results: Interlisted Stocks}

In this section we discuss our empirical analysis of companies with international listings. Section 8.4.1 examines the pricing error results. In section 8.4.2 we present a variance decomposition analysis that assesses the contribution of both local and global factors to the returns of cross-listed stocks. This decomposition provides a possible rationale for our pricing error test results. Finally, as a related issue we examine the exchange rate exposure of interlisted firms in section 8.4.3.

\subsubsection{Pricing Error}

As previous studies indicate that firms with international listings are predominantly internationally oriented, our hypothesis is that these corporations have a considerable pricing 
error. The first column of table 8.2 presents rejection percentages of the Pricing Error test for interlisted companies. This test examines whether the firm's cost of capital is different when estimated with the domestic CAPM instead of the multifactor ICAPM. We find a significant pricing error for approximately 12 percent of the 336 firms. It is interesting to note that companies with a significant pricing error are typically from the large countries in our sample, such as Germany, Japan, and the U.S.

Table 8.2

Pricing Error Test Results for Interlisted Companies

This table contains the rejection frequencies for the pricing error tests for interlisted stocks. The Pricing Error test examines whether a pricing error exists between the domestic CAPM and the multifactor ICAPM. The Global Beta test is similar to the Pricing Error test but focuses on the beta error of the domestic CAPM versus the multifactor ICAPM. Both test statistics are Chi-squared distributed and robust to heteroskedasticity. Rejection frequencies are defined as the percentage of firms in a country for which the null-hypothesis is rejected at the 5 percent significance level. The row labeled "Average" depicts a weighted average of the percentages of firms in each individual country for which the null-hypothesis is rejected. The weights of the rejection frequencies are the number of firms in each country as depicted in table 8.1. The sample period is 1980:02. 1999:06. This table also shows the rejection frequencies for both tests for two subsamples. The first subsample consists of the period 1980:02-1989:12. The second subsample is 1990:01-1999:06. Data on domestic and global market indices is obtained from MSCl. Data on individual stocks is obtained from the Datastream equity lists. Nominal exchange rates are taken from the International Financial Statistics (IFS) tape. Stocks with incomplete price or dividend data, stocks with outlier observations, and illiquid stocks have been removed from the dataset.

\begin{tabular}{lcccccc}
\hline Country & \multicolumn{3}{c}{$\begin{array}{c}\text { Pricing Error Test } \\
\text { percentage rejections }\end{array}$} & \multicolumn{3}{c}{$\begin{array}{c}\text { Global Beta Test } \\
\text { percentage rejections }\end{array}$} \\
\hline & $1980-1999$ & $1980-1989$ & $1990-1999$ & $1980-1999$ & $1980-1989$ & $1990-1999$ \\
\hline Australia & 4.17 & 4.17 & 4.35 & 4.17 & 8.33 & 17.39 \\
Canada & 6.90 & 3.45 & 3.45 & 6.90 & 13.79 & 6.90 \\
France & 4.55 & 0.00 & 4.55 & 0.00 & 13.64 & 0.00 \\
Germany & 12.50 & 4.17 & 4.17 & 4.17 & 4.17 & 4.17 \\
Japan & 19.69 & 4.80 & 11.02 & 14.17 & 20.80 & 9.45 \\
Netherlands & 3.85 & 0.00 & 0.00 & 3.85 & 0.00 & 0.00 \\
Switzerland & 7.14 & 14.29 & 0.00 & 0.00 & 21.43 & 0.00 \\
United Kingdom & 5.88 & 0.00 & 11.76 & 0.00 & 0.00 & 0.00 \\
United States & 11.32 & 5.66 & 11.54 & 3.77 & 1.89 & 11.54 \\
& & & & & & 11.98 \\
Average & 12.20 & 4.19 & 7.78 & 7.44 & 7.49 \\
\hline
\end{tabular}


The fourth column of table 8.2 contains rejection frequencies of the Global Beta test. This test evaluates the significance of the first element of the pricing error, also referred to as the beta error. The beta error is computed as the difference between the "indirect" beta (the global beta of the local market $d_{L I}$ multiplied by the CAPM beta $b_{i}$ ) and the "direct" beta (the multifactor ICAPM beta $d_{i l}$ ) of a firm. The beta error is significantly different from zero for 7.44 percent of the cross-listed firms.

In addition, table 8.2 shows rejection frequencies of the Pricing Error test and the Global Beta test for two subperiods. For the period 1980:02-1989:12, the Pricing Error test rejects for 4.19 percent of the 336 firms in the sample and the rejection frequency of Global Beta test is equal to 11.98 percent. The hypothesis of no pricing error is rejected for 26 out of 334 interlisted companies in the subperiod 1990:01-1999:06. The Global Beta test rejects for 7.49 percent of the firms. The fact that the hypothesis that the pricing error is equal to zero is rejected for a similar number of firms over the two subsamples suggests that the assumption that betas are not time-varying only has a marginal impact on our results.

Table 8.3 shows the average, the average of the absolute value, the standard deviation, the minimum, and the maximum of the beta error for our sample of cross-listed stocks. The average beta error is depicted in the first column of table 8.3 and is relatively close to zero. ${ }^{33}$ The second column shows that the absolute beta error amounts to around 0.1 for most countries, varying from 0.056 for the Germany to 0.142 for Canada. The average of the absolute beta errors of all interlisted firms in the U.S. is equal to 0.067 .

In the absence of exchange rate risk premia, the expression $\left(d_{L} b_{i}-d_{i}\right) E\left[R_{G}-r_{0}\right]$ gives an estimate of implied the cost of capital differential between the CAPM and the ICAPM. As shown in chapter 7, the global market risk premium in U.S. dollars amounted to approximately 7.4 percent over the period 1980-1999. The implied cost of capital differential between the CAPM and the ICAPM is then 50 basis points on average for U.S. firms. In cost of capital terms the beta error amounts to 53 basis points for Germany, 90 basis points for Japan, 80 basis points for the U.K., and 112 basis points for Canada. Averaged over all countries, the implied cost of capital difference is approximately 80 basis points for interlisted stocks. This indicates that, in view of the large uncertainties involved in estimating the cost of equity capital for individual firms, the pricing error for interlisted firms is relatively minor in economic terms.

Overall, our pricing error results provide little evidence for our hypothesis that the pricing error is economically and statistically large for cross-listed firms. Section 8.4.2 further explores these results by decomposing the variance of a cross-listed stock into local and global factors. The aim of this analysis is to assess the marginal contribution of the global market index and the currency factors to the explanatory power of the domestic stock market portfolio.

\footnotetext{
33 As pointed out in chapter 7 , the pricing error for an individual stock might be different from zero, but the value-weighted average of the pricing errors of all stocks in the domestic market index is equal to zero.
} 
Table 8.3

Summary Statistics of the Beta Error for Interlisted Companies

\begin{tabular}{|c|c|c|c|c|c|}
\hline Country & Mean & Abs & StDv & Min & Max \\
\hline Australia & -0.009 & 0.094 & 0.128 & -0.306 & 0.209 \\
\hline Canada & -0.005 & 0.142 & 0.179 & -0.355 & 0.449 \\
\hline France & -0.063 & 0.118 & 0.124 & -0.278 & 0.187 \\
\hline Germany & -0.026 & 0.056 & 0.071 & -0.202 & 0.081 \\
\hline Japan & -0.032 & 0.137 & 0.171 & -0.469 & 0.330 \\
\hline Netherlands & -0.055 & 0.081 & 0.080 & -0.226 & 0.118 \\
\hline Switzerland & -0.100 & 0.103 & 0.088 & -0.280 & 0.013 \\
\hline United Kingdom & -0.051 & 0.104 & 0.154 & -0.528 & 0.158 \\
\hline United States & -0.024 & 0.067 & 0.084 & -0.251 & ก 385 \\
\hline
\end{tabular}

\subsubsection{Variance Decomposition}

In this section we investigate how much of the risk that is specific in the local market is systematic in the global capital market. We analyze the respective contributions of the local market, the global market, and the vector of exchange rate changes to an individual asset $i$ 's return by applying the variance decomposition analysis described in section 7.5. The analysis may shed light on our finding that the domestic CAPM leads to a different estimate of a firm's cost of capital than the multifactor ICAPM for just a small percentage of the firms with foreign listings in our sample.

For a detailed discussion of the variance decomposition technique we refer to chapter 7. The underlying intuition is that the decomposition assesses how much the global market factor and the currency risk factors add to the local market index as a measure of systematic risk in the CAPM. Note that the contribution of the global factors should be zero under the hypothesis that the cost of capital differential is equal to zero.

Figure 8.1 presents the average variance decomposition of all cross-listed firms per country. The variance decomposition for a country is a weighted average of the decompositions for all individual firms in that country with the specific risk of these firms as weights. The marginal contribution of the global factors $Z$ across firms in one country is very small on average. While the exchange rate risk factors exhibit some explanatory power, the 
contribution of the global market index is trivial. Figure 8.1 thus confirms our finding that the domestic CAPM and the multifactor ICAPM yield a different estimate of the cost of capital for a relatively small percentage of firms. The variance decomposition analysis indicates that significant country effects exist in interlisted stock returns, consistent with Heston and Rouwenhorst (1994).

\section{Figure 8.1}

\section{Average Pricing Error Decomposition for Interlisted Companies}

This figure presents a variance decomposition analysis for cross-listed companies. The general idea behind this decomposition is that the orthogonalized global market factor and the currency risk factors are added to the CAPM regression, as depicted in equation (7.10). Equation (7.11) shows that the variance of firm $i$ can then be expressed as the sum of systematic local market risk, additional global risk in the global factors that is orthogonal to the local market, and specific risk. With this metric we are able to estimate to what extent the global market and the exchange rate risk factors add explanatory power to the domestic CAPM. Under the null-hypothesis of no pricing error, the global factors should have no contribution to the total variance. The variance decomposition for a country is equal to the weighted average of all decompositions of individual firms in that country with $\left(1 / \sigma_{1}^{2}\right) /\left(\Sigma 1 / \sigma_{1}^{2}\right)$ as weights. The vertical axis depicts the explanatory power of each of the factors in terms of the percentage of the total variance of a stock which can be explained by that factor. The sample period is 1980:021999:06.

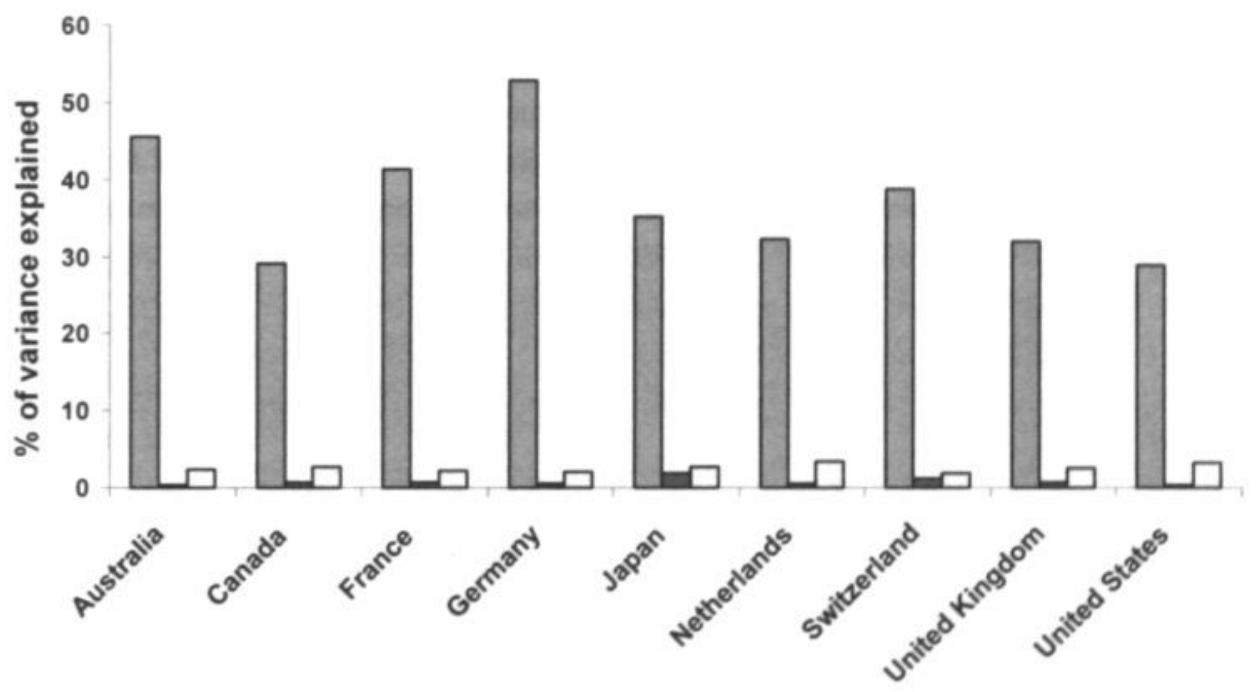

口Local a Global DCurrency 
Figure 8.1 indicates that our result of chapter 7 that most firms within one country exhibit a joint exposure to global factors also holds for firms with foreign listings. The exposure of cross-listed companies to the global market index and exchange rates is captured in the international pricing of the local market index. This implies that even for interlisted stocks, which can be expected to have a relatively great exposure to global factors, the domestic market index can serve as a sufficient statistic for the omitted global factors in the domestic CAPM. As discussed in section 7.5, this may well be related to a lack of real capital market integration as indicated by a recent study by De Ménil (1999). In section 8.4 .3 we explicitly estimate the sensitivity of the interlisted firms in our sample to exchange rate fluctuations.

Table 8.4

Exchange Rate Exposure Test Results for Interlisted Companies

This table presents rejection frequencies for the foreign exchange exposure tests for interlisted companies. The Exposure test examines exchange rate exposure of individual stocks when controlled for the local market index. The Total Exposure test tests for exchange rate exposure when controlled for fluctuations in the local and global market indices that are orthogonal to all exchange rates. The Currency Betas test tests for exposure of individual firms when the global market return is included in the regression. All test statistics are Chi-squared distributed and robust to heteroskedasticity. Rejection frequencies are defined as the percentage of firms in a country for which the null-hypothesis is rejected at the 5 percent significance level. The row labeled "Average" depicts a weighted average of the percentages of firms in each individual country for which the null-hypothesis is rejected. The weights of the rejection frequencies are the number of firms in each country as depicted in the first column of table 8.1. The sample period is 1980:02-1999:06.

\begin{tabular}{lccc}
\hline Country & $\begin{array}{c}\text { Exposure Test } \\
\text { percentage rejections }\end{array}$ & $\begin{array}{c}\text { Total Exposure Test } \\
\text { percentage rejections }\end{array}$ & $\begin{array}{c}\text { Currency Betas Test } \\
\text { percentage rejections }\end{array}$ \\
\hline Australia & 20.83 & 91.67 & 95.83 \\
Canada & 20.69 & 86.21 & 82.76 \\
Franice & 18.18 & 77.27 & 59.09 \\
Germany & 33.33 & 87.50 & 87.50 \\
Japan & 34.65 & 83.46 & 83.46 \\
Netherlands & 15.38 & 84.62 & 19.23 \\
Switzerland & 0.00 & 92.86 & 57.14 \\
United Kingdom & 5.88 & 82.35 & 58.82 \\
United States & 20.75 & 64.15 & 64.15 \\
& & & 72.62 \\
Average & 24.70 & 81.55 & \\
\hline
\end{tabular}




\subsubsection{Exchange Rate Exposure}

In this section we analyze the exchange rate exposure of cross-listed companies. First, we briefly discuss our testing methodology as developed in section 7.6. We test for currency exposure of individual companies in the time series regression ${ }^{34}$

$$
R_{i}=\gamma_{i 0}+R_{L} \gamma_{i t}+S^{\prime} \gamma_{i 2}+\varepsilon_{i} .
$$

The null-hypothesis of the test for currency exposure can be formulated as $H_{0}: \gamma_{i 2}=0$. This test is called the "Exposure" test. It uses a subset of the orthogonality conditions in equation (8.5). As argued in section 7.6, the Exposure test can also be interpreted as a pricing error test as it analyzes whether the risk of a firm that the domestic CAPM indicates to be diversifiable contains any systematic currency risk. We also apply two alternative exchange rate exposure tests. The "Total Exposure" test analyzes exposure in a regression in which the orthogonalized local and global market portfolios are included as control variables. A third test examines exposure in a regression that controls for the global instead of the local market portfolio. This test is referred to as the "Currency Betas" test.

Recent studies in the literature, e.g. Jorion (1990), Bartov and Bodnar (1994), and He and $\mathrm{Ng}$ (1998), hardly find any evidence of significant exchange rate exposure in a variety of samples. Bartov and Bodnar argue that these results may be partly due to sample selection criteria. We expect to find considerable exposure to exchange rates in our sample of crosslisted companies, as a high percentage of their sales are realized abroad.

Table 8.4 shows the percentage of interlisted firms with significant exposure to exchange rates. Column 1 depicts the rejection percentages of the Exposure test per country. This test is rejected for 25 percent of the cross-listed companies. This result is comparable to e.g. He and $\mathrm{Ng}$ (1998), who find significant exposure for 25 percent in a sample of Japanese firms. The rejection percentages of the Total Exposure test as depicted in column 2 of table 8.4 are importantly higher than those of the Exposure test. Almost 82 percent of the crosslisted stocks exhibit significant exposure to currency fluctuations. Similar figures are obtained with the Currency Betas test. Hence, we find strong evidence for our hypothesis that the value of stocks with overseas listings is meaningfully affected by fluctuations in exchange rates.

\subsection{Empirical Results of Benchmark Sample: Domestic Stocks}

This section analyzes the empirical results for our benchmark sample of 2,957 domestic companies. In section 8.5.1 we discuss the pricing error results. Our pricing error results are further explored with a variance decomposition in section 8.5.2. Section 8.5.3 examines to what extent the value of domestic firms is affected by exchange rate fluctuations.

\footnotetext{
34 Recent papers in the literature, e.g. Jorion (1990), Bartov and Bodnar (1994), and He and $\mathrm{Ng}$ (1998), base their tests on an analogous regression, but use a trade-weighted exchange rate index.
} 


\subsubsection{Pricing Error}

Table 8.5 depicts the results of both pricing error tests for domestic stocks. The first column of this table depicts the percentage of purely domestic firms for which the hypothesis of no pricing error is rejected at the 95 percent confidence level. On average, the Pricing Error test rejects for 4.40 percent of the firms. This number varies only slightly across countries. Column 4 of table 8.5 shows the rejection percentages per country of the Global Beta test. This test evaluates the significance of the difference between the direct and the indirect estimate of a firm's global beta. We find a significant beta error for 2.44 percent of the domestic corporations. Table 8.5 also presents test results for subperiods, which are remarkably similar to the results for the whole sample period.

Table 8.5

Pricing Error Test Results for Domestic Companies

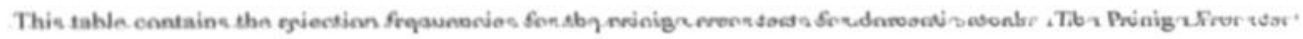
examines whether a pricing error exists between the domestic CAPM and the multifactor ICAPM. The Global Beta test is similar to the Pricing Error test but focuses on the beta error of the domestic CAPM versus the multifactor ICAPM. Both test statistics are Chi-squared distributed and robust to heteroskedasticity. Rejection frequencies are defined as the percentage of firms in a country for which the null-hypothesis is rejected at the 5 percent significance level. The row labeled "Average" depicts a weighted average of the percentages of firms in each individual country for which the null-hypothesis is rejected. The weights of the rejection frequencies are the number of firms in each country as depicted in table 8.1. The sample period is 1980:02-1999:06. This table also shows the rejection frequencies for both tests for two subsamples. The first subsample consists of the period 1980:02-1989:12. The second subsample is 1990:01-1999:06.

Country

Pricing Error Test

percentage rejections
Global Beta Test

percentage rejections

\begin{tabular}{lcccccc}
\hline & $1980-1999$ & $1980-1989$ & $1990-1999$ & $1980-1999$ & $1980-1989$ & $1990-1999$ \\
\hline Australia & 4.76 & 3.19 & 2.72 & 1.19 & 3.19 & 8.15 \\
Canada & 3.68 & 3.47 & 3.80 & 6.84 & 5.94 & 8.54 \\
France & 6.67 & 1.85 & 2.09 & 5.71 & 4.63 & 9.41 \\
Germany & 5.84 & 3.82 & 2.45 & 1.95 & 4.46 & 2.94 \\
Japan & 3.28 & 2.47 & 3.32 & 2.14 & 7.40 & 7.06 \\
Netherlands & 8.25 & 1.00 & 2.24 & 5.16 & 6.00 & 7.46 \\
Switzerland & 2.61 & 7.38 & 3.60 & 0.87 & 9.02 & 2.00 \\
United Kingdom & 4.16 & 4.18 & 2.85 & 1.45 & 4.00 & 4.89 \\
United States & 5.46 & 3.77 & 4.74 & 2.73 & 4.56 & 5.45 \\
& & & & & & \\
Average & 4.40 & 3.60 & 3.21 & 2.44 & 5.21 & 6.16 \\
\hline
\end{tabular}


Summary statistics of the first element of the pricing error for domestic firms are presented in table 8.6. The average beta error is depicted in the first column and is close to zero, as expected. The second column shows that the absolute beta error is approximately 0.1 for most countries, varying from 0.077 for the U.S. to 0.123 for France. The implied cost of capital differential is equal to 57 basis points for the U.S., 75 basis points for Germany and Japan, 70 basis points for the U.K., and 106 basis points for Switzerland. On average, the estimated cost of capital differential for domestic stocks is very similar to the differential for interlisted stocks. In the next section we use a variance decomposition metric to further analyze these findings.

Table 8.6

Summary Statistics of the Beta Error for Domestic Companies

This table shows summary statistics of the beta error for domestic firms. The beta error is computed as the difference between the "indirect" beta (the global beta of the local market $d_{L /}$ multiplied by the CAPM beta $b_{i}$ ) and the "direct" beta (the multifactor ICAPM beta $d_{i l}$ ) of a firm. The columns present the mean, the mean of the absolute value, the standard deviation, the minimum, and the maximum value of the beta errors, respectively. The sample period is 1980:02-1999:06.

\begin{tabular}{lccccc}
\hline Country & Mean & Abs & StDv & Min & Max \\
\hline Australia & -0.010 & 0.122 & 0.169 & -0.693 & 0.487 \\
Canada & -0.042 & 0.118 & 0.151 & -0.489 & 0.616 \\
France & -0.033 & 0.123 & 0.153 & -0.497 & 0.384 \\
Germany & -0.012 & 0.079 & 0.103 & -0.310 & 0.306 \\
Japan & 0.027 & 0.114 & 0.150 & -0.495 & 0.853 \\
Netherlands & -0.058 & 0.101 & 0.118 & -0.441 & 0.276 \\
Switzerland & -0.077 & 0.104 & 0.112 & -0.426 & 0.158 \\
United Kingdom & -0.003 & 0.091 & 0.122 & -0.642 & 0.577 \\
United States & -0.039 & 0.077 & 0.107 & -0.478 & 0.457 \\
\hline
\end{tabular}

\subsubsection{Variance Decomposition}

This section examines the marginal contribution of the global factors to the explanatory power of the CAPM in a variance decomposition analysis. Figure 8.2 presents the average variance decomposition of the individual stocks in each country. The marginal contribution of the global market index and the exchange rate factors is trivial. This further underlines our finding that the domestic CAPM and the multifactor ICAPM very infrequently lead to different estimates of the cost of capital. 
Figure 8.2

\section{Average Pricing Error Decomposition for Domestic Companies}

This figure presents a variance decomposition analysis for domestic companies. The general idea behind this decomposition is explained in figure 8.1. The variance decomposition for a country is equal to the weighted average of all decompositions of individual firms in that country with $\left(1 / \sigma_{i}^{2}\right) /\left(\Sigma 1 / \sigma_{1}^{2}\right)$ as weights. The vertical axis depicts the explanatory power of each of the factors in terms of the percentage of the total variance of a stock which can be explained by that factor. The sample period is 1980:02-1999:06.

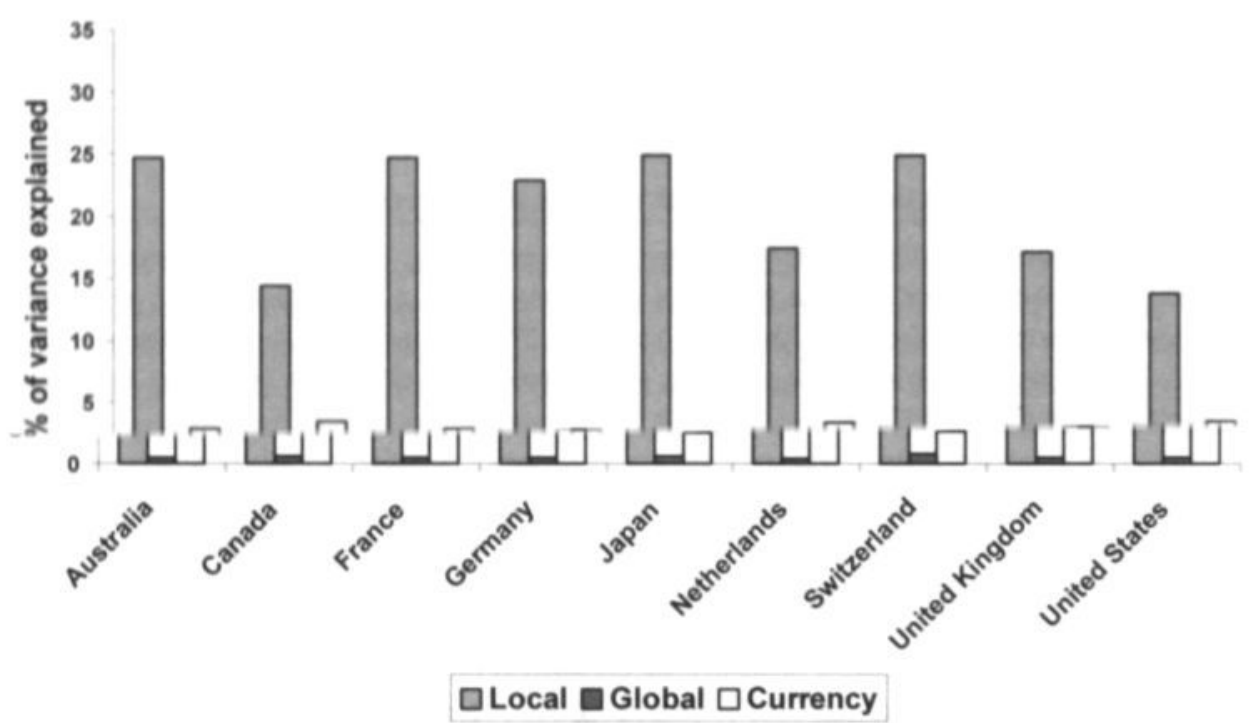

Figure 8.2 indicates that domestic firms are exposed to global factors in a similar way as the average firm in a country. The local market index serves as a sufficient statistic for the sensitivity of domestic corporations to global factors. Like companies with foreign listings, domestic stock returns thus show important country factors. Section 8.5.3 demonstrates that even if the sensitivity to global factors varies considerably over the stocks in a country, this does not imply frequent rejections of the null-hypothesis that the pricing error is equal to zero.

\subsubsection{Exchange Rate Exposure}

Rejection frequencies of three currency exposure tests are presented in table 8.7. The first column depicts the number of domestic stocks for which the hypothesis of no exposure is rejected at the 95 percent confidence level. The Exposure test is rejected for approximately 13 percent of all firms in our benchmark sample. The results in section 8.5.2, however, suggests that part of the exchange rate exposure may be absorbed by the local market index. The Total Exposure test was designed for taking account of this effect. Column 2 indeed shows rejection 
percentages up to 69 percent (for Australia), amounting to 41 percent on average. The results of the Currency Betas test are comparable.

The fact that we find greater exposure for interlisted than for domestic firms suggests that even if there are considerable differences between companies within a country with respect to the sensitivity to global factors, rejection frequencies of the pricing errors can still be small. This result can be illustrated by comparing the rejection frequencies of the Exposure and the Total Exposure tests. The latter tests shows frequencies that are much higher for cross-listed than for domestic firms. This difference is smaller, however, for the Exposure test, in which the local market index is not orthogonalized. Therefore, the percentage of interlisted companies for which the pricing error is statistically significant is only slightly higher than the percentage of domestic corporations with a significant pricing error.

Table 8.7

Exchange Rate Exposure Test Results for Domestic Companies

This table presents rejection frequencies for the exchange rate exposure tests for domestic companies. The Exposure test examines exchange rate exposure of individual stocks when controlled for the local market index. The Total Exposure test tests for exchange rate exposure when controlled for fluctuations in the local and global market indices that are orthogonal to all exchange rates. The Currency Betas test tests for exposure of individual firms when the global market return is included in the regression. All test statistics are Chi-squared distributed and robust to heteroskedasticity. Rejection frequencies are defined as the percentage of firms in a country for which the null-hypothesis is rejected at the 5 percent significance level. The row labeled "Average" depicts a weighted average of the percentages of firms in each individual country for which the null-hypothesis is rejected. The weights of the rejection frequencies are the number of firms in each country as depicted in the second column of table 8.1. The sample period is 1980:02-1999:06.

\begin{tabular}{lccc}
\hline Country & $\begin{array}{c}\text { Exposure Test } \\
\text { percentage rejections }\end{array}$ & $\begin{array}{c}\text { Total Exposure Test } \\
\text { percentage rejections }\end{array}$ & $\begin{array}{c}\text { Currency Betas Test } \\
\text { percentage rejections }\end{array}$ \\
\hline Australia & 9.52 & 69.05 & 67.86 \\
Canada & 11.58 & 41.05 & 46.32 \\
France & 15.24 & 44.76 & 43.81 \\
Germany & 18.18 & 42.86 & 39.61 \\
Japan & 12.82 & 46.87 & 71.37 \\
Netherlands & 17.53 & 45.36 & 20.62 \\
Switzerland & 7.83 & 53.04 & 32.17 \\
United Kingdom & 11.32 & 35.69 & 26.50 \\
United States & 14.08 & 35.71 & 36.97 \\
& 12.65 & & 42.61 \\
Average & & 41.33 & \\
\hline
\end{tabular}




\subsection{Conclusions}

As companies become more and more internationally oriented, international listings are an increasingly important part of a firm's long-term strategic policy. Two main issues can be distinguished in the literature on stocks with overseas listings. The first strand of the literature focuses on the question whether the stock market performance, the liquidity, and the cost of capital of a company change as a consequence of listing abroad. The second strand examines the motivations and features of companies that obtain an overseas listing.

We focus on the question whether international and domestic asset pricing models lead to different estimates of the cost of capital for interlisted companies. We examine the socalled pricing error, which is linearly related to the computed cost of capital differential. In the previous chapter we derived statistical tests for the pricing error between the domestic CAPM and the multifactor ICAPM of Solnik (1983) and Sercu (1980) including both the global market portfolio and exchange rate risk premia. We analyzed a sample of almost 3,300 firms from nine countries over the period 1980-1999 and rejected the null-hypothesis of no pricing error for only a very small number of stocks.

In this chapter we separate our sample of monthly data into 336 stocks with foreign listings and 2,957 domestic stocks. Our hypothesis is that the pricing error is considerable for interlisted firms, as they are relatively internationally oriented. We find a significant cost of capital differential for only 12 percent of the cross-listed corporations. The cost of capital differential between the domestic CAPM and the ICAPM amounts to 50 basis points for the U.S., 75 basis points for the U.K. and 100 basis points for France. Our analysis provides little evidence in favor of our hypothesis that companies with an overseas listing exhibit a relatively large pricing error. Using a variance decomposition analysis we demonstrate that our pricing error results are probably related to the strong country factors in the data. We tentatively argue that the strong country-specific factors in individual stock returns are related to a lack of real capital market integration, due to both cyclical, structural, and institutional country-specific factors.

The second issue of this chapter is exchange rate exposure. Several recent studies in the literature have found unexpectedly small effects of exchange rate fluctuations on the value of a company in a variety of samples. We expect to find relatively large currency exposure, as corporations with foreign listings exhibit a high level of sales abroad. We find that exchange rate exposure is significant for more than 80 percent of the stocks in our sample.

We compare our results for cross-listed stocks with our benchmark sample of domestic stocks with no foreign listings. Approximately 4.4 percent of these stocks exhibit a significant pricing error and around 40 percent shows significant exposure to exchange rates. 


\section{Chapter 9}

\section{Summary}

The writing of this thesis was motivated by the continuing globalization of international capital markets in recent years. Nowadays, investors in Europe and the U.S. can buy financial assets of companies in a large number of foreign countries. Cross-border transactions in financial securities have grown spectacularly. In addition, companies increasingly raise capital in financial markets abroad. As a result of these developments, financial exchanges world-wide have engaged in more intense competition for both listings and order flow.

In this thesis we deal with two major issues related to the globalization of capital markets, both of which have attracted a lot of attention in the recent finance literature. Part I of this thesis examines the impact of the institutional design of financial exchanges on market performance. As contended in chapter 2, market design has become a central topic in the market microstructure literature, which may in part be related to the fact that several stock exchanges have recently modified their trading mechanism. In chapters 3 and 4 we investigate the effect of quote and trade disclosure, respectively inter-dealer trading on the price efficiency and the trading costs in an experimental multiple-dealer asset market. We argue that an experimental methodology allows for a thorough assessment of a precisely specified change in the trading system without restricting the strategic behavior of the market participants. Multiple-dealer markets, such as NASDAQ and the spot foreign exchange market, have been relatively disregarded in the recent literature.

Part II of this thesis analyzes several puzzles in international finance. Despite the relatively high degree of capital market integration among developed economies, numerous recent studies have reported a remarkably weak relation between international factors and 
domestic financial markets. Chapter 5 reviews the recent literature on a number of puzzles in international financial markets. In chapter 6 we take an alternative look at purchasing power parity in a panel framework. In chapters 7 and 8 we introduce formal statistical tests for the difference in the estimate of a firm's cost of equity capital implied by domestic and international versions of the capital asset pricing model. We evaluate the significance of this so-called pricing error for a large sample of corporations. Furthermore, we propose an alternative testing methodology for foreign exchange exposure. We examine the exposure of the firms in our sample to fluctuations in several major exchange rates.

Chapter 3 analyzes the influence of market transparency on the trading process in an experimental multiple-dealer asset market. We distinguish between pre-trade transparency, which concerns the disclosure of quotes, and post-trade transparency, which involves trade publication. We create four different transparency regimes by varying the level of both pretrade and post-trade transparency across the trading rounds. Before the start of each trading round, one of the five competing market makers receives information about the underlying value of the asset. Our hypothesis is that price discovery is faster in more transparent markets, as it may be harder to hide private information when quotes and trades are publicly disclosed. We indeed find that post-trade transparency improves price efficiency. However, quote disclosure hampers price discovery, as market makers use less aggressive price adjustments and insiders find it easier to hide when all quotes in the market are observed. Consistent with theoretical predictions, we find that trade disclosure leads to wider bid-ask spreads, as market makers have an incentive to compete for informative order flow when post-trade transparency is low. On the other hand, pre-trade transparency reduces bid-ask spreads.

In chapter 4 we study the effect of inter-dealer trading in a multiple-dealer framework. Four market makers compete for order flow in two markets with a different institutional design. In one market, market makers only trade with computerized informed and liquidity traders. In the other market, market makers are also allowed to initiate trades with other dealers in a parallel inter-dealer market. As post-trade transparency is low, asymmetric information is a major motivation for inter-dealer trading in our experiments. Risk sharing is relatively unimportant. This is confirmed by the finding that the dispersion of dealer profits is much larger in the presence of an inter-dealer market. Several recent studies, in which risk sharing is the prime motive for inter-dealer trading, find that inter-dealer trading leads to smaller execution costs for external customers. Our investigation shows that spreads are importantly wider when inter-dealer trading is allowed in an asymmetric information setting. The adverse-selection component of the bid-ask spread is larger when inter-dealer trades are possible. Moreover, market makers have fewer incentives to quote competitive prices, as they focus on exploiting information asymmetries. We argue that information asymmetries should receive more attention in discussions about inter-dealer trading. More research is needed in order to assess the relative importance of the risk sharing and private information motives in actual financial markets. 
In chapter 6 we find evidence for relative purchasing power parity (PPP) for a large panel of currencies at horizons of one to four years. We build on recent panel studies of PPP by making our panel estimation results invariant to the choice of the numeraire currency. This allows us to cope with the cross-sectional dependence of real exchange rates against a common numeraire that adversely affects the size and the power of traditional panel tests for PPP. A further contribution of our analysis is that we introduce individual country effects in our methodology in order to facilitate evaluation of the PPP hypothesis for each currency pair in the sample separately. We find that relative PPP accurately describes quarterly movements in exchange rates at horizons longer than one year. Our evidence in favor of PPP is strong for the currency bloc around Germany and relatively weak for the U.S.-Canada currency bloc. Further research should shed more light on the nature of the PPP relation for the Japanese yen, for which a trending variable seems to be omitted from our regressions. We reckon that future studies should focus on the issue of why PPP holds within and not between various currency blocs.

Chapter 7 analyzes whether domestic and international asset pricing models lead to a different estimate of a firm's cost of capital. While theory suggest the use of an international capital asset pricing model (CAPM) in integrated capital markets, the domestic CAPM does not necessarily imply an incorrect estimate of the cost of capital. We evaluate the pricing error between the single factor domestic version and the multifactor international version of the capital asset pricing model including exchange rate factors for a large sample of firms from developed economies. We find that the pricing error is small, both in statistical and in economic terms. Our pricing error tests reject the null-hypothesis of no pricing error for only approximately 5 percent of the companies in our sample. The implied cost of capital differential amounts to around 50 basis points on average for the U.S., roughly 75 basis points for Germany and Japan, and about 100 basis points for France. Our examination suggests that these results may be related to the strong country factors we detect in the data. An explanation for these strong country factors is a lack of real integration between international capital markets. Several recent studies suggest that cyclical, structural, and institutional countryspecific factors closely tie together the fortunes of all firms in a country. Hence, corporations within a country by and large share a common exposure to global risk factors. This joint exposure is captured in the international pricing of the domestic stock market portfolio. More research is necessary in order to pinpoint the economic rationale for the strong country factors. It would also be interesting to find out whether country-specific economic shocks become less important over time. The second puzzle we address in chapter 7 is the foreign exchange exposure puzzle. Tests for exchange rate exposure turn out to be very similar to pricing error tests. Our findings suggest that only around 14 percent of the firms in our sample exhibit significant exposure to exchange rates. In traditional exposure tests, however, the domestic market factor is incorporated as a control variable. We argue that this could obscure the test results, as exposure to exchange rate fluctuations is at least to some extent absorbed 
by the domestic market index. Correcting for this effect, we detect significant exposure for 45 percent of the corporations in our sample.

Chapter 8 examines the pricing error for the companies in our sample with international equity listings. It is well documented that firms with equity listings abroad are typically large multinationals characterized by a strong international orientation. The exposure of these companies probably deviates from the other firms in the same country. Therefore, our hypothesis is that the systematic risk of cross-listed stocks implied by the domestic CAPM is significantly different from the systematic risk implied by the multifactor ICAPM. We find that over 80 percent of the interlisted corporations in our sample are significantly exposed to exchange rates. The pricing error is significant for only 12 percent of the firms with foreign equity listings, however. We show that the variation in the stock returns of interlisted firms can be explained by country factors as well. Further research is called for in order to identify firm characteristics that are related to the pricing error. Suggestions for firm characteristics are industry and the percentage of sales realized abroad.

We deem that five major lessons can be drawn from the research presented in this thesis. First, in a multiple-dealer market with asymmetrically informed market makers, pretrade and post-trade transparency involve opposite trade-offs between efficiency and liquidity. Second, inter-dealer trading motivated by information asymmetries induces wider bid-ask spreads and thus higher execution costs for external customers in a multiple-dealer framework. Third, for horizons longer than one year, purchasing power parity constitutes a relatively good description of exchange rates within the currency bloc around Germany, and a relatively poor description of the exchange rate between the Canadian dollar and the U.S. dollar. Fourth, the cost of equity capital implied by the domestic capital asset pricing model is significantly different from the cost of equity capital computed by the multifactor international CAPM for a very small number of firms. This appears to be related to the strong country factors present in international stock returns. Fifth, alternative testing methodologies for foreign exchange exposure detect a much larger number of firms significantly exposed to fluctuations in exchange rates than commonly found with traditional tests. 


\section{References}

Abuaf, N., and P. Jorion, 1990, "Purchasing Power Parity in the Long Run," Journal of Finance, 45, 157-174.

Adler, M., and B. Dumas, 1983, "International Portfolio Choice and Corporation Finance: A Synthesis,” Journal of Finance, 38, 925-984.

Adler, M., and B. Dumas, 1984, "Exposure to Currency Risk: Definition and Measurement," Financial Management, 13, 41-50.

Admati, A., and P. Pfleiderer, 1988, "A Theory of Intraday Patterns: Volume and Price Variability,” Review of Financial Studies, 1, 3-40.

Amihud, Y., 1994, "Evidence on Exchange Rates and Valuation of Equity Shares," in Y. Amihud, and R. M. Levich (eds.), Exchange Rates and Corporate Performance, Irwin, New York.

Baltagi, B. H., 1995, Econometric Analysis of Panel Data, John Wiley \& Sons, New York.

Bartov, E., and G. M. Bodnar, 1994, "Firm Valuation, Earnings Expectations, and the Exchange-Rate Exposure Effect," Journal of Finance, 49, 1755-1785.

Benveniste, L., A. Marcus, and W. Wilhelm, 1992, "What's Special about the Specialist?," Journal of Financial Economics, 32, 61-86.

Biddle, G., and S. Saudagaran, 1989, "The Effects of Financial Disclosure Levels on Firms' Choices among Alternative Foreign Stock Exchanges,” Journal of International Financial Management and Accounting, 1, 55-87.

Bloomfield, R., and M. O'Hara, 1999, "Market Transparency: Who Wins and Who Loses?," Review of Financial Studies, 12, 5-35.

Bodnar, G. M., and W. M. Gentry, 1993, "Exchange Rate Exposure and Industry Characteristics: Evidence from Canada, Japan, and the USA," Journal of International Money and Finance, 12, 29-45. 
Bohn, H., and L. L. Tesar, 1996, "U.S. Equity Investment in Foreign Markets: Portfolio Rebalancing or Return Chasing?," American Economic Review, 86, 77-81.

Campbell, J. Y., A. W. Lo, and A. C. McKinlay, 1997, The Econometrics of Financial Markets, Princeton University Press, Princeton, New Jersey.

Chinn, M., and L. Johnston, 1996, "Real Exchange Rate Levels, Productivity and Demand Shocks: Evidence from a Panel of 14 Countries," NBER Working Paper, 5709.

Cooper, I., and E. Kaplanis, 1994, "Home Bias in Equity Portfolios, Inflation Hedging, and International Capital Market Equilibrium," Review of Financial Studies, 7, 45-60.

Copeland, T., and D. Friedman, 1991, "Partial Revelation of Information in Experimental Asset Markets," Journal of Finance, 46, 265-295.

Copeland, T., and D. Galai, 1983, "Information Effects and the Bid-Ask Spread," Journal of Finance, 38, 1457-1469.

de Jong, E., and J. E. Ligterink, 1992, "Valutaire Invloeden op Veertien Nederlandse Bedrijven," Tijdschrift voor Bedrijfsadministratie, 96, 246-254.

de Jong, F., and P. Dassen, 1997, "Wie is er Bang voor de Dollarkoers?," Economisch Statistische Berichten, 4109, 454-455.

de Jong, F., T. Nijman, and A. A. Röell, 1995, "A Comparison of the Cost of Trading French Shares on the Paris Bourse and on Seaq International," European Economic Review, 39, 1277-1301.

De Ménil, G., 1999, "Real Capital Market Integration in the EU: How Far Has it Gone? What Will the Effect of the Euro Be? (with discussion)," Economic Policy, 28, 167-204.

De Santis, G., and B. Gérard, 1998, "How Big is the Premium for Currency Risk?," Journal of Financial Economics, 49, 375-412.

Doukas, J., and L. N. Switzer, 2000, "Common Stock Returns and International Listing Announcements: Conditional Tests of the Mild Segmentation Hypothesis," Journal of Banking and Finance, 24, 471-502.

Dumas, B., and B. Solnik, 1995, "The World Price of Exchange Rate Risk," Journal of Finance, 50, 445-479.

Easley, D., and M. O'Hara, 1992, "Time and the Process of Security Price Adjustment," Journal of Finance, 47, 577-606.

Edison, H. J., 1987, "Purchasing Power Parity in the Long Run: A Test of the Dollar/Pound Exchange Rate (1890-1978)," Journal of Money, Credit, and Banking, 4, 361-372.

Edison, H. J., J. E. Gagnon, and W. R. Melick, 1997, "Understanding the Empirical Literature on Purchasing Power Parity: The Post Bretton Woods Era," Journal of International Money and Finance, 16, 1-17.

Engel, C., 1996, "The Forward Discount Anomaly and the Risk Premium: A Survey of Recent Evidence," Journal of Empirical Finance, 3, 123-191. 
Errunza, V., K. Hogan, and M.-W. Hung, 1999, "Can the Gains from International Diversification Be Achieved Without Trading Abroad?," Journal of Finance, 54, 2075-2107.

Euronext press release, 2000, “Amsterdam, Brussels and Paris Merge to Create Leading European Exchange: Euronext," March 20.

Fama, E. F., and K. R. French, 1993, "Common Risk Factors in the Returns on Stocks and Bonds," Journal of Financial Economics, 33, 3-56.

Fama, E. F., and K. R. French, 1997, "Industry Costs of Equity," Journal of Financial Economics, 43, 153-193.

Fama, E. F., and K. R. French, 1998, "Value versus Growth: The International Evidence," Journal of Finance, 53, 1975-1999.

Ferson, W. E., and C. R. Harvey, 1993, "The Risk and Predictability of International Equity Returns," Review of Financial Studies, 6, 527-566.

Het Financieele Dagblad, 1998, "Bedrijfsomzet AEX-fondsen voor $80 \%$ uit Buitenland," July 11.

Flood, M. D., R. Huisman, C. G. Koedijk, and R. K. Lyons, 1999, "Search Costs: The Neglected Spread Component," working paper, Office of Thrift Supervision.

Flood, M. D., R. Huisman, C. G. Koedijk, and R. J. Mahieu, 1999, "Quote Disclosure and Price Discovery in Multiple Dealer Financial Markets," Review of Financial Studies, $12,37-59$.

Flood, M. D., R. Huisman, C. G. Koedijk, and A. A. Röell, 1999, "Post-Trade Transparency in Multiple Dealer Financial Markets," working paper, Erasmus University Rotterdam.

Flood, M. D., C. G. Koedijk, M. A. van Dijk, and I. W. van Leeuwen, 2001, "Dividing the Pie: Asymmetrically Informed Dealers and Market Transparency," working paper, Maastricht University.

Foerster, S. R., and G. A. Karolyi, 1993, "International Listings of Stocks: The Case of Canada and the U.S.," Journal of International Business Studies, 24, 763-784.

Foerster, S. R., and G. A. Karolyi, 1998, "The Effects of Market Segmentation and Investor Recognition on Asset Prices: Evidence from Foreign Stock Listings in the U.S.," working paper, Ohio State University.

Forsythe, R., T. R. Palfrey, and C. R. Plott, 1982, "Asset Valuation in an Experimental Market," Econometrica, 50, 537-582.

Foster, F. D., and S. Viswanathan, 1990, "A Theory of the Intraday Variations in Volume, Variance and Trading Costs in Securities Markets," Review of Financial Studies, 3, 593-624.

Frankel, J. A., and A. K. Rose, 1996, "A Panel Project on Purchasing Power Parity: Mean Reversion within and between Countries," Journal of International Economics, 40, 209-224. 
Franks, J. and S. Schaefer, 1995, "Equity Market Transparency on the London Stock Exchange," Journal of Applied Corporate Finance, 8, 70-77.

Friedman, D., and S. Sunder, 1994, Experimental Methods: A Primer for Economists, Cambridge University Press, Cambridge.

Froot, K. A., and K. Rogoff, 1995, "Perspectives on PPP and Long-Run Real Exchange Rates," in G. Grossman, and K. Rogoff (eds.), Handbook of International Economics, volume III, North-Holland, Amsterdam, 1647-1688.

Fuerst, O., 1998, “A Theoretical Analysis of the Investor Protection Regulations Argument for Global Listing of Stocks," working paper, Yale University.

Garfinkel, J., and M. Nimalendran, 1998, "Market Structure and Trader Anonymity: An Analysis of Insider Trading," working paper, Securities and Exchange Commission.

Gehrig, T., 1993, “An Information Based Explanation of the Domestic Bias in International Equity Investment," Scandinavian Journal of Economics, 95, 97-109.

Gemmill, G., 1996, "Transparency and Liquidity: A Study of Block Trades on the London Stock Exchange under Different Publication Rules," Journal of Finance, 51, 1765-1790.

Glosten, L. R., 1999, "Introductory Comments: Bloomfield and O'Hara, and Flood, Huisman, Koedijk, and Mahieu," Review of Financial Studies, 12, 1-3.

Glosten, L. R., and P. R. Milgrom, 1985, "Bid, Ask and Transaction Prices in a Specialist Market with Heterogeneously Informed Traders," Journal of Financial Economics, 14, $71-100$.

Gould, J. F., and A. W. Kleidon, 1994, "Market Maker Activity on NASDAQ: Implications for Trading Volume," Stanford Journal of Law, Business \& Finance, 1, 1-17.

Grauer, F. L. A., R. H. Litzenberger, and R. E. Stehle, 1976, "Sharing Rules and Equilibrium in an International Capital Market under Uncertainty," Journal of Financial Economics, 3, 233-256.

Griffin, J. M., 2002, “Are the Fama and French Factors Global or Country Specific?," Review of Financial Studies, 15, 783-803.

Griffin, J. M., and G. A. Karolyi, 1998, “Another Look at the Role of the Industrial Structure of Markets for International Diversification Strategies," Journal of Financial Economics, 50, 351-373.

Harvey, C. R., 1991, "The World Price of Covariance Risk," Journal of Finance, 46, 111-157.

He, J., and L. K. Ng, 1998, "The Foreign Exchange Exposure of Japanese Multinational Corporations," Journal of Finance, 53, 733-753.

Heston, L. H., and K. G. Rouwenhorst, 1994, "Does Industrial Structure Explain the Benefits of International Diversification?," Journal of Financial Economics, 36, 3-27.

Ho, T. S. Y., and H. R. Stoll, 1981, "Optimal Dealer Pricing under Transactions and Return Uncertainty," Journal of Financial Economics, 9, 47-73. 
Ho, T. S. Y., and H. R. Stoll, 1983, "The Dynamics of Dealer Markets under Competition," Journal of Finance, 38, $1053-1074$.

Huang, R. D., and H. R. Stoll, 1996, "Dealer versus Auction Markets: A Paired Comparison of Execution Costs on NASDAQ and the NYSE," Journal of Financial Economics, 41, 313-357.

Huisman, R., and C. G. Koedijk, 1998, "Financial Market Competition: The Effects of Transparency," De Economist, 146, 463-473.

Huisman, R., C. G. Koedijk, C. J. M. Kool, and F. G. J. A. Nissen, 1998, "Extreme Support for Uncovered Interest Parity," Journal of International Money and Finance, 17, 211-228.

International Monetary Fund, 1998, International Capital Markets: Developments, Prospects, and Key Policy Issues, September.

James, D., and R. M. Isaac, 2000, “Asset Markets: How They are Affected by Tournament Incentives for Individuals," American Economic Review, 90, 995-1004.

Jorion, P., 1990, "The Exchange-Rate Exposure of U.S. Multinationals," Journal of Business, $63,331-345$.

Jorion, P., and E. Schwartz, 1986, "Integration vs. Segmentation in the Canadian Stock Market,” Journal of Finance 41, 603-616.

Jorion, P., and R. Sweeney, 1996, "Mean Reversion in Real Exchange Rates: Evidence and Implications for Forecasting," Journal of International Money and Finance, 15, 535-550.

Karolyi, G. A., 1998, "Why Do Companies List Shares Abroad?: A Survey of the Evidence and Its Managerial Implications," Financial Markets, Institutions \& Instruments, 7(1).

Keck, T., E. Levengood, and A. Longfield, 1998, "Using Discounted Cash Flow Analysis in an International Setting: A Survey of Issues in Modeling the Cost of Capital," Journal of Applied Corporate Finance, 3, 82-99.

Koedijk, C. G., C. J. M. Kool, P. C. Schotman, and M. A. van Dijk, 2001, "The Cost of Capital in International Financial Markets: Local or Global?," CEPR Discussion Paper, 3062, forthcoming (2002) Journal of International Money and Finance.

Koedijk, C. G., and J. Kremers, 1996, "Market Opening, Regulation, and Growth (with discussion)," Economic Policy, 23, 443-468.

Koedijk, C. G., and P. C. Schotman, 1990, "How to Beat the Random Walk: An Empirical Model of Real Exchange Rates,” Journal of International Economics, 29, 311-332.

Koedijk, C. G., P. C. Schotman, and M. A. van Dijk, 1998, "The Reemergence of PPP in the 1990s," Journal of International Money and Finance, 17, 51-61.

Koedijk, C. G., and M. A. van Dijk, 2002, "The Cost of Capital of Cross-Listed Firms," working paper, Erasmus University Rotterdam.

Koedijk, C. G., M. A. van Dijk, and I. W. van Leeuwen, 2001, "Asymmetric Information and Inter-Dealer Trading,” working paper, Maastricht University. 
Kool, C. J. M., and M. Schweitzer, 1997, "Dollar en Aandelenkoersen," Economisch Statistische Berichten, 4104, 348-351.

Kyle, A. S., 1985, "Continuous Auctions and Insider Trading," Econometrica, 53, 1315-1335.

Lamoureux, C. G., and C. R. Schnitzlein, 1997, "Herd Through the Grapevine: Winner's Curse in a Fragmented Asset Market," working paper, Washington University/University of Arizona.

Lee, C. M., 1993, "Market Integration and Price Execution for NYSE Listed Securities," Journal of Finance, 48, 1009-1038.

Leland, H. E., 1992, “Insider Trading: Should It Be Prohibited?," Journal of Political Economy, 100, 859-887.

Lewis, K. K., 1995, "Puzzles in International Financial Markets," in G. Grossman, and K. Rogoff (eds.), Handbook of International Economics, volume III, North-Holland, Amsterdam, 1913-1971.

Lewis, K. K., 1999, "Trying to Explain the Home Bias in Equities and Consumption," Journal of Economic Literature, 37, 571-608.

London Stock Exchange, 1999, Markets Analysis: Trading Market Update, November.

Lothian, J. R., 1998, "Some New Stylized Facts of Floating Exchange Rates," Journal of International Money and Finance, 17, 29-39.

Lothian, J. R., and M. P. Taylor, 1996, "Real Exchange Rate Behavior: The Recent Float from the Perspective of the Past Two Centuries," Journal of Political Economy, 104, 488-509.

Lyons, R. K., 1996a, "Foreign Exchange Volume: Sound and Fury Signifying Nothing?," in J. Frankel, G. Galli, and A. Giovannini (eds.), The Microstructure of Foreign Exchange Markets, University of Chicago Press, Chicago, Illinois, 183-201.

Lyons, R. K., 1996b, “Optimal Transparency in a Dealership Market with an Application to Foreign Currency Exchange," Journal of Financial Intermediation, 5, 225-254.

Madhavan, A., 1992, "Trading Mechanisms in Securities Markets," Journal of Finance, 47, $607-641$.

Madhavan, A., 1995, "Consolidation, Fragmentation, and the Disclosure of Trading Information," Review of Financial Studies, 8, 579-603.

Madhavan, A., and M. Cheng, 1997, "In Search of Liquidity: Block Trades in the Upstairs and Downstairs Markets," Review of Financial Studies, 10, 175-203.

Mahieu, R. J., and P. C. Schotman, 1994, "Neglected Common Factors in Exchange Rate Volatility," Journal of Empirical Finance, 1, 279-311.

Martinez-Solano, P., 1998, "Foreign Exchange Exposure on the Spanish Stock Market: Sources of Risk and Hedging," working paper, Lancaster University.

Meredith, G., and M. Chinn, 2000, "Testing Uncovered Interest Parity at Short and Long Horizons," working paper, University of California at Santa Cruz. 
Naik, N., A. Neuberger, and S. Viswanathan, 1999, "Trade Disclosure Regulation in Markets with Negotiated Trades," Review of Financial Studies, 12, 873-900.

Nydahl, S., 1999, "Exchange Rate Exposure, Foreign Involvement and Currency Hedging of Firms: Swedish Evidence," European Financial Management, 5, 241-257.

Obstfeld, M., and K. Rogoff, 2000, "The Six Major Puzzles in International Macroeconomics: Is There a Common Cause?," NBER Working Paper, 7777.

O'Connell, P. G. J., 1998, "The Overvaluation of Purchasing Power Parity," Journal of International Economics, 44, 1-19.

Office of Fair Trading, 1994, "Trade Publication Rules and the London Stock Exchange," $A$ report to the Chancellor of the Exchequer by the Director General of Fair Trading under the Financial Services Act 1986, United Kingdom, November.

O'Hara, M., 1995, Market Microstructure Theory, Blackwell, Malden, Massachusetts.

Pagano, M., and A. A. Rőell, 1996, "Transparency and Liquidity: A Comparison of Auction and Dealer Markets with Informed Trading," Journal of Finance, 51, 579-611.

Pagano, M., A. A. Röell, and J. Zechner, 2002, "The Geography of Equity Listing: Why Do Companies List Abroad?," Journal of Finance, forthcoming.

Papell, D., and H. Theodoridis, 1998, "Increasing Evidence of Purchasing Power Parity over the Current Float," Journal of International Money and Finance, 17, 41-50.

Plott, C. R., 1982, "Industrial Organization Theory and Experimental Economics," Journal of Economic Literature, 20, 1485-1527.

Plott, C. R., and S. Sunder, 1982, "Efficiency of Experimental Security Markets with Insider Information: An Application of Rational-Expectations Models," Journal of Political Economy, 90, 663-698.

Reiss, P. R., and I. M. Werner, 1998, "Does Risk Sharing Motivate Inter-Dealer Trading?," Journal of Finance, 53, 1657-1703.

Röell, A. A., 1996, “Stock Market Transparency," working paper, Université Libre de Bruxelles.

Rogoff, K., 1996, "The Purchasing Power Parity Puzzle," Journal of Economic Literature, 34, 647-668.

Rouwenhorst, K. G., 1999, "Local Equity Markets and EMU," Financial Analyst Journal, May-June, 57-64.

Saudagaran, S., 1988, “An Empirical Study of Selected Factors Influencing the Decision to List on Foreign Stock Exchanges," Journal of International Business Studies, 19, 101-127.

Schnitzlein, C. R., 1996, "Call and Continuous Trading Mechanisms under Asymmetric Information: An Experimental Investigation," Journal of Finance, 51, 613-636.

Schnitzlein, C. R., 1997, "The Importance of Common Knowledge Assumptions in Models of Insider Trading: An Experimental Investigation," working paper, University of Arizona. 
Schotman, P. C., and H. K. van Dijk, 1991, "A Bayesian Analysis of the Unit Root Hypothesis in Real Exchange Rates," Journal of Econometrics, 49, 195-238.

Seppi, D., 1990, "Equilibrium Block Trading and Asymmetric Information," Journal of Finance, 45, 73-94.

Sercu, P., 1980, "A Generalization of the International Asset Pricing Model," Revue de I'Association Française de Finance, 1, 91-135.

Sercu, P., and R. Uppal, 1995, International Financial Markets and the Firm, South-Western College Publishing, Cincinnatti, Ohio.

Solnik, B., 1974, “An Equilibrium Model of the International Capital Market," Journal of Economic Theory, 8, 500-524.

Solnik, B., 1983, "International Arbitrage Pricing Theory," Journal of Finance, 38, 449-457.

Stock, J., 1996, "Cointegration, Long-Run Comovements, and Long-Horizon Forecasting," in

D. M. Kreps, and K. F. Wallis (eds.), Advances in Economics and Econometrics:

Theory and Applications, volume II, Cambridge University Press, Cambridge.

Stulz, R. M., 1981, “A Model of International Asset Pricing," Journal of Financial Economics, 9, 383-406.

Stulz, R. M., 1995a, "International Portfolio Choice and Asset Pricing: An Integrative Survey," in R. A. Jarrow, V. Maksimovic, and W. T. Ziemba (eds.), Handbooks in Operations Research and Management Science, 9: Finance, North-Holland, Amsterdam, 201-223.

Stulz, R. M., 1995b, "The Cost of Capital in Internationally Integrated Markets: The Case of Nestlé," European Financial Management, 1, 11-22.

Stulz, R. M., 1998, "The Globalization of Equity Markets and the Cost of Capital," working paper, Ohio State University.

Sunder, S., 1995, "Experimental Asset Markets: A Survey," in J. Kagel, and A. Roth (eds.), The Handbook of Experimental Economics, Princeton University Press, Princeton, New Jersey, 445-500.

Tesar, L. L., and I. M. Werner, 1995, "Home Bias and High Turnover," Journal of International Money and Finance, 14, 467-492.

Viswanathan, S., and J. J. D. Wang, 1999, "Why is Inter-Dealer Trading so Pervasive in Financial Markets?,” working paper, Fuqua School of Business, Duke University.

Vogler, K.-H., 1997, "Risk Allocation and Inter-Dealer Trading," European Economic Review, 41, 1615-1634.

Warnock, F. E., 2001, "Home Bias and High Turnover Reconsidered," International Finance Discussion Paper, 702, Federal Reserve Bank.

Werner, L., and A. Kleidon, 1996, "U.S. and U.K. Trading of British Cross-Listed Stocks: An Intraday Analysis of Market Integration," Review of Financial Studies, 9, 619-664.

World Bank, 2001, Global Development Finance. 


\section{Samenvatting (Summary in Dutch)}

De afgelopen decennia werden gekenmerkt door de toenemende globalisatie van internationale kapitaalmarkten. Zowel formele restricties als minder formele restricties op internationale investeringen zijn voor een groot deel verdwenen. Europese en Amerikaanse beleggers kunnen tegenwoordig zonder veel barrières investeren in aandelen en obligaties in een groot aantal vreemde landen. Deze ontwikkelingen werden versterkt door de oprichting van de Europese Monetaire Unie en de introductie van de Euro aan het begin van 1999. Het Internationaal Monetair Fonds (1998) signaleert drie trends die het proces van internationalisatie illustreren. Ten eerste is het aantal grensoverschrijdende transacties in financiële instrumenten enorm gestegen. Ten tweede trekken ondernemingen steeds meer kapitaal aan in het buitenland. Ten derde is een toenemend aantal bedrijven genoteerd aan een buitenlandse effectenbeurs.

Dit proefschrift bestudeert twee onderwerpen die gerelateerd zijn aan de internationalisatie van kapitaalmarkten en die relatief veel aandacht hebben gekregen in de recente financieel-economische literatuur. Deel I van dit proefschrift analyseert het effect van de institutionele organisatie van financiële beurzen op de prijsvorming. Een van de meest in het oog springende gevolgen van de globalisatie van kapitaalmarkten is de verhevigde concurrentie tussen internationale financiële markten. Dit heeft geleid tot de vorming van een aantal strategische allianties en fusies tussen aandelenbeurzen. In 2000 werden bijvoorbeeld de beurzen van Amsterdam, Brussel en Parijs gefuseerd tot Euronext. De toegenomen concurrentie uit zich ook in een aantal veranderingen, dat onlangs is doorgevoerd in de handelssystemen van verscheidene Europese effectenbeurzen. In oktober 1997 voerde de London Stock Exchange het elektronische orderboek in voor de FTSE 100 aandelen. Dit ging gepaard met een vergroting van de transparantie door middel van snellere publicatie van transactie-informatie. Ook de aandelen- en optiehandel in Amsterdam verloopt na de totstandkoming van Euronext via andere systemen. 
Een relevante vraag is in welke mate deze en andere veranderingen in de institutionele structuur van een financiële markt van invloed zijn op de prestaties in termen van efficiëntie, liquiditeit en transactiekosten. De literatuur op het gebied van de microstructuur van financiële markten tracht deze vraag te beantwoorden. In tegenstelling tot het meeste economische onderzoek, dat abstraheert van de manier waarop de prijs totstandkomt in een markt, richten microstructuurstudies zich expliciet op het prijsvormingsproces. In hoofdstuk 2 van dit proefschrift geven we een beknopt overzicht van de microstructuurliteratuur. We bespreken de belangrijkste theoretische onderzoeken uit de jaren ' 80 , waaronder de studies van Kyle (1985) en Glosten en Milgrom (1985). Daarnaast richten we ons op recent onderzoek naar het effect van de transparantie van een effectenbeurs op de prijsvorming. Hoofdstuk 3 en 4 zijn gebaseerd op een gesimuleerde effectenbeurs voor een onderzoek naar het effect van markttransparantie, respectievelijk een parallelle interdealermarkt op de prijsefficiëntie en de transactiekosten. In deze experimentele financiële markt concurreren verscheidene dealers of market makers met elkaar voor de orders van externe klanten. De rol van dealer wordt in de experimenten vervuld door professionele market makers op de Amsterdamse optiebeurs en door economiestudenten. Het voordeel van een experimentele methodologie is, dat de invloed van een zeer specifieke verandering in het handelsmechanisme kan worden geanalyseerd zonder dat strikte aannames betreffende het gedrag van de marktparticipanten noodzakelijk zijn.

Deel 2 van dit proefschrift onderzoekt een aantal puzzels in internationale financiële markten. Ondanks de relatief hoge mate van economische integratie van kapitaal- en goederenmarkten, concludeert een groot aantal wetenschappelijke artikelen, dat de invloed van internationale factoren op binnenlandse markten verbazingwekkend klein is. Twee voorbeelden illustreren dit. Ten eerste is het algemeen aanvaard, dat de voordelen van internationale diversificatie van beleggingsportefeuilles aanzienlijk zijn. Volgens de portefeuilletheorie van Markowitz houden beleggers in geïntegreerde kapitaalmarkten de marktgewogen portefeuille van alle aandelen aan. In de praktijk blijken investeerders uit diverse Europese landen echter een relatief klein deel van hun vermogen in buitenlandse aandelen te beleggen. Voor verschillende landen lopen de schattingen uiteen van 10 tot 40 procent, hetgeen veel lager is dan verwacht. Dit fenomeen wordt ook wel de 'home bias' puzzel genoemd. Ten tweede zijn veel economen van mening, dat fluctuaties in wisselkoersen een substantieel effect hebben op de waarde van beursgenoteerde undernemingen. Verscheidene recente onderzoeken vinden echter een onverwacht kleine invloed van wisselkoersveranderingen op de aandelenrendementen van een groot aantal Europese bedrijven. Een significant wisselkoerseffect wordt gevonden voor niet meer dan zo'n 25 procent van de aandelen. Ondanks het feit, dat Nederlandse bedrijven zeer internationaal georiënteerd zijn, blijkt dat slechts 8 van de grootste 50 Nederlandse ondernemingen significant waren blootgesteld aan veranderingen in acht wisselkoersen over de periode 19801999. Aan dit verschijnsel wordt gerefereerd als de 'foreign exchange exposure' puzzel. Hoofdstuk 5 bespreekt kort de recente ontwikkelingen in de literatuur over een vijftal 
internationale financiële puzzels. In hoofdstuk 6 beschouwen we een alternatieve manier om naar de puzzel van de koopkrachtpariteit te kijken met een panelmodel. In hoofdstuk 7 introduceren we formele statistische toetsen op de significantie van het verschil in de schatting van de kapitaalkosten van een bedrijf, gemaakt met behulp van lokale en internationale varianten van het capital asset pricing model (CAPM). We schatten de omvang van deze zogenaamde 'pricing error' voor een groot aantal bedrijven uit geîndustrialiseerde landen. Bovendien stellen we een andere methode voor om de invloed van wisselkoersen op aandelenrendementen te meten. We schatten de gevoeligheid van de bedrijven in onze steekproef voor fluctuaties in een aantal wisselkoersen. Hoofdstuk 8 onderzoekt de pricing error en de wisselkoersgevoeligheid voor een substeekproef van bedrijven met een buitenlandse aandelennotering.

In hoofdstuk 3 bestuderen we het effect van zowel 'pre-trade' als 'post-trade' transparantie op het handelsproces in een experimentele effectenmarkt die overeenkomsten vertoont met NASDAQ en wisselkoersmarkten. Pre-trade transparantie heeft betrekking op de publicatie van informatie over de bied- en de laatkoersen van dealers. Post-trade transparantie betreft de openbaarmaking van transactie-informatie. Voor aanvang van een handelsronde ontvangt een van de vijf market makers informatie over de onderliggende waarde van het verhandelde aandeel. Onze hypothese is, dat de prijsontwikkeling sneller verloopt en de markt dus efficiënter is als de transparantie groot is. We vinden inderdaad, dat post-trade transparantie een gunstig effect op marktefficiëntie heeft. Pre-trade transparantie blijkt daarentegen de prijsontwikkeling nadelig te beïnvloeden. Market makers kunnen namelijk volstaan met minder agressieve prijsaanpassingen en dealers met superieure informatie kunnen zich gemakkelijker verbergen als de bied- en laatkoersen in de markt openbaar zijn. De centrale weergave van transactie-informatie leidt tot een grotere spreiding tussen bied- en laatkoersen, omdat dealers scherpere prijzen stellen om informatieve orders binnen te halen wanneer de post-trade transparantie gering is. Pre-trade transparantie heeft lagere transactiekosten tot gevolg.

Hoofdstuk 4 analyseert de invloed van een afzonderlijke markt voor transacties tussen dealers. Vier market makers zetten bied- en laatprijzen in twee markten met een verschillende microstructuur. In de ene markt handelen market makers uitsluitend met geautomatiseerde investeerders die aandelen kopen en verkopen op basis van liquiditeitsbehoeften of op basis van informatie over de onderliggende waarde. In de andere markt kunnen market makers ook transacties aangaan met andere dealers in een aparte interdealermarkt. Omdat transactiegegevens niet openbaar zijn, is asymmetrische informatie een belangrijke beweegreden voor interdealerhandel in onze experimenten. Risicospreiding, het andere veelgenoemde motief voor handel tussen market makers, is van ondergeschikt belang. Dit wordt bevestigd door het feit, dat de spreiding van dealerwinsten veel groter is als er een interdealermarkt bestaat. Onze resultaten geven aan, dat het toestaan van interdealerhandel in een situatie met asymmetrische informatie resulteert in hogere transactiekosten voor externe klanten. Dealers blijken de spreiding tussen hun bied- en laatprijzen te vergroten ter 
compensatie van de zogenaamde 'adverse selection' kosten. Asymmetrische informatie zou volgens ons een grotere rol moeten spelen in beleidsdiscussies over interdealerhandel. Meer onderzoek is nodig om het relatieve belang van risicospreiding en asymmetrische informatie als beweegreden voor handel tussen dealers in bestaande financiële markten vast te stellen.

Hoofdstuk 6 presenteert empirisch bewijs voor relatieve koopkrachtpariteit voor een panel van 17 landen voor termijnen langer dan een jaar. We bouwen voort op recente panelstudies door onze methodologie invariant te maken voor de keuze van de valuta die als numeraire gebruikt wordt. O'Connell (1998) toont aan, dat de gewoonte om alle reële wisselkoersen in een panelmodel uit te drukken ten opzichte van één numeraire leidt tot statistische afhankelijkheid tussen deze wisselkoersen. Deze afhankelijkheid heeft een ongunstig effect op de 'size' en de 'power' van de statistische toetsen. Een andere bijdrage van ons onderzoek is, dat onze methodologie het mogelijk maakt om voor elke wisselkoers afzonderlijk een uitspraak te doen over koopkrachtpariteit. Onze analyse geeft aan, dat koopkrachtpariteit een adequate beschrijving vormt van driemaandelijkse veranderingen in reële wisselkoersen tussen de DeutschMark en gerelateerde valuta. Het bewijs voor koopkrachtpariteit tussen de Verenigde Staten en Canada is daarentegen relatief zwak. Toekomstig onderzoek zou zich ons inziens moeten richten op de vraag waarom koopkrachtpariteit opgaat binnen, maar niet tussen verschillende valutablokken.

Hoofdstuk 7 bestudeert de vraag, of verschillende versies van het capital asset pricing model een andere schatting van de kosten van aandelenkapitaal van een onderneming impliceren. We evalueren de grootte van de pricing error tussen het lokale CAPM en het multifactor internationale CAPM voor meer dan 3.000 bedrijven. De pricing error is zowel statistisch als economisch gering. De hypothese dat de pricing error gelijk is aan nul wordt verworpen voor slechts 5 procent van de ondernemingen. Het gemiddelde verschil in de schatting van de kapitaalkosten bedraagt ongeveer 50 basispunten voor de Verenigde Staten, 75 basispunten voor Duitsland en Japan en 100 basispunten voor Frankrijk. Een mogelijke grond voor deze bevindingen wordt gevormd door het feit, dat aandelenrendementen voor een groot deel verklaard kunnen worden uit landspecifieke factoren. Een aantal recente studies suggereert dat cyclische, structurele en institutionele landspecifieke factoren een gebrek aan reële integratie tussen internationale kapitaalmarkten tot gevolg hebben. Dat wil zeggen dat bedrijven binnen een land over het algemeen een gemeenschappelijke gevoeligheid vertonen voor internationale risicofactoren. Deze gezamenlijke gevoeligheid wordt gevangen in de prijsbepaling van de lokale marktindex in de internationale kapitaalmarkt. Hoofdstuk 7 gaat ook nader in op de 'foreign exchange exposure' puzzel. Voor slechts circa 14 procent van de ondernemingen in de steekproef kunnen we de hypothese verwerpen, dat fluctuaties in wisselkoersen geen invloed hebben op de waarde van het aandeel. We betogen echter, dat het opnemen van de lokale marktportefeuille als controlevariabele in de traditionele statistische toets voor wisselkoersgevoeligheid de resultaten kan verbloemen. Als we hiervoor corrigeren, vinden we, dat ruim 45 procent van de bedrijven substantieel door wisselkoersen beïnvloed wordt. 
In hoofdstuk 8 onderzoeken we de pricing error en de wisselkoersgevoeligheid van de bedrijven in onze steekproef met minstens één aandelennotering aan een buitenlandse beurs. Recente artikelen tonen aan, dat dergelijk bedrijven over het algemeen grote multinationals zijn met een sterk internationaal karakter. We vermoeden daarom, dat deze ondernemingen een relatief grote pricing error maken als ze het lokale CAPM in plaats van het internationale CAPM gebruiken om de kapitaalkosten te berekenen. Onze analyse toont aan, dat ruim 80 procent van deze aandelen invloed ondervindt van wisselkoersschommelingen. Echter, de pricing error is slechts voor ongeveer 12 procent van de onderzochte bedrijven statistisch significant. Dit lijkt te maken te hebben met het feit, dat ook de aandelenrendementen van ondernemingen met internationale effectennoteringen voor een aanzienlijk deel verklaard kunnen worden met landspecifieke factoren. Nader onderzoek is vereist om de economische grondslag van deze factoren te verduidelijken. Ook zou het interessant zijn na te gaan welke bedrijfskenmerken wel gerelateerd zijn aan de pricing error. 



\section{Biography}

Mathijs A. van Dijk was born on May 12, 1973 in Hoorn, the Netherlands. He received his M.Sc. in Economics (cum laude) from Erasmus University Rotterdam in 1996. He majored in econometrics and in monetary economics. He spent three months as a visiting student in the M.Sc. in Economics and Finance program at Warwick Business School in 1994. Mathijs van Dijk joined the Department of Finance of Maastricht University as a Ph.D. student in 1996. He spent the fall term of 1999 as a visiting graduate student at the Department of Economics of Princeton University. He was appointed as an Assistant Professor of Finance at Maastricht University in January 2000. He joined the faculty of Erasmus University Rotterdam in November 2000 and presently holds a position as an Assistant Professor of Finance at the Department of Financial Management. Mathijs van Dijk's research and teaching focus on international finance. He has published in Economics Letters and the Journal of International Money and Finance. He has been involved in consulting and executive teaching and has presented his work at various international conferences. 
